\title{
Synopsis of the parasitoid wasp genus Cotesia Cameron, 1891 (Hymenoptera: Braconidae: Microgastrinae) in Australia, with the description of seven new species
}

\author{
Erinn P. FAGAN-JEFFRIES ${ }^{1, *}$ \& Andrew D. AUSTIN ${ }^{2}$ \\ ${ }^{1,2}$ Australian Centre for Evolutionary Biology \& Biodiversity and School of Biological Sciences, \\ The University of Adelaide, Australia. \\ ${ }^{1,2}$ South Australian Museum, Adelaide, Australia. \\ *Corresponding author: erinn.fagan-jeffries@adelaide.edu.au \\ 2Email: andy.austin@adelaide.edu.au \\ ${ }^{1}$ urn:1sid:zoobank.org:author:C724E269-029E-49E8-8D95-6F5A5DA6BAAF \\ ${ }^{2}$ urn:1sid:zoobank.org:author:DE71F924-750D-490D-84A7-F5960066F7CC
}

\begin{abstract}
The genus Cotesia Cameron, 1891 is one of the most diverse of the Microgastrinae, a subfamily of wasps that are exclusively endoparasitic on lepidopteran larvae. Species of Cotesia are widely utilised as biological control agents across the world. In Australia, there are currently 10 confirmed native species as well as four species introduced for the management of lepidopteran pests. The genus is morphologically conserved and has not been studied in the Australasian region for many decades. In this study, we use both comparative morphology and sequence data from the COI gene to delineate species, and in so doing describe seven new species from Australia: C. lasallei sp. nov., C. medusae sp. nov., C. ocellata sp. nov., C. reidarum sp. nov., C. scripta sp. nov., C. tjapekki sp. nov. and C. wonboynensis sp. nov., raising the number of species of Cotesia formally recorded in Australia to 21. We also provide updated descriptions of the previously described native species, diagnoses for the introduced species and a key to all currently described species found on the continent and from Papua New Guinea. This study treats only a fraction of the likely diversity of Cotesia, but provides a solid framework for future work.
\end{abstract}

Keywords. Biological control, lepidopteran pests, microgastrine, DNA barcoding, parasitoid wasp.

Fagan-Jeffries E.P. \& Austin A.D. 2020. Synopsis of the parasitoid wasp genus Cotesia Cameron, 1891 (Hymenoptera: Braconidae: Microgastrinae) in Australia, with the description of seven new species. European Journal of Taxonomy 667: 1-70. https://doi.org/10.5852/ejt.2020.667

\section{Introduction}

Microgastrinae are an extremely diverse, cosmopolitan subfamily of braconid parasitoid wasps. All species in the subfamily are endoparasitoids of lepidopteran larvae and often extremely host specific (Smith et al. 2008). Cotesia Cameron, 1891 is one of the most utilised genera of Microgastrinae Foerster, 1862 for the biological control of lepidopteran pests, with numerous species translocated around the world (Whitfield 1997). There are approximately 320 species described worldwide (Yu et al. 2016; 
Fernández-Triana et al. 2020), however, as with all microgastrines, this represents a small fraction of its true diversity. In Australia, there are currently 10 described native species $(C$. anthelae (Wilkinson, 1928), C. australiensis (Ashmead, 1900), C. deliadis (Bingham, 1906), C. geometricae Austin, 2000, C. nonagriae (Olliff, 1893), C. philoeampa (Cameron, 1911), C. radiantis (Wilkinson, 1929), C. ruficrus (Haliday, 1834), C. rufiventris (Bingham, 1906) and C. urabae Austin \& Allen, 1989), with an additional four species introduced as biological control agents (C. glomerata (Linnaeus, 1758), C. kazak (Telenga, 1949), C. rubecula (Marshall, 1885) and C. vestalis (Haliday, 1834) (the senior synonym of C. plutellae (Kurdjumov, 1912))). Additionally, strains of C. ruficrus were introduced to Australia from Pakistan (Cumber et al. 1977; Michael 1985) and the species is listed above as native only due to successive questionable synonymies with $C$. sydneyensis (Cameron, 1911) based on morphological data in the 1920s.

Generally, Cotesia is very conserved morphologically among species and also shows a large intraspecific variation in characters often used to delimit species of microgastrines in other genera, such as the intensity of propodeal and tergite sculpturing. This causes difficulties in delimiting potentially new species from historically described species where no molecular or host information are available. In this study, we use a molecular dataset partly developed for a recent large-scale DNA barcoding study on Australian microgastrines (Fagan-Jeffries et al. 2018) to inform and direct species discovery and delimitation, and also to place some of the described species in relation to the new species, using publically available cytochrome oxidase subunit $1(\mathrm{COI})$ data. We describe seven new species of Cotesia from Australia and provide a key to all described species found on the continent and from Papua New Guinea. We update the descriptions of native species with additional measurements and characters not included in original descriptions and, for the introduced species, include a diagnosis against other Australian species. Whilst both molecular data and examination of material in collections suggest that many more species of Cotesia exist on the continent, this study provides a firm starting point from which further work on the genus can be conducted.

\section{Material and methods}

Terms for general morphology follow Fernández-Triana et al. (2014) who combined traditional microgastrine morphological terms, such as those used by Mason (1981), with the standards introduced in the Hymenoptera Anatomy Ontology (HAO) project (Yoder et al. 2010; Seltmann et al. 2012) (Fig. 34). Terms for sculpture follow Eady (1968). For new species, measurements of holotypes are given, with those for paratypes (where measured) following in parentheses as ranges (see Fernández-Triana et al. (2014) for measurement terminology and appendix 1 in the same paper for discussion on characters prone to variable results when measuring). We define colour as either pale (white, cream or pale yellow), orange, light brown or dark (dark brown or black).

Distribution data presented in Austin \& Dangerfield (1992) is included, but no attempts were made in this study to verify these data with specimens in collections and it should therefore be treated with caution. We use the Australian Faunal Directory (https://biodiversity.org.au/afd/home) for the current accepted names of lepidopteran hosts. Host data are only provided for the region of Australasia, several of the introduced species of Cotesia have wider host ranges in other part of the world. Images of specimens of Cotesia and characters were generated using a Visionary Digital BK+ imaging system with a Canon EOS 7D 18 megapixel camera, compiled in Zerene Stacker, Zerene Systems LLC, PMax software, and cropped and resized in Adobe Photoshop CS6 (Adobe Systems Inc., San Jose, CA, USA). Scanning Electron Microscope (SEM) images were generated on a FEI Quanta 450 FEG Environmental SEM. 
The following abbreviations are used throughout the paper:

$\begin{array}{ll}\text { ACT } & =\text { Australian Capital Territory } \\ \text { M/T } & =\text { Malaise trap } \\ \text { NSW } & =\text { New South Wales } \\ \text { OOL } & =\text { ocular-ocellar line } \\ \text { POL } & =\text { posterior interocellar distance } \\ \text { Qld } & =\text { Queensland } \\ \text { S. Aust } & =\text { South Australia } \\ \text { Tas } & =\text { Tasmania } \\ \text { T1 } & =\text { first mediotergite } \\ \text { T2 } & =\text { second mediotergite } \\ \text { T3 } & =\text { third mediotergite } \\ \text { Vic } & =\text { Victoria } \\ \text { WA } & =\text { Western Australia }\end{array}$

\section{Institutional abbreviations:}

$\begin{array}{ll}\text { ANIC } & =\text { Australian National Insect Collection, Canberra, Australia } \\ \text { MV } & =\text { Museum Victoria, Melbourne, Australia } \\ \text { NHMUK } & =\text { Natural History Museum, London, England } \\ \text { NMI } & =\text { National Museum of Ireland, Dublin, Ireland } \\ \text { OUMNH } & =\text { Oxford University Museum of Natural History, Oxford, England } \\ \text { QM } & =\text { Queensland Museum, Brisbane, Australia } \\ \text { SAMA } & =\text { South Australian Museum, Adelaide, Australia } \\ \text { WINC } & =\text { Waite Insect and Nematode Collection, The University of Adelaide, Australia } \\ \text { ZIN } & =\text { Zoological Institute, Russian Academy of Sciences, St. Petersburg, Russia }\end{array}$

Nearly all specimens of the new species included in this study have had legs removed for DNA extraction, and thus nearly all type specimens are missing 1-3 legs. DNA extraction and sequencing methods for newly sequenced specimens follow the Sanger sequencing methods in Fagan-Jeffries et al. (2018), other than the specimen BOLD: AUMIC544-19, which was sequenced with the primers LepF (Hebert et al. 2004) and C113R (Smith et al. 2008). A Bayesian tree of the standard barcoding region for COI of the specimens of Cotesia and Glyptapanteles sequenced in Fagan-Jeffries et al. (2018), plus several newly generated sequences, and all sequences of species of Cotesia known to occur in Australasia publicly available on the Barcode of Life Database (BOLD), was constructed using the program MrBayes (Ronquist et al. 2012). COI was not partitioned and a GTR $+\mathrm{I}+\mathrm{G}$ model of evolution was used. The tree was run for 20000000 generations and convergence was established using the program Tracer (Rambaut et al. 2018) ensuring ESS values were $>200$. The resulting tree was edited in FigTree ver. 1.4.3 (http://tree.bio.ed.ac.uk/software/figtree) and Adobe Illustrator CC 2018. A sequence of Choeras bushblitz Fagan-Jeffries \& Austin, 2019 and multiple Glyptapanteles spp. from Australia were used as outgroups, but removed from the presented phylogeny for simplicity. A full list of the sequences in this phylogeny is available as supplementary material.

\section{Results}

From the large COI DNA barcoding dataset of Microgastrinae for Australia (Fagan-Jeffries et al. 2018), and additional specimens sequenced for this study, 16 potential new species of Cotesia from Australia were recognised using a $2 \%$ divergence level threshold approach, as validated for microgastrines in previous studies (Smith et al. 2008, 2013) (Fig. 1). Seven of these species are not treated here due to being represented by single specimens. Two species were not able to be definitively separated from described species (C. icipe Fernández-Triana \& Fiaboe, 2017 and C. radiantis), and further discussion on these cases is provided below. The remaining seven species are here described as new. 


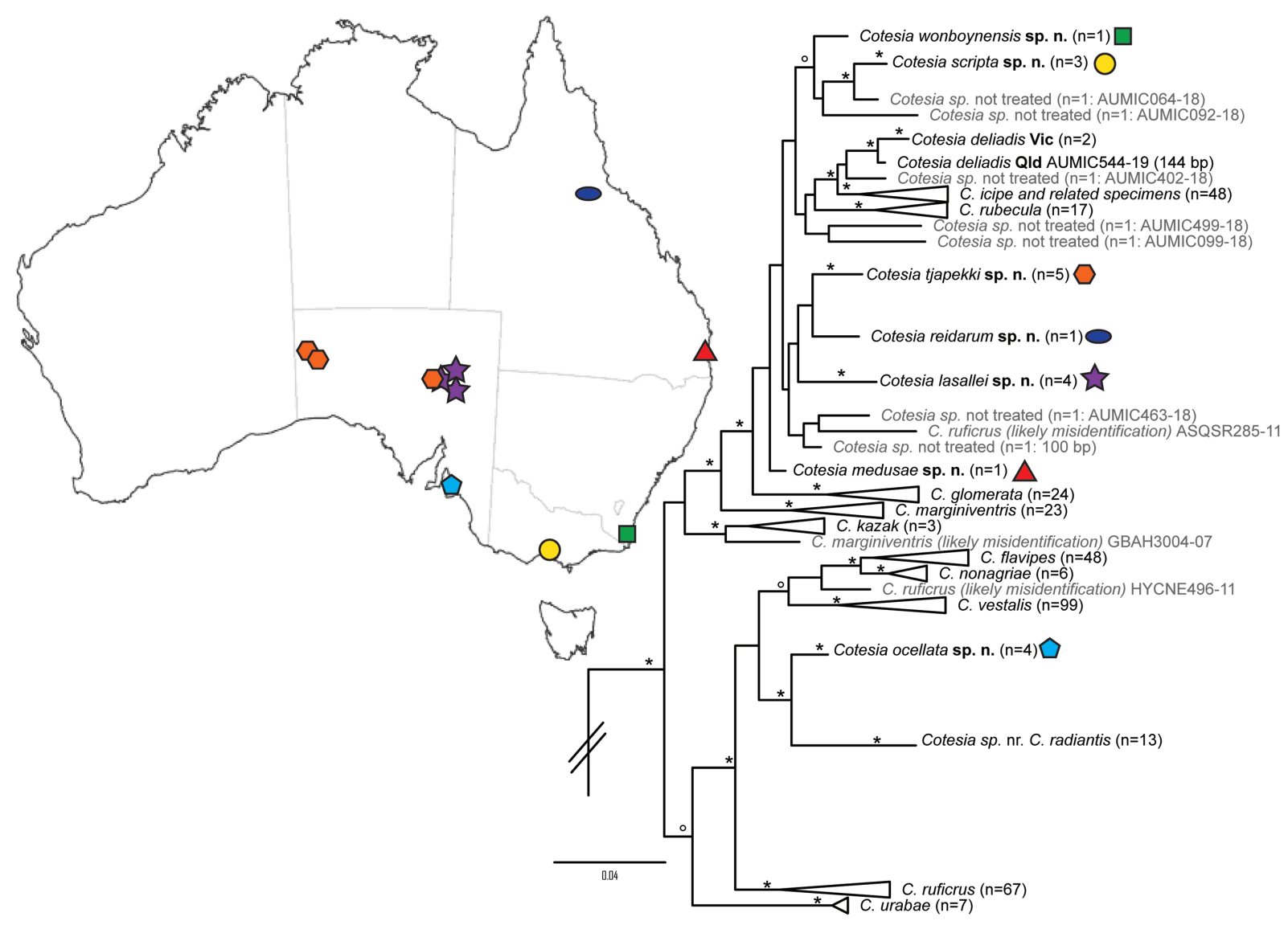

Fig. 1. Map of Australia showing the collection locations of the seven newly described species of Cotesia as well as a Bayesian phylogeny of these species and the other Cotesia spp. known to occur in Australia with publically available COI data. Species listed in black are those treated in this study, whilst those in grey are not treated due to being represented by single specimens, or are BOLD sequences that fall outside the rest of that species clade and are therefore possible misidentifications. BOLD codes for these single specimens are given at the end of the label in the tree. Symbols on the map correspond to the symbols on the phylogeny. Bayesian posterior probability values of $\geq 95$ are represented by *, whilst those of 90-94 inclusive are represented by ${ }^{\circ}$. The number of sequences in collapsed clades are given in brackets $(\mathrm{n}=\mathrm{x})$. Outgroups have been removed for simplicity.

\section{Taxonomic treatment of species}

Class Insecta Linnaeus, 1758

Order Hymenoptera Linnaeus, 1758

Family Braconidae Latreille, 1829

Subfamily Microgastrinae Foerster, 1862

Genus Cotesia Cameron 1891

\section{Type species}

Cotesia flavipes Cameron, 1891: 185. For a complete list of synonyms and bibliography, see FernándezTriana et al. (2020). 


\section{Comments}

Cotesia is one of the largest genera of Microgastrinae and was previously treated as the glomeratus group of Apanteles sensu lato (s.1.). A detailed description of the genus can be found in Mason (1981), whilst supplementary notes, a discussion of putative relationships and a list of world species can be found in Fernandez-Triana et al. (2020). Members of the genus can be diagnosed by the absence of a fore wing areolet, possessing a short inflexible hypopygium and a short ovipositor, T1 generally parallelsided or broadening posteriorly (occasionally in the Australian fauna with T1 narrowing posteriorly but never to the extent as in Glyptapanteles) and T2 normally broad and rectangular. Often species have the propodeum with a medial carina, and the propodeum, T1 and T2 coarsely sculptured.

\section{Host information for Australian species of Cotesia}

In Australia, species of Cotesia are known to parasitise at least nine different lepidopteran families (Table 1), with some species appearing highly specialised on individual host species or genera, whilst others (e.g., C. ruficrus) are recorded from numerous genera within a single family. The host information presented below, and in the following key, are restricted to records from Australia; for extra-limital host records see references listed under the treatment of each species.

\section{Key to the described species of Cotesia in Australia and Papua New Guinea}

This key is based on adult females and should be treated with some caution due to the variable nature of some characters in Cotesia, and the limited number of specimens available for some species during the construction of the key. Wherever possible, morphological identification should be supported by COI barcoding or host information.

1. T1 evenly broadening towards posterior margin (Fig. 2A)

- T1 mostly parallel sided or barrel shaped (Fig. 2C), in some species broadening on anterior $0.6-0.7$ and then curving inwards to meet T2 (Fig. 2B)

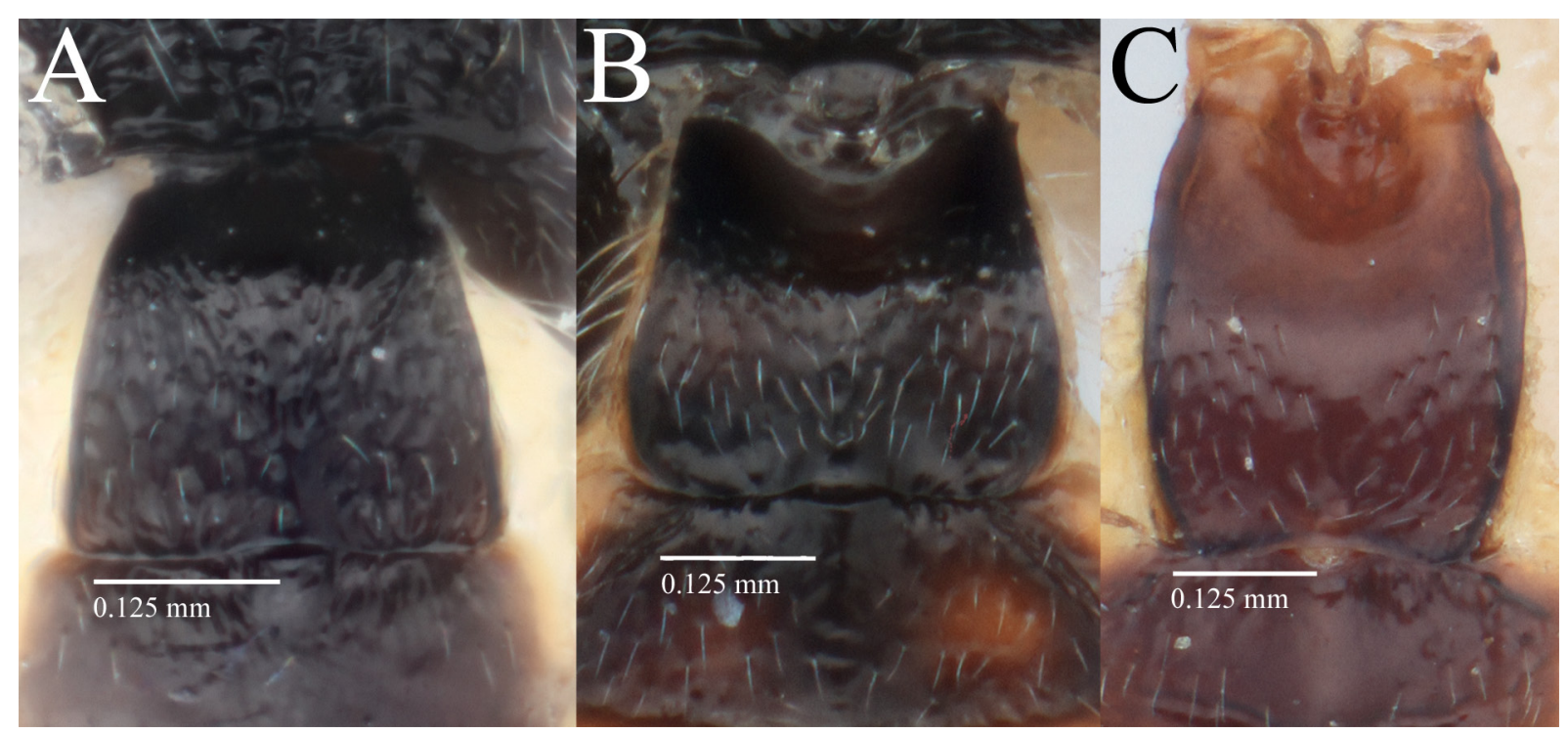

Fig. 2. A. Cotesia ocellata sp. nov., T1 (SAMA 32-44404). B. Cotesia reidarum sp. nov., T1 (QM T246703). C. Cotesia deliadis (Bingham, 1906), T1 (paralectotype, NHMUK). 
2. Scutellar disk with large, strong circular punctures (Fig. 3A) .....................................................

- Scutellar disk smooth or with small punctures associated with setae (Fig. 3B)............................ 4

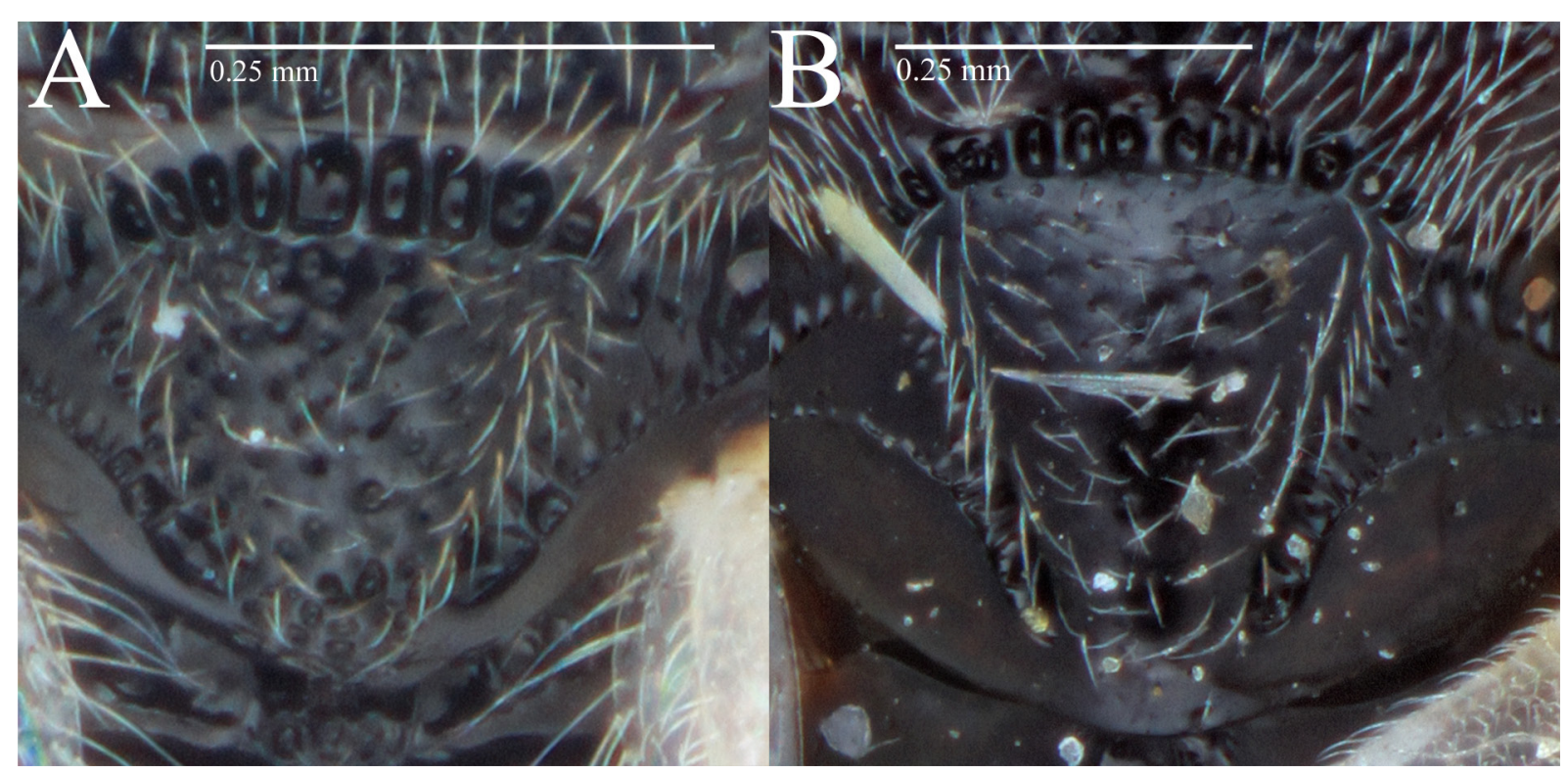

Fig. 3. A. Cotesia ruficrus (Haliday, 1834), scutellar disk (ANIC 32 130230). B. C. rufiventris (Bingham, 1906), scutellar disk (paralectotype NHMUK).

3. T3 with only a single row of setae, often in posterior half (Fig. 4A) often row of setae is irregular or undulating [gregarious parasitoid of noctuid species]...

C. ruficrus (Haliday, 1834)

- T3 with multiple rows of setae, particularly visible at lateral edges (Fig. 4B) [solitary parasitoid of Plutella xylostella].. C. vestalis (Haliday, 1834)
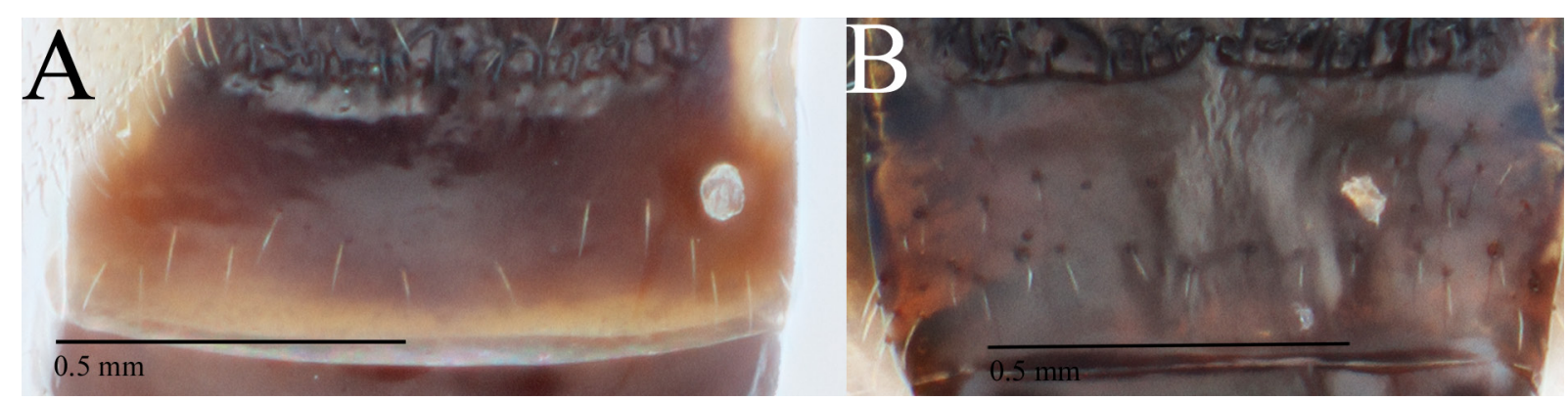

Fig. 4. A. Cotesia ruficrus (Haliday, 1834), T3 (ANIC 32 130230). B. Cotesia vestalis (Haliday, 1834), T3 (WINC). 
4. Mesosoma dorsoventrally flattened, in lateral view its length more than $2.0 \times$ its height (Fig. 5A) [scutellar disk completely smooth, no small punctures, anteromesoscutum punctures widely spaced (distance between punctures sometimes greater than diameter of punctures)].

- Mesosoma not dorsoventrally flattened, in lateral view its length less than $2.0 \times$ its height (Fig. 5B) [scutellar disk with at least some micropunctures associated with setae].

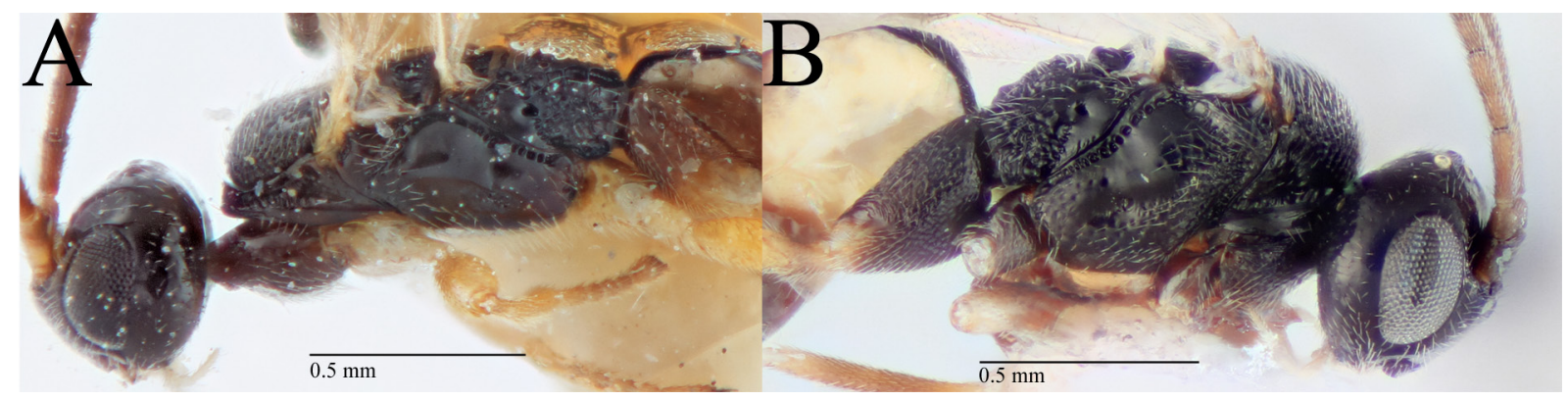

Fig. 5. A. Cotesia nonagriae (Olliff, 1893), head and mesosoma in lateral view. B. Cotesia ocellata sp. nov., head and mesosoma in lateral view (holotype, SAMA 32-44404).

5. Face projection between base of antennae slightly rounded, with smooth margin (Fig. 6C)......... .C. Alavipes Cameron $1981^{*}$

- Face projection between base of antennae less rounded, with margin appearing almost tri-lobed under high magnification (Fig. 6A-B)

C. nonagriae (Olliff, 1893)*

* (see notes under C. nonagriae for explanation of difficulties in separating these two species)

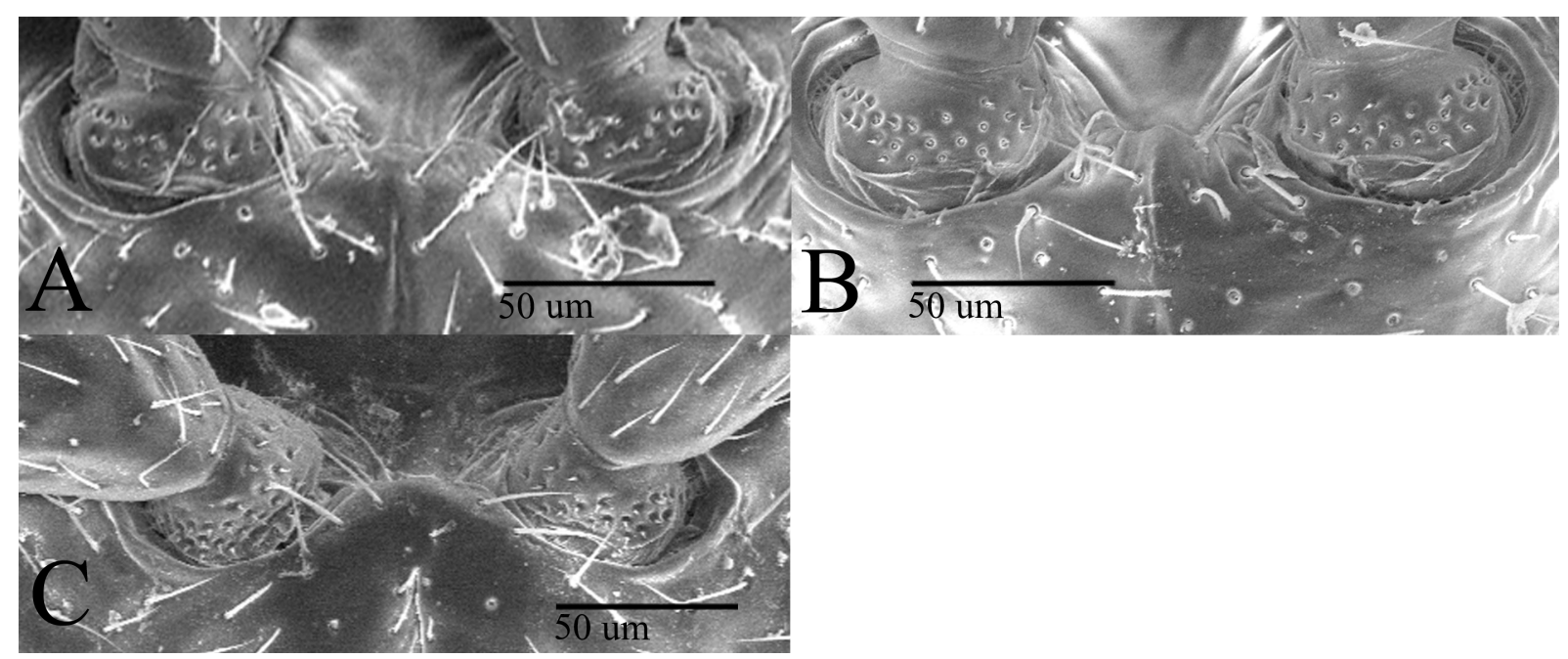

Fig. 6. A. Cotesia nonagriae (Olliff, 1893), Giru, Australia (WINC). B. C. nonagriae, Bundaberg Australia (WINC). C. C. flavipes Cameron 1981, Indonesia (WINC). 
6. Hind coxa and metasoma significantly paler than mesosoma, dorsal metasoma light brown to yellow (Fig. 28A-B) [parasitoid of the native butterfly Ogyris zosine Hewitson, 1853].

C. rufiventris (Bingham, 1906)

- Hind coxa and metasoma as dark or only slightly paler than mesosoma. Dorsal metasoma dark....7

7. Ocelli small, OOL/posterior ocellus diameter ratio $>2.5$ (Fig. 7A) [dorsal head smooth and polished with sparse setae, scutum punctate, propodeum strongly sculptured, T2 mostly smooth with some striate sculpturing].

C. ocellata sp. nov.

- Ocelli normal sized, OOL/posterior ocellus diameter $<2.4$ (Fig. 7B).
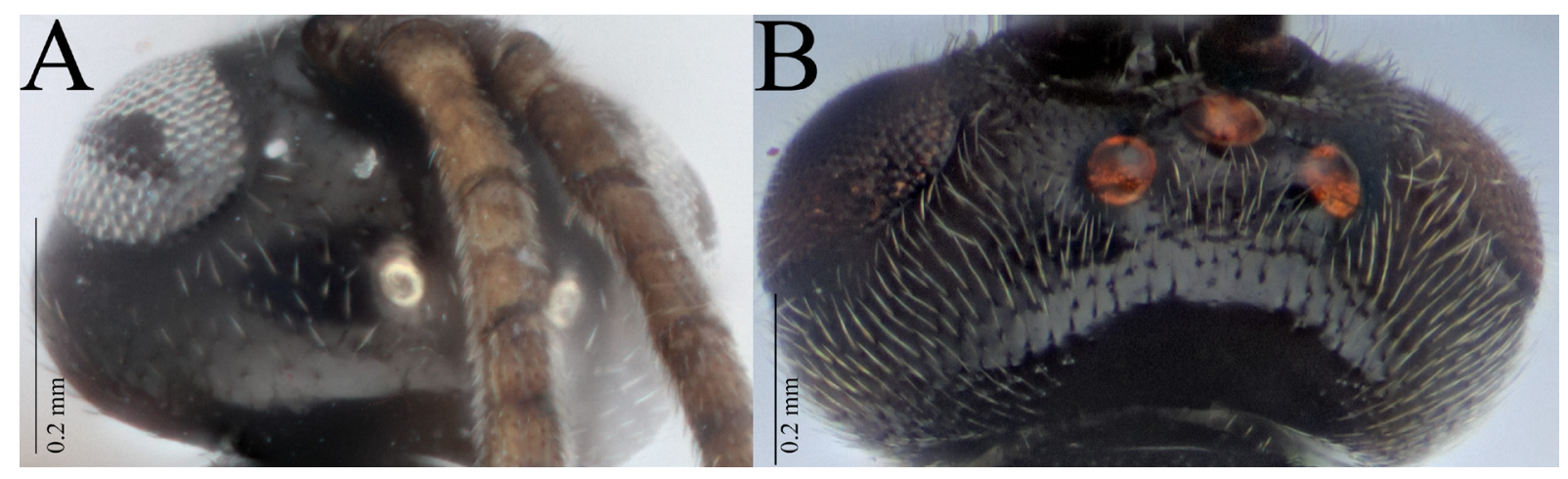

Fig. 7. A. Cotesia ocellata sp. nov., head in dorsal view (holotype, SAMA 32-44404). B. C. rubecula (Marshall, 1885), head in dorsal view (WINC).

8. Fore wing vein $r$ shorter than $2 \mathrm{RS}$ [anteromesoscutum very strongly punctate reticulate along notauli, much smoother in centre and lateral areas, gregarious parasitoid of Agrotis munda (Walker,1857)]..

C. radiantis (Wilkinson, 1929)

- Fore wing vein $\mathrm{r}$ normally longer than, occasionally of similar length, to 2RS [anteromesoscutum punctate to punctate reticulate, slightly stronger along lines of notauli and smoother in centre and lateral areas].

9. Distal quarter of hind tibia darkened, including in lateral view [scutellum sometimes with small posteromedian band of rugosity, parasitoid of the introduced Pieris rapae (Linnaeus, 1758) in Australia and therefore associated with agricultural crops and urban gardens].....

C. rubecula (Marshall, 1885)

- Hind tibia with only a very small darkened patch, mainly in dorsal view [scutellum without posteromedian band of rugosity; parasitoid of the native Uraba lugens Walker, 1866]

C. urabae Austin \& Allen, 1989

10. Fore wing vein $2 \mathrm{RS}$ extending past junction with $\mathrm{r}$, creating a 'stub' (Fig. $23 \mathrm{~A}$ ) [r shorter than or approximately equal length of 2RS, T1 mostly parallel sided, broadening on anterior $0.6-0.7$ and then curving inwards to meet T2; Fig 23B].....

C. philoeampa (Cameron, 1911)

- Fore wing 2RS not creating a 'stub' by extending slightly past junction [vein r equal in length or longer than $2 \mathrm{RS}]$......

11. Anteromesoscutum relatively smooth, slightly punctate or punctulate, only generally sparse, small punctures (Fig. 8A)...

- Anteromesoscutum densely sculptured, strongly and coarsely punctate or punctate reticulate (Fig. 8B). 


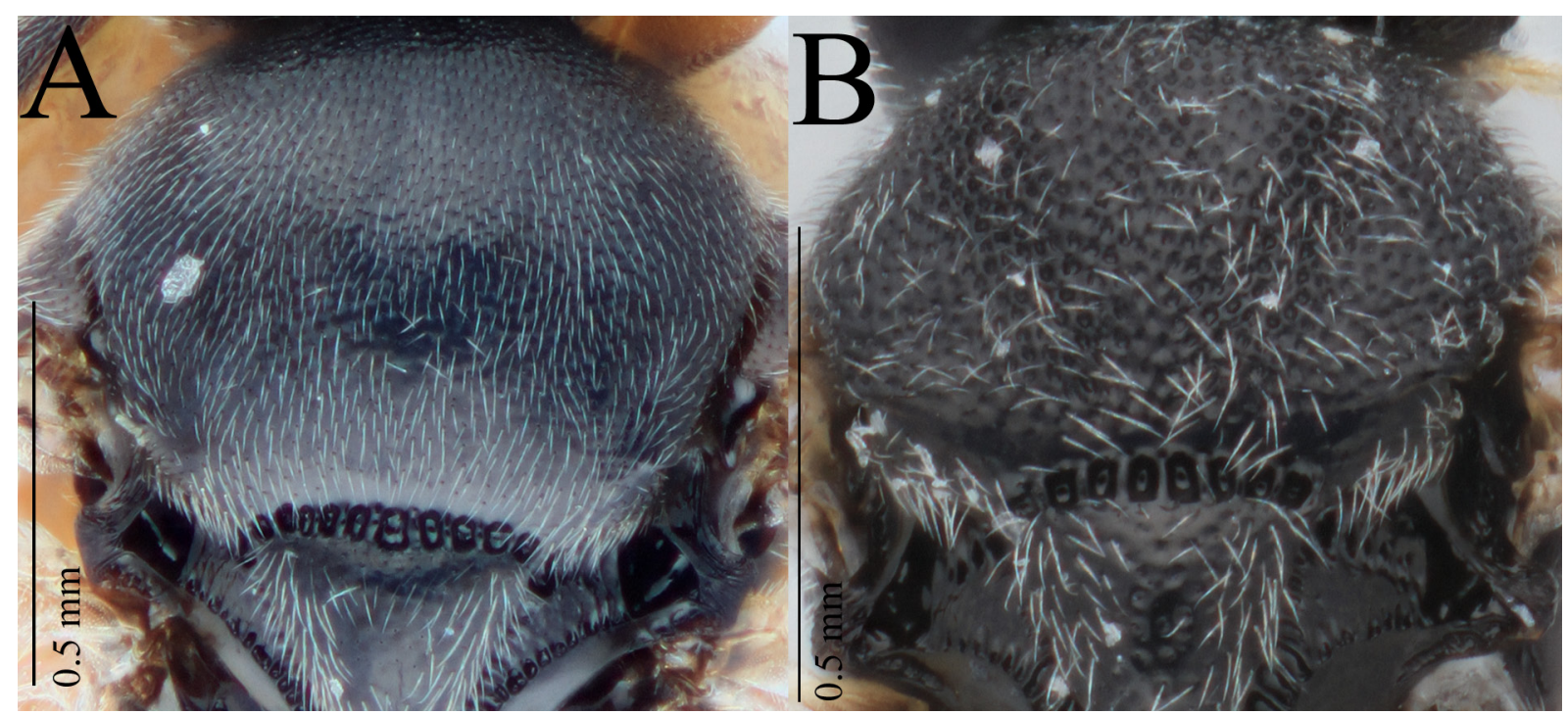

Fig. 8. A. Cotesia kazak (Telenga, 1949), anteromesoscutum (WINC, Mariginiup specimen). B. C. reidarum sp. nov., anteromesoscutum (holotype, QM T246703).

12. T3 densely setose for all of length

C. $\boldsymbol{k a z a k}$ (Telenga, 1949)

- T3 only sparsly setose, mostly in posterior one-third.

13. Ventral hypopygium deeply emarginate (Fig. 18C) [gregarious parasitoid of the introduced Pieris rapae (Linnaeus, 1758)]...

C. glomerata (Linnaeus, 1758)

- Ventral hypopygium not emarginate [gregarious parasitoid of the native Mnesampela privata Guenée, 1858 on Eucalyptus spp.].....

C. geometricae Austin, 2000

14. T3 pale (Figs 16A, 25A)

- T3 mostly dark or dark with pale lateral areas..

15. T1-2 mostly pale, antennae pale [introduced into Papua New Guinea, parasitoid of the introduced Erionota thrax (Linnaeus, 1767)]

C. erionotae (Wilkinson, 1928)

- T1-2 mostly dark, antennae dark [Australia, parasitoid of the native Candalides delospila (Waterhouse, 1903)].

C. reidarum sp. nov.

16. Scutellum with small posteromedian band of rugosity (Fig. 9A)

C. sp. nr icipe Fernández-Triana \& Fiaboe, 2017

- Scutellum without small posteromedian band of rugosity (Fig. 9B).

17. Scutellar disk with very strong, distinct punctures scattered over whole area [anteromesoscutum, propodeum and T1-2 strongly sculptured, T3 densely setose in posterior two-thirds].

C. tjapekki sp. nov.

- Scutellar disk smooth, or with only shallow punctures or dents normally associated with setae.......18

18. T3 with sparse setae only in posterior half [gregarious parasitoid of Delias aganippe (Donovan, 1805) and D. argenthona Fabricius, 1793]....

C. deliadis (Bingham, 1906)

- T3 with sparse or dense setae over all or at least posterior two-thirds of tergite. 


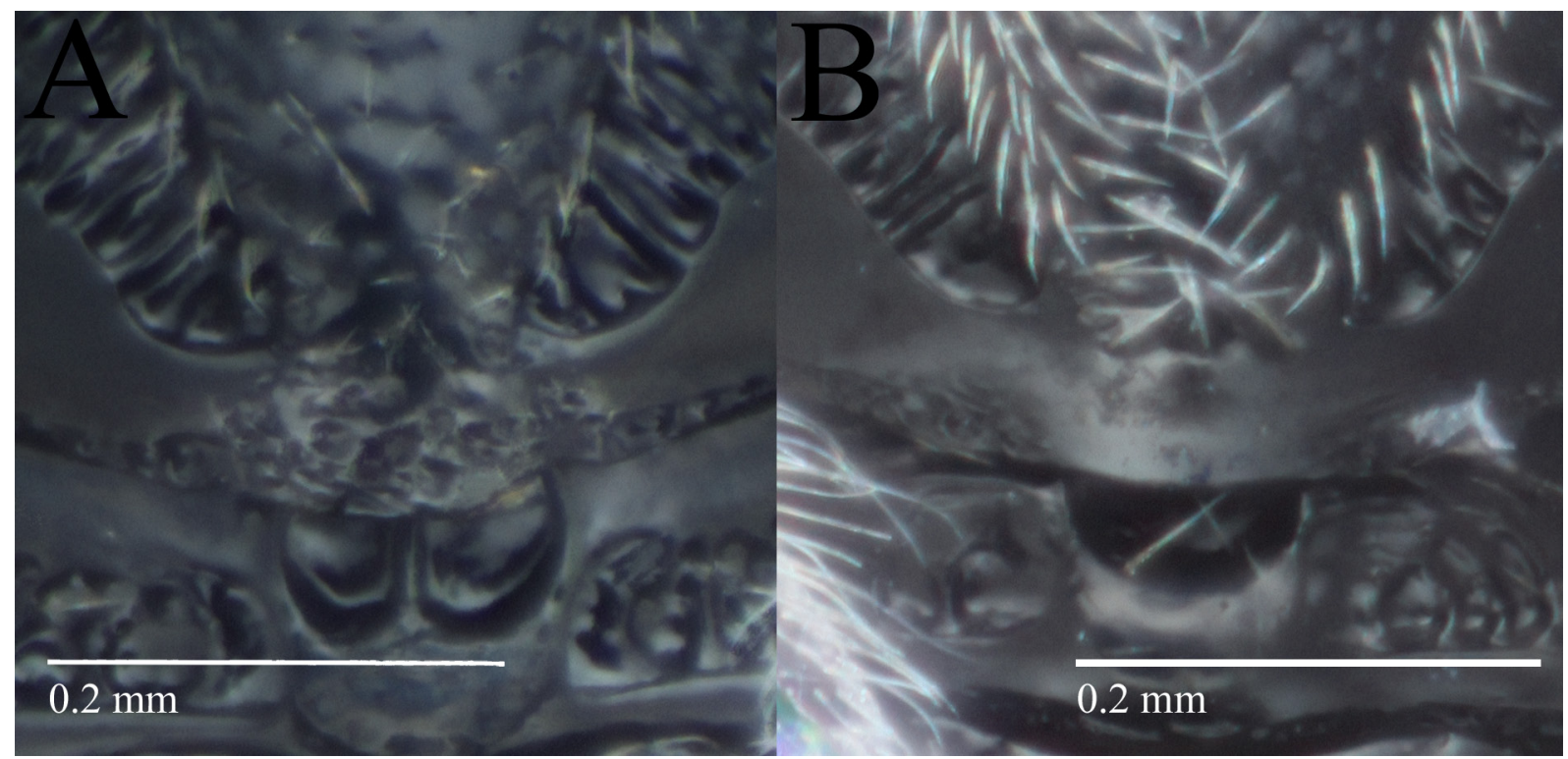

Fig. 9. A. Cotesia sp. nr icipe, medial posterior band of the scutellum (WINC, Cox Scrub). B. C. lasallei sp. nov., medial posterior band of the scutellum (holotype, SAMA 32-44401).

19. T2 ovoid, occasionally semicircle shaped, with very strong, wide crenulate border, T2 often with large punctures on most of tergite (Fig. 10A-B).

- T2 semicircle shaped or trapezoid, border with T3 smoothly indented (Fig. 10D) or occasionally with fine shallow crenulate border (Fig. 10C), T2 often mostly smooth, with shallow and sparse punctures limited to the margins......

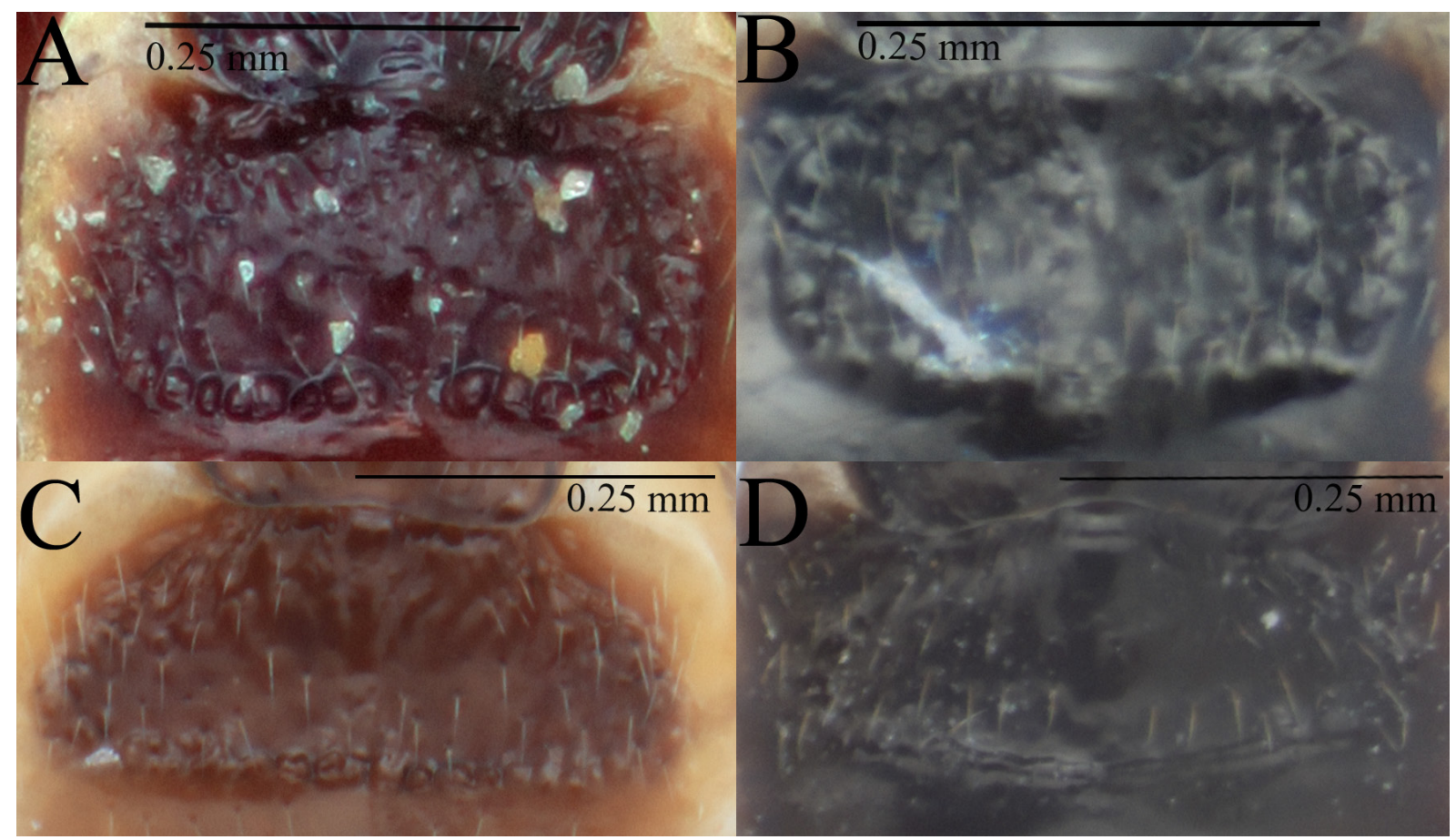

Fig. 10. A. Cotesia anthelae (Wilkinson, 1928), T2 (paratype, NHMUK 3.c.002). B. C. wonboynensis sp. nov., T2 (holotype ANIC 32 130294). C. C. medusae sp. nov., T2 (paratype, QM T246705). D. C. scripta sp. nov., T2 (paratype, MV T22495). 
20. Scutoscutellar sulcus with approximately 6-8 large pits [parasitoid of Anthela ocellata (Walker, 1855)].

C. anthelae (Wilkinson, 1928)

- Scutoscutellar sulcus with approximately 9-11 pits [gregarious parasitoid of Anthela connexa (Walker, 1855)]

C. wonboynensis sp. nov.

21. Fore wing vein $\mathrm{r}$ subtly curved (Fig. 11B) [T1-2 mostly smooth, gregarious parasitoid of Epicoma contristis Hübner, 1823]

C. scripta sp. nov.

- Fore wing vein $\mathrm{r}$ straight (Fig. 11A, C-D)

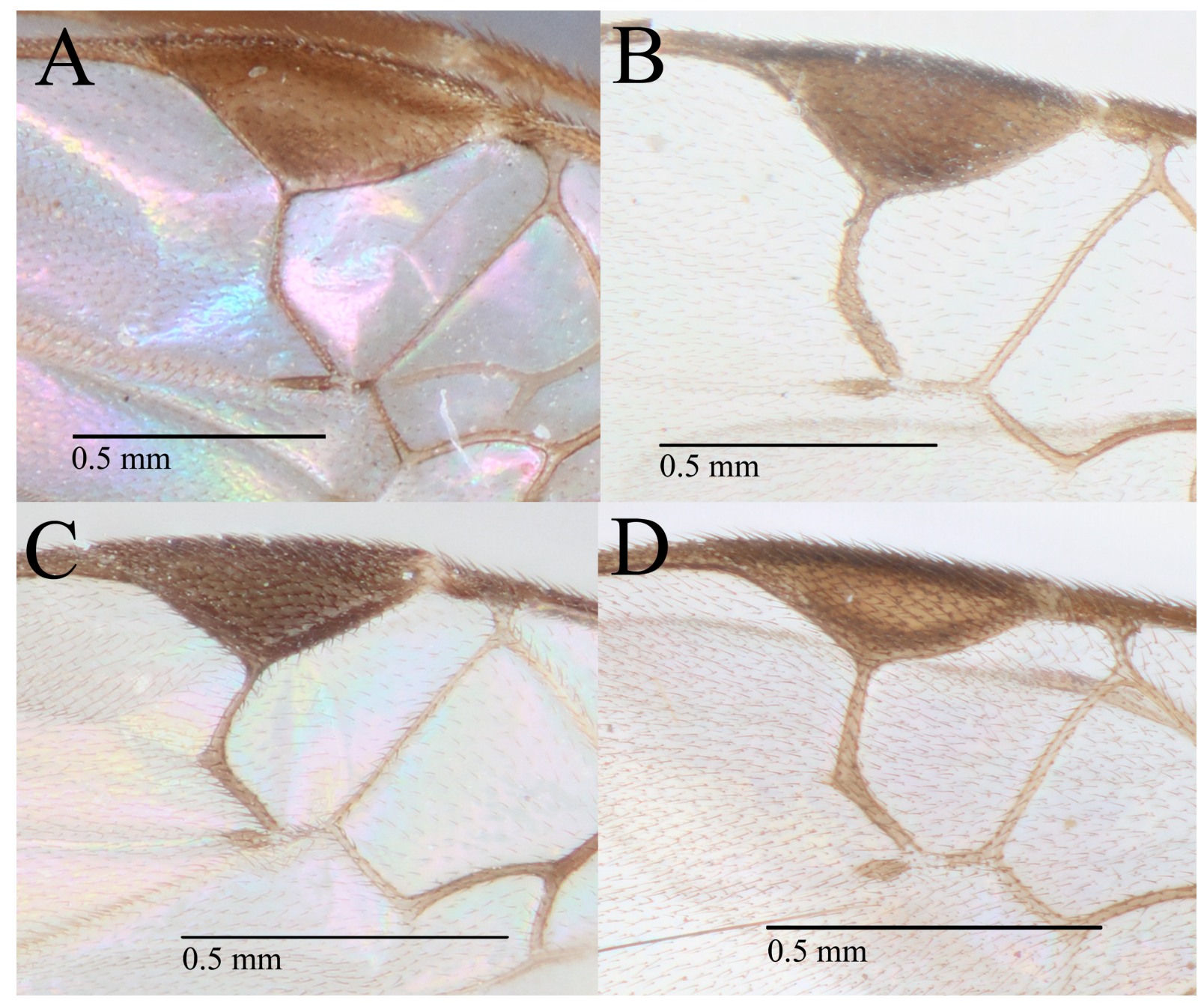

Fig. 11. A. Cotesia australiensis (Ashmead, 1900), fore wing vein $r$ straight (ANIC 32 151532). B. C. scripta sp. nov., fore wing vein $\mathrm{r}$ subtly curved (holotype, MV T22495). C. C. lasallei sp. nov., fore wing vein $r$ straight (holotype, SAMA 32-44401). D. C. medusae sp. nov., fore wing vein $r$ straight (paratype QM T246705). 
22. Antennal flagellomere 14 length/width $<1.5$ (T1-2 mostly smooth).

- Antennal flagellomere 14 length/width $>2$.

23. Scutellar sulcus generally with eight very strong, large punctures, anteromesoscutum with reticulate rugose sculpturing medially (Fig. 12A) [gregarious parasitoid of Catopsilia gorgonphone (Boisduval, 1836)].

C. medusae sp. nov.

- Scutellar sulcus generally with more than eight small, irregular punctures, anteromesoscutum punctate medially, with smooth spaces visible between punctures (Fig. 12B) [gregarious parasitoid of Opodipthera eucalypti (Scott, 1864)]

C. australiensis (Ashmead, 1900)

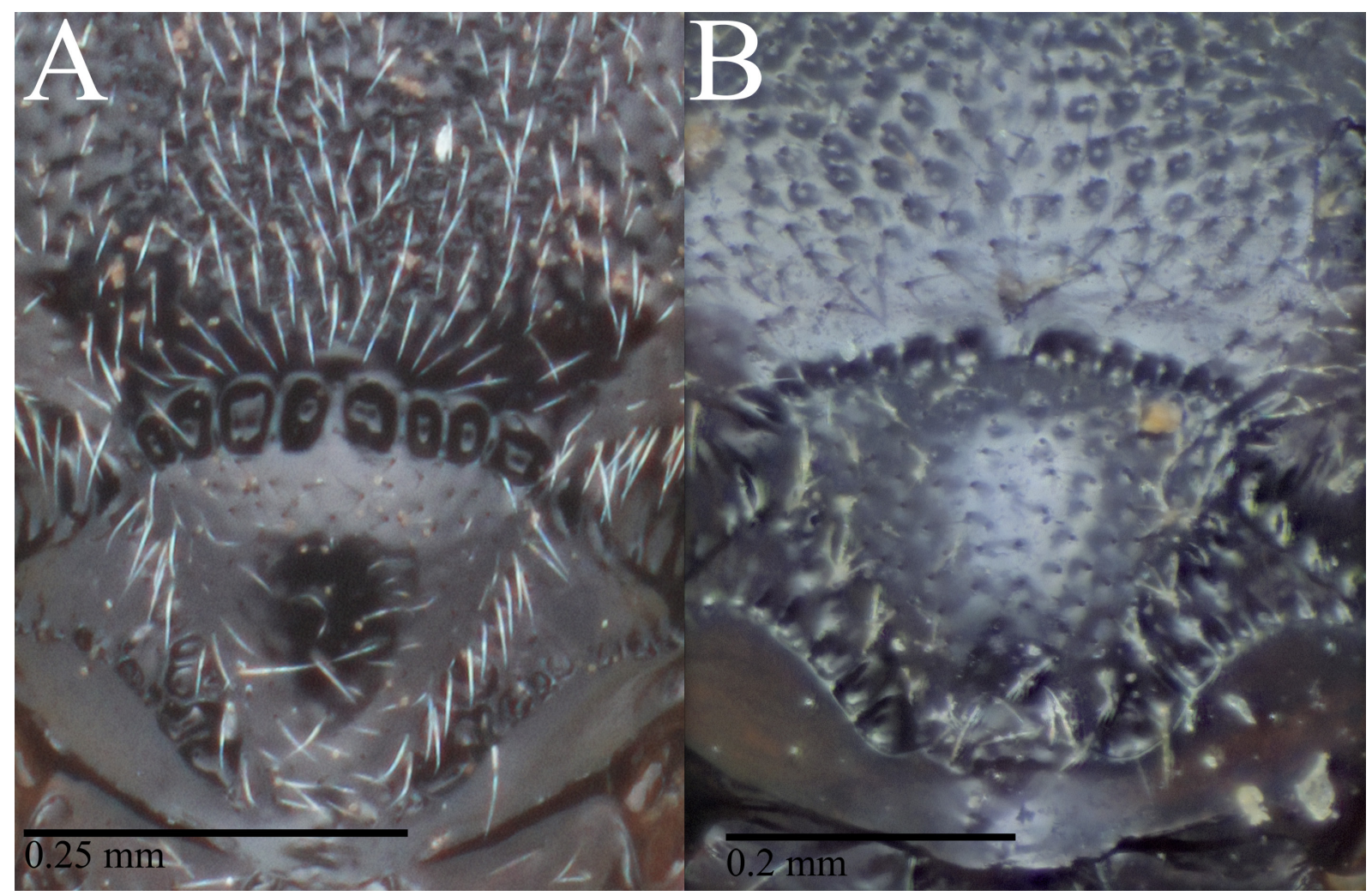

Fig. 12. Scutellar disk, scutellar sulcus and partial anteromesoscutum. A. Cotesia medusae sp. nov. (paratype, QM T246705). B. C. australiensis (Ashmead, 1900) (ANIC 32 151535).

Cotesia anthelae (Wilkinson, 1928)

Figs 10A, 13

Apanteles anthelae Wilkinson, 1928a: 102 (holotype,, , NHMUK).

Cotesia anthelae - Austin \& Dangerfield 1992: 21 (transfer from Apanteles s.1.).

\section{Diagnosis}

Cotesia anthelae can be separated from all other species of Cotesia currently described from Australia and Papua New Guinea by the following combination of characters: T2 ovoid shaped with very strong, distinct crenulate margins; scutoscutellar sulcus with 6-8 pits; scutellar disk mostly smooth with some shallow punctures; T1 mostly parallel sided. 
Table 1. Host-parasitoid checklist for the Australasian Cotesia fauna. Abbreviations: $\mathrm{S}=$ solitary; $\mathrm{G}=$ gregarious; $\mathrm{U}=$ unknown.

\begin{tabular}{|c|c|c|c|c|}
\hline Cotesia sp. & $\mathbf{S} / \mathbf{G} / \mathbf{U}$ & Host & Host family & Reference \\
\hline anthelae & $\mathrm{U}$ & Anthela ocellata & Anthelidae & Type material \\
\hline australiensis & G & Opodiphthera eucalypti & Saturniidae & Wilkinson 1930 \\
\hline \multirow[b]{2}{*}{ deliadis } & \multirow[b]{2}{*}{ G } & Delias argenthona & Pieridae & Type material \\
\hline & & Delias aganippe & Pieridae & $\begin{array}{l}\text { Examined material, new host record from this } \\
\text { study }\end{array}$ \\
\hline erionotae & G & Erionota thrax & Hesperiidae & Type material \\
\hline \multirow{2}{*}{ flavipes } & \multirow{2}{*}{ G } & Sesamia spp. & Noctuidae & Muirhead et al. 2012 \\
\hline & & Chilo spp. & Noctuidae & Li 1990 \\
\hline geometricae & $\mathrm{G}$ & Mnesampela privata & Geometridae & Type material; original description \\
\hline glomerata & G & Pieris rapae & Pieridae & Shenefelt 1972: 519; examined material \\
\hline \multirow{2}{*}{ kazak } & \multirow{2}{*}{$\mathrm{S}$} & Helicoverpa armigera & Noctuidae & Original description; le Masurier 1987 \\
\hline & & Helicoverpa punctigera & Noctuidae & Examined material; Austin \& Dangerfield 1992 \\
\hline lasallei & $\mathrm{U}$ & Unknown & & \\
\hline medusae & G & Catopsilia gorgophone & Pieridae & Type material \\
\hline nonagriae & G & Bathytricha truncata & Noctuidae & Muirhead et al. 2008 \\
\hline ocellata & $\mathrm{U}$ & Unknown & & \\
\hline philoeampa & $\mathrm{U}$ & Unknown & & \\
\hline radiantis & G & Agrotis munda & Noctuidae & Type material \\
\hline reidarum & $\mathrm{S}$ & Candalides delospila & Lycaenidae & Type material \\
\hline rubecula & $\mathrm{S}$ & Pieris rapae & Pieridae & Original description \\
\hline \multirow{11}{*}{ ruficrus } & \multirow{11}{*}{ G } & Agrotis ipsilon & Noctuidae & Austin \& Dangerfield 1992 \\
\hline & & Agrotis ipsilon & Noctuidae & from examined material \\
\hline & & Agrotis sp. & Noctuidae & from original description of $A$. antipoda \\
\hline & & Chrysodeixis argentifera & Noctuidae & Austin \& Dangerfield 1992 \\
\hline & & Chrysodeixis eriosoma & Noctuidae & Austin \& Dangerfield 1992 \\
\hline & & Graphania ustistriga & Noctuidae & Austin \& Dangerfield 1992 \\
\hline & & Helicoverpa armigera & Noctuidae & from examined material \\
\hline & & Hypsipyla robusta & Noctuidae & Austin \& Dangerfield 1992 \\
\hline & & Mythimna convecta & Noctuidae & from examined material \\
\hline & & Naranga diffusa & Noctuidae & Austin \& Dangerfield 1992 \\
\hline & & Plusia sp. & Noctuidae & $\begin{array}{l}\text { record from specimens from original description } \\
\text { of } A \text {. sydneyensis }\end{array}$ \\
\hline rufiventris & G & Ogyris zosine & Lycaenidae & Dodd 1906 and examined material \\
\hline scripta & G & Epicoma contristis & Notodontidae & Type material \\
\hline tjapekki & $\mathrm{U}$ & Unknown & & \\
\hline urabae & $\mathrm{S}$ & Uraba lugens & Noctuidae & Original description \\
\hline vestalis & $\mathrm{S}$ & Plutella xylostella & Plutellidae & Examined material \\
\hline wonboynensis & G & Anthela connexa & Anthelidae & Type material \\
\hline sp. nr. icipe & $\mathrm{U}$ & Unknown & & \\
\hline
\end{tabular}




\section{Material examined}

Holotype

AUSTRALIA - ; Victoria; "Apanteles dardalae Cam. type"; on moth Darala ocellata; NHMUK 3.c.002. Card contains the type marked with a $\mathrm{x}$ and an additional $q$ specimen, here referred to as the paratype.

\section{Paratype}

AUSTRALIA • 1 \%; same collection data as for holotype; NHMUK 3.c.002.

\section{Redescription}

\section{Female}

From holotype; propodeum, T1 and metatibal spur/metabasitarsus ratio measured and imaged on paratype due to position of wings and legs in holotype.

Colour. Head, antenna and mesosoma dark, T1-2 dark, rest of metasoma pale at anterior end, darkening towards hypopygium, (fore-, mid-, hind coxa) dark, dark, dark; femora (fore-, mid-, hind femur) pale, pale, pale darkening distally; tibiae (fore-, mid-, hind tibia) light brown, light brown, light brown (paler at proximal end); tegula and humeral complex light brown; pterostigma light brown; fore wing veins light brown.

Body LENGTH. Head to apex of metasoma: $2.6 \mathrm{~mm}$.

HEAD. Antenna slightly longer than body length; OOL/posterior ocellus diameter 2.1; IOD/posterior ocellus diameter 2.1; antennal flagellomere 2 length/width 4.4; antennal flagellomere 14 length/width 3.1.

Mesosoma. Anteromesoscutum irregularly punctate, punctures not perfectly round, some areas tending towards reticulate rugose; number of pits in scutoscutellar sulcus 7 or 8; scutellar disc mostly smooth with some shallow punctures; maximum height of mesoscutellum lunules/maximum height of lateral face of mesoscutellum (unable to measure due to wing placement).

WINGS. Fore wing length $3.0 \mathrm{~mm}$; length of veins $\mathrm{r} / 2 \mathrm{RS} 1.0$; length of veins $2 \mathrm{RS} / 2 \mathrm{M} 1.5$; length of veins $2 \mathrm{M} /(\mathrm{RS}+\mathrm{M}) \mathrm{b} 0.9$; pterostigma length/width 3.3 .

LEGS. Hind tibia inner spur length/metabasitarsus length 0.6.

Propodeum. Medial carina present, propodeum smooth and shiny at anterior corners, posterior to this propodeum with irregular rugose sculpturing, posterior corner thirds with shiny area amongst sculpturing carinae.

Metasoma. T1 length / T1 width at posterior margin 1.7; T1 generally parallel sided, very slightly narrowing at centre, and more significantly curving inwards (narrowing) at posterior corners, smooth in anterior half, with large shallow punctures in posterior half; T2 width at posterior margin / T2 length 1.6, the sclerotised area of T2 very rounded, sculpturing irregular in anterior half, smoother in posterior half, with clear short crenulate furrow at posterior boundary and lateral edges; T2 length / T3 length 0.7; T3 sculpture smooth and shiny; ovipositor sheaths length/hind tibial length 0.2 .

\section{Male \\ Unknown.}




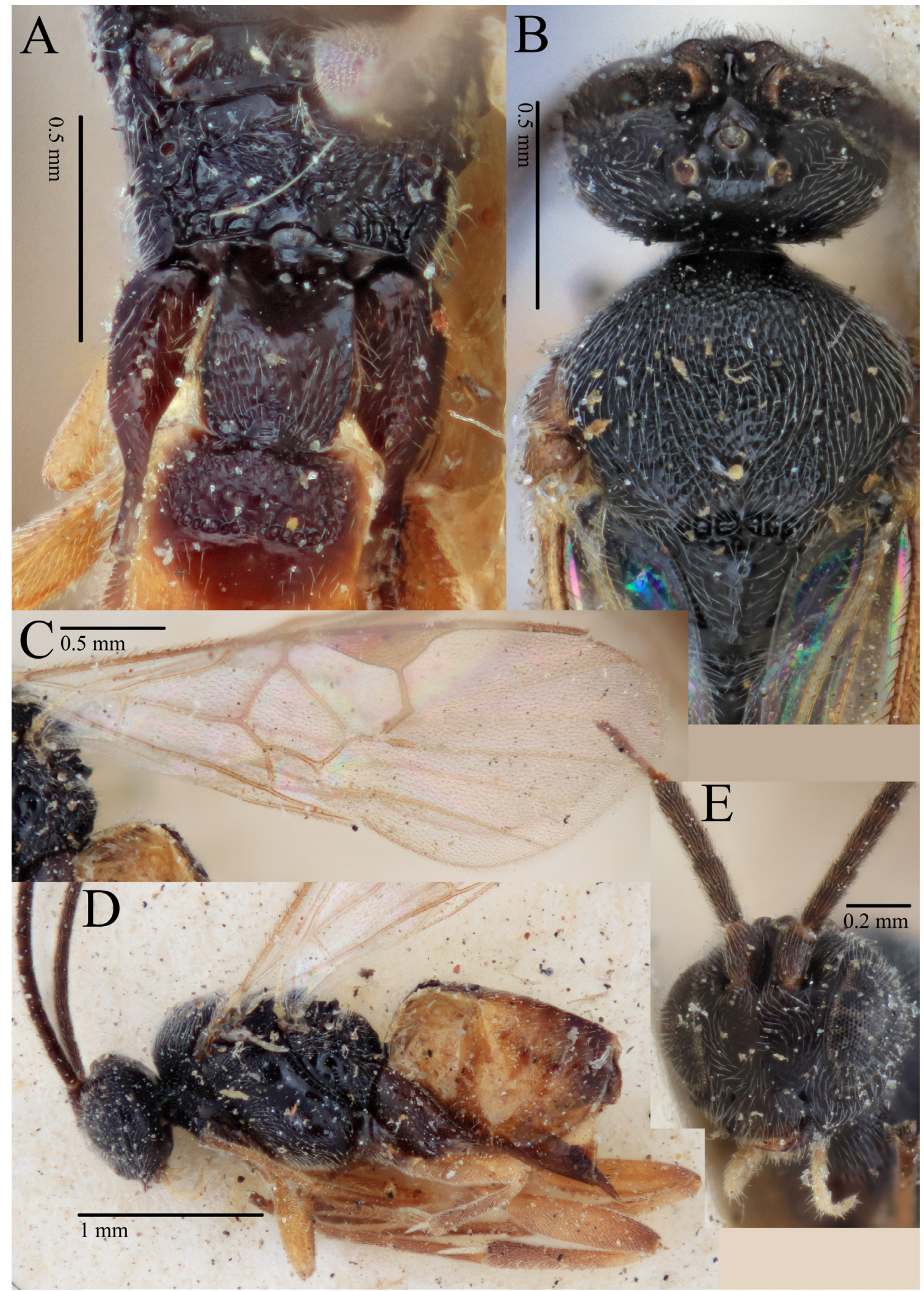

Fig. 13. Cotesia anthelae (Wilkinson, 1928). A. Paratype (NHMUK 3.c.002). B-E. Holotype (NHMUK 3.c.002). A. Propodeum and T1-2. B. Anteromesoscutum. C. Fore wing. D. Habitus in lateral view. E. Head in anterior view. 


\section{Distribution}

Vic (type specimens), NSW (record from Austin \& Dangerfield 1992).

\section{Host}

Anthela ocellata (Walker, 1855) (record from type specimens) (Anthelidae), cocoons white. Opodiphthera eucalypti (Scott, 1864) (from Austin \& Dangerfield 1992, this record remains unconfirmed as no corresponding specimens were located in collections, and is possibly erroneous).

\section{Remarks}

Wilkinson (1928a) notes in the description of this species that the manuscript name "Apanteles dardalae" given by Cameron on the holotype label appears to have not been published.

\section{Cotesia australiensis (Ashmead, 1900)}

Figs 11A, 12B, 14

Apanteles australiensis Ashmead, 1900: 356 (holotype, +, USNM).

Apanteles australiensis - Wilkinson 1928a: 99 (redescription); 1930: 485 (host record).

Cotesia australiensis - Austin \& Dangerfield 1992: 21 (transfer from Apanteles s.1.).

\section{Diagnosis}

Cotesia australiensis can be separated from all other species of Cotesia currently described from Australia and Papua New Guinea by the following combination of characters: anteromesoscutum punctate; fore wing $\mathrm{r}$ vein straight; antennal flagellomere 14 length/width $>2$; scutellar disk mostly smooth with some shallow punctures and centre of the medial posterior band of the scutellum smooth; T1 parallel sided; T2 trapezoid with shallow crenulate border with T3; T3 with very sparse setae over most of tergite, mostly dark.

\section{Material examined}

Holotype (only images examined)

AUSTRALIA • क; [A.] Koebele [leg.]; USNM 4913.

\section{Other material}

AUSTRALIA • 3 우, 2 ??; Victoria, Beaconsfield; Mar. 1929; A.M. Wade leg.; ex. Anther[a]ea eucalypti; "Apanteles australiensis Ashmead det. D.S. Wilkinson 1930 compared with type series"; ANIC 32151532 to 32151536.

\section{Redescription}

Female (from ANIC specimen 151536)

Colour. Head, antenna, mesosoma and metasoma dark other than lateral sides of T1-2 which are paler; (fore-, mid-, hind coxa) dark, dark, dark; femora (fore-, mid-, hind femur) pale, pale, pale with distal dark patch; tibiae (fore-, mid-, hind tibia) pale, pale, pale darkening distally; tegula and humeral complex light brown to dark; pterostigma light brown to dark; fore wing veins light brown.

BODY LENGTH. Head to apex of metasoma: $2.5 \mathrm{~mm}$.

HEAD. Antenna slightly longer than body length; OOL/posterior ocellus diameter 1.7; POL/posterior ocellus diameter 1.6; antennal flagellomere 2 length/width 3; antennal flagellomere 14 length/width 2.5 . 


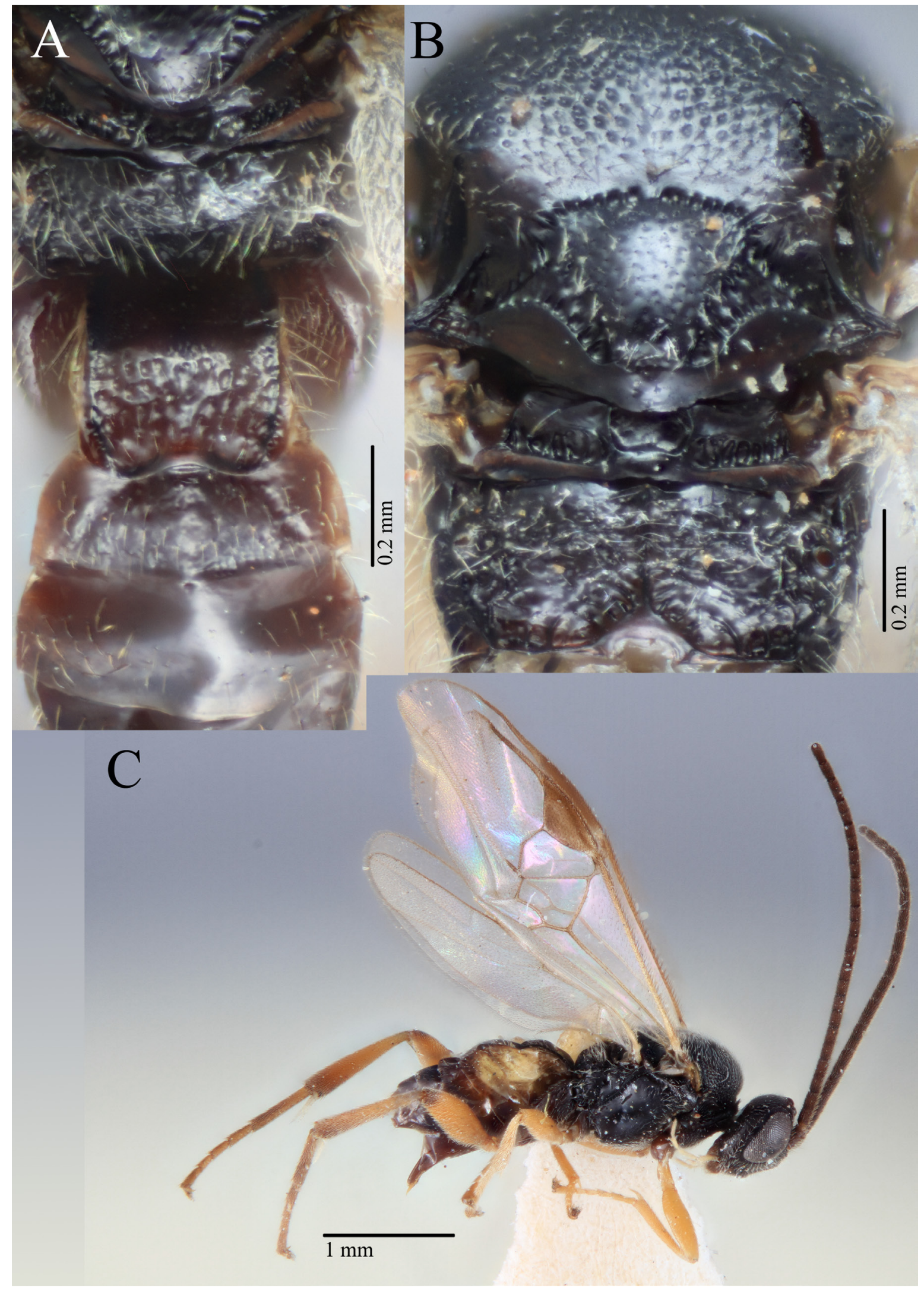

Fig. 14. Cotesia australiensis (Ashmead, 1900). A. Propodeum, T1-3 (ANIC 32 151536). B. Mesosoma (ANIC 32 151535). C. Habitus in lateral view (ANIC 32 151532). 
Mesosoma. Anteromesoscutum with regular, shallow, small punctures, appearing smoother than most species treated; number of pits in scutoscutellar sulcus 10; scutellar disc mostly smooth with some shallow punctures; maximum height of mesoscutellum lunules/maximum height of lateral face of mesoscutellum 0.6.

WINGS. Fore wing length $2.8 \mathrm{~mm}$; length of veins r/2RS 0.8 ; length of veins $2 \mathrm{RS} / 2 \mathrm{M} 1.8$; length of veins $2 \mathrm{M} /(\mathrm{RS}+\mathrm{M}) \mathrm{b}$ 0.9; pterostigma length/width 3.3 .

LEGS. Hind tibia inner spur length/metabasitarsus length 0.5 .

Propodeum. Medial carina present, propodeum with irregular and sparse sculpturing.

Metasoma. T1 length/T1 width at posterior margin 1.3; T1 parallel sided, curved at posterior corners, smooth in anterior half, with large shallow punctures in posterior half; T2 width at posterior margin/T2 length 2.3, the sclerotised area of T2 almost an isosceles trapezium, mostly smooth with some irregular sculpturing, wide, very shallow crenulate border at lateral edges; T3 sculpture smooth and shiny; ovipositor sheaths length/hind tibial length 0.2 .

\section{Male}

Unknown.

\section{Distribution}

Type locality given only as Australia. Vic (record from examined material), NSW, Tas (records from Austin \& Dangerfield 1992).

\section{Host}

Opodiphthera eucalypti (Scott, 1864) (Saturniidae Boisduval, 1837). Gregarious cocoon mass (record from Wilkinson 1930).

\section{Remarks}

We base the redescription and measurements of this species on the series of specimens in ANIC, with reference also to the images of the holotype available on the Smithsonian Entomology Collections database (http://n2t.net/ark:/65665/3639803ce-5025-4c10-bd7c-42bba8777cdf).

Cotesia deliadis (Bingham, 1906)

Figs $2 \mathrm{C}, 15$

Apanteles deliadis Bingham, 1906: 125 (lectotype,, , OUMNH).

Apanteles deliadis - Wilkinson 1928: 99 (redescription).

Cotesia deliadis - Austin \& Dangerfield 1992: 21 (lectotype designation and transfer from Apanteles s.1.).

\section{Diagnosis}

Cotesia deliadis can be separated from all other species of Cotesia currently described from Australia and Papua New Guinea by the following combination of characters: anteromesoscutum punctate; scutellar disk smooth with some shallow punctures associated with setae; centre of medial posterior band of the scutellum smooth; T1 mostly parallel sided; T3 dark with sparse setae only in posterior half; fore wing 2RS not creating a 'stub' at junction with $r$. 


\section{Material examined}

\section{Paralectotype}

AUSTRALIA • 1 \%; Queensland, Townsville; "bred Jan.2.03 [2 Jan 1903] fr. larva Delias argenthona, F. \& pres 1906 by F.P. Dodd"; NHMUK.

\section{Other material}

AUSTRALIA • 4 우, 1 O; “Q” [Queensland], Townsville; 20 Aug. 1993; M.F. Braby leg.; reared from larva Delias argenthona on Dendrophthoe Mart. 1830; BOLD: AUMIC544-19; ANIC 32130300 - 2 o $ᄋ$; Victoria; St Arnaud; 2013; E. and J. Reid leg.; reared from larva of Delias aganippe; BOLD: AUMIC033-18, AUMIC039-18; WINC.

\section{Redescription}

Female (from paralectotype)

Colour. Head, antenna and mesosoma dark, T1-2 dark, rest of metasoma pale on non-sclerotised areas with dark sclerotised areas on dorsal surface, pale laterally, (fore-, mid-, hind coxa) dark, dark, dark; femora (fore-, mid-, hind femur) pale, pale, pale; tibiae (fore-, mid-, hind tibia) pale, pale, pale; tegula and humeral complex pale to light brown; pterostigma light brown; fore wing veins light brown.

Body LENGTH. Head to apex of metasoma: $2.3 \mathrm{~mm}$.

HEAD. Antenna slightly longer than body length; OOL/posterior ocellus diameter 1.9; POL/posterior ocellus diameter 2.4; antennal flagellomere 2 length/width 3.0; antennal flagellomere 14 length/width 2.9.

Mesosoma. Anteromesoscutum punctate, punctures reasonably regular but denser along notauli lines compared to lateral areas and very centre; number of pits in scutoscutellar sulcus 9 or 10; scutellar disc mostly smooth with some shallow punctures associated with setae; maximum height of mesoscutellum lunules/maximum height of lateral face of mesoscutellum 0.5 .

WINGS. Fore wing length $2.7 \mathrm{~mm}$; length of veins r/2RS 1.3; length of veins $2 \mathrm{RS} / 2 \mathrm{M} 1.3$; length of veins $2 \mathrm{M} /(\mathrm{RS}+\mathrm{M}) \mathrm{b}$ 0.9; pterostigma length/width 2.6.

LEGS. Hind tibia inner spur length/metabasitarsus length [couldn't measure due to leg placement] $>0.5$ (Wilkinson 1928a).

Propodeum. Medial carina present, irregularly rugose and punctate, posterior third smooth and shiny with sparse carinae.

Metasoma. T1 length/T1 width at posterior margin 1.8; T1 generally parallel sided, very slightly narrowing at posterior corners, very smooth, some very shallow punctures in posterior half; $\mathrm{T} 2$ width at posterior margin / T2 length 2.6, the sclerotised area of T2 not well distinguished at lateral edges, curved at anterior margin, T2 mostly smooth, some irregular pits by anterior and lateral edges; T2 length / T3 length $0.7 ; \mathrm{T} 3$ sculpture smooth and shiny; ovipositor sheaths length/hind tibial length 0.18 .

Male (from M.F. Braby specimens)

As female, but with denser (still shallow) punctures on scutellar disc, T2 slightly longer in relation to posterior width, sclerotised area of T2 more sharply defined, closer in shape to subtriangular or hemispherical.

\section{Distribution}

Qld (type specimens, recorded material), Vic (material examined). 


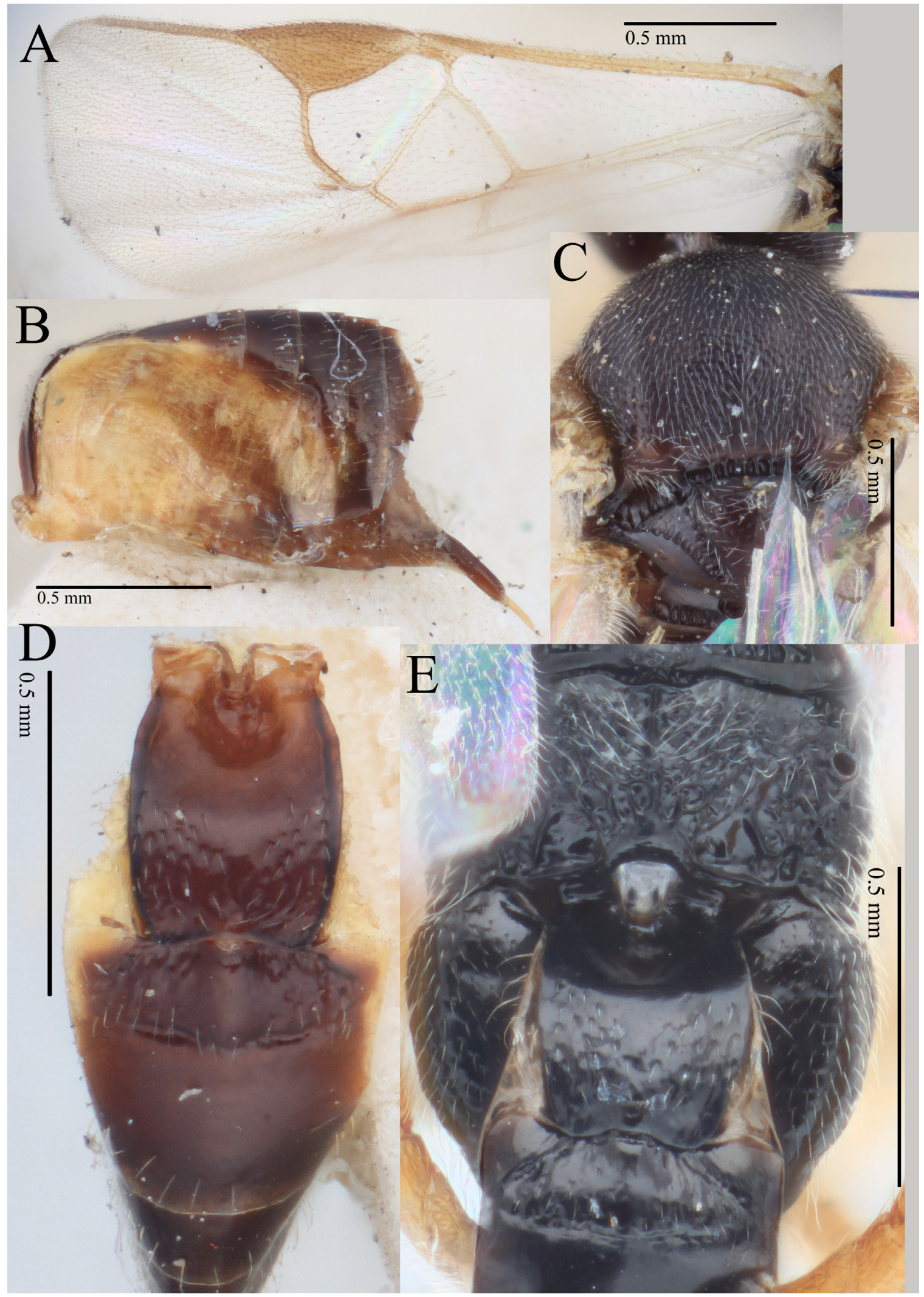

Fig. 15. A-D. Cotesia deliadis (Bingham, 1906), paralectotype (NHMUK). A. Fore wing. B. Metasoma in lateral view. C. Anteromesoscutum. D. Metasoma in dorsal view. E. C. deliadis from Victoria (WINC), with propodeum and T1-2 showing darker colouration. 


\section{Host}

Delias argenthona (Pieridae Swainson, 1820) (record from type specimens and examined material), Delias aganippe (Donovan) (record from examined material - new host record for this species) gregarious.

\section{Remarks}

We examined and sequenced specimens reared from Delias aganippe in Victoria by E. and J. Reid, which are morphologically very similar to $C$. deliadis, but much darker in colouration. With a $145 \mathrm{bp}$ $C O I$ barcode available for a specimen identified as $C$. deliadis and reared from $D$. argenthona from the type locality in Qld (BOLD: AUMIC544-19), which differs by only 1 bp from the sequences of the Victorian specimens (BIN BOLD:ADL3255, Fig. 1), we assign the Victorian specimens to C. deliadis. Darker colouration in conspecific specimens further south in Australia is common, and this therefore expands the distribution of $C$. deliadis. Correspondingly, we assign the full-length $\mathrm{COI}$ barcode from the Victorian specimens to $C$. deliadis.

We also note that the species C. deliadis strongly resembles Glyptapanteles deliasa Austin \& Dangerfield (1992) which parasitises D. aganippe in South Australia, but we were unsuccessful in obtaining DNA from paratypes of this species for comparison and therefore do not treat G. deliasa here.

Cotesia erionotae (Wilkinson, 1928)

Fig. 16A

Apanteles erionotae Wilkinson, 1928: 83 (holotype,, , NHMUK).

Cotesia erionotae - Austin \& Dangerfield 1992: 21 (transfer from Apanteles s.1.).

\section{Diagnosis}

Cotesia erionotae can be separated from all other species of Cotesia currently described from Australia and Papua New Guinea by the following combination of characters: T3 pale; T1-2 mostly pale; antennae pale.

\section{Material examined}

\section{Holotype}

MALAYSIA • 1 q; Parit Buntar; Mar. 1922; G.H. Corbett leg.; parasite from Erionota thrax (Linnaeus, 1767); "233”; NHMUK 3.c.1037.

\section{Distribution}

Malaysia (from type specimens); Papua New Guinea (introduced, see Waterhouse et al. 1998); Thailand, Mauritius (introduced), Guam (introduced), Hawaii (introduced), Saipan (introduced) (Waterhouse \& Norris 1989).

\section{Host}

Erionota thrax (Hesperiidae) (record from type material), gregarious (Okolle et al. 2006).

\section{Remarks}

We include this species in the key due to its presence in Papua New Guinea, but it is not known to occur in Australia. 


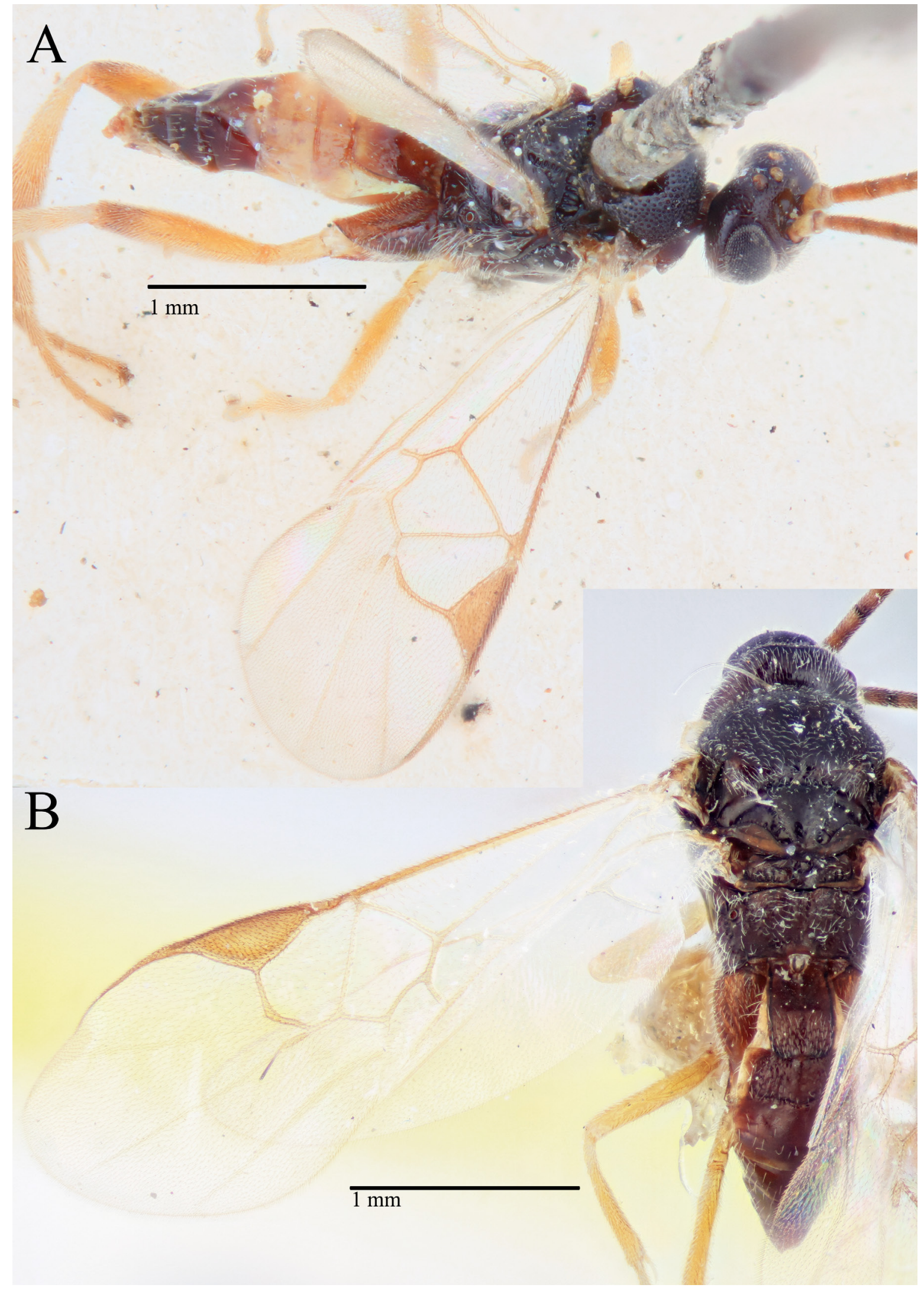

Fig. 16. A. Cotesia erionotae (Wilkinson, 1928), holotype, $q$ (NHMUK 3.c.1037). B. Cotesia geometricae Austin, 2000, paratype (WINC). 
Cotesia flavipes Cameron, 1981

Figs $6 \mathrm{C}, 17$

Cotesia flavipes Cameron, 1891: 185 (holotype, $\widehat{\jmath}$, NHMUK).

Apanteles nonagriae Viereck 1913: 645.

Apanteles flavipes Wilkinson, 1928a: 93 (synonymy with A. nonagriae), see Shenefelt (1972), Yu et al.

(2016) and Fernández-Triana et al. (2020) for extra-limital synonyms and notes.

\section{Diagnosis}

Cotesia flavipes can be separated from nearly all other species of Cotesia currently described from Australia and Papua New Guinea by the dorsoventrally flattened mesosoma, and can be separated from the closely related Cotesia nonagriae (described from Australia, presence in Papua New Guinea unconfirmed) most easily by molecular data (e.g., Genbank: DQ232336 from India, DQ232335 from Pakistan) (Muirhead et al. 2012; also see under C. nonagriae), and also by the shape of the face projection between the antennal bases. When viewed under SEM, the projection is more prominent and rounded with a relatively smooth margin, compared to $C$. nonagriae which has the margin tri-lobed and the projection less prominent.

\section{Material examined}

Other material

INDONESIA • 1 q; Sumatra, Lapung; 2 Jul. 1982; 4965; ex. L. Chilo sacchariphagus (Bojer, 1856); CIE A14465; WINC.

INDIA • 1 +; "H.P. Solan, Deothi”; ex. Chilo partellus (C. Swinhoe, 1885); Sep. 1982; Ram Pratap No.9; CIE A14665; WINC.

\section{Distribution}

Cotesia flavipes is a cosmopolitan species which has been introduced into several countries (e.g., Barbados, Brazil, Colombia, Kenya, Mauritius, Peru, Rèunion, South Africa, USA) for biological control purposes (Muirhead et al. 2006). In the Australasian region it is recorded from Papua New Guinea (Muirhead et al. 2012).

\section{Host}

Known to parasitise many different species of Noctuidae Latreille, 1809 and Crambidae Latreille, 1810; in Papua New Guinea reared from Sesamia grisecens Warren, 1911 (Noctuidae), gregarious (Muirhead et al. 2006).

\section{Remarks}

We include this species in the key due to its presence in Papua New Guinea. Until recently, C. flavipes was recorded as being present in Australia, but the Australian specimens have been identified as $C$. nonagriae, and this species raised from synonymy (Muirhead et al. 2008). Cotesia flavipes is therefore not currently recorded from Australia, but may possibly be introduced in the future for the control of stem-boring pests.

Cotesia geometricae Austin, 2000

Fig. 16B

Cotesia geometricae Austin, 2000 in Schumacher et al. 2000: 11 (holotype,, , ANIC). 


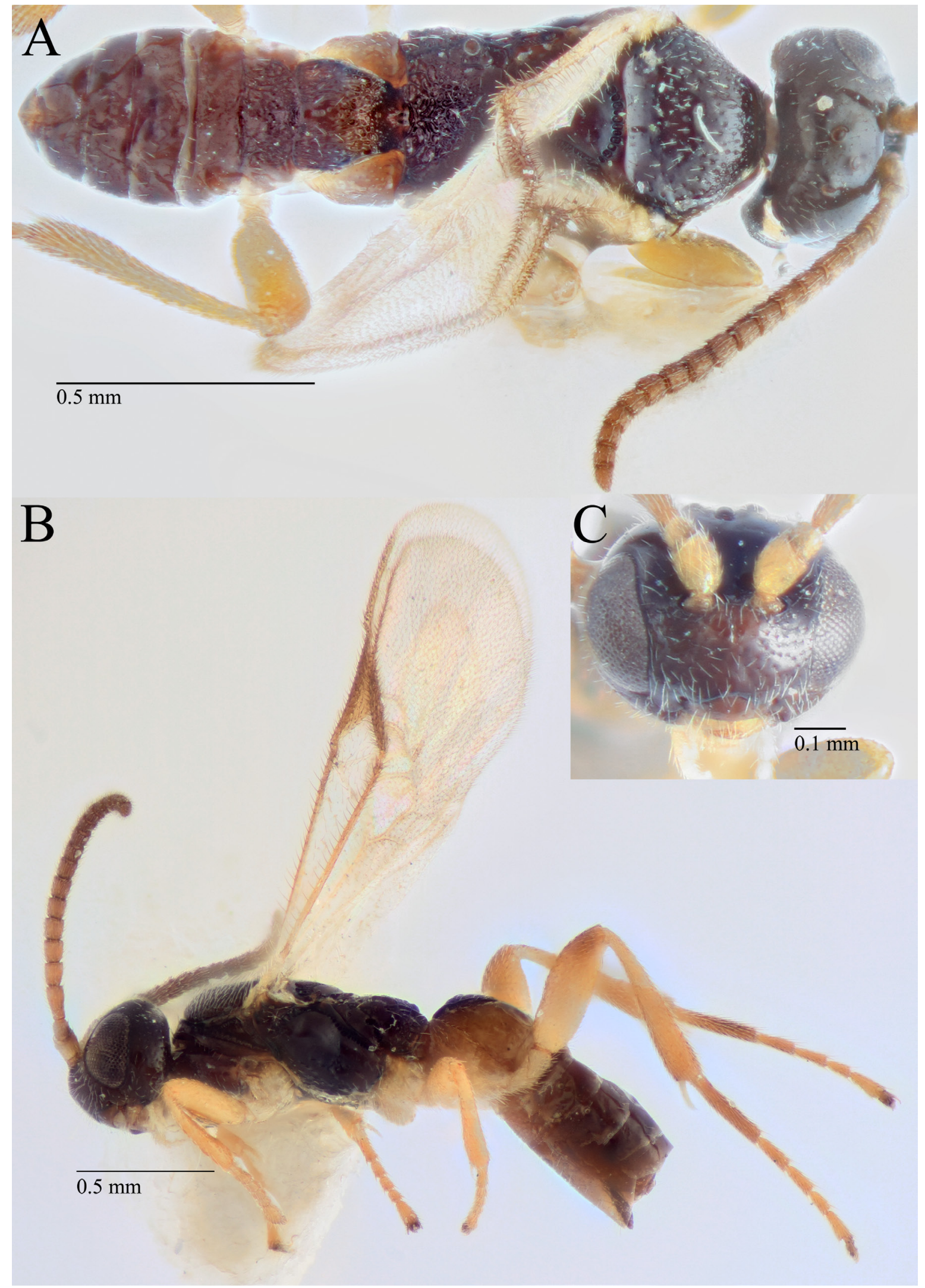

Fig. 17. Cotesia flavipes Cameron, 1981, from India (WINC). A. Habitus in dorsal view. B. Habitus in lateral view. C. Head in anterior view. 


\section{Diagnosis}

Cotesia geometricae can be separated from all other species of Cotesia currently described from Australia and Papua New Guinea by the following combination of characters: anteromesoscutum punctulate, much smoother than most other species; T3 only sparsley setose, mostly in posterior third; T1 parallel sided; fore wing vein 2RS not extending past junction with $r$, not creating a 'stub', hypopygium not emarginate.

\section{Material examined}

Paratypes

AUSTRALIA • 2 qo; Victoria, Alona, Dow Chemical Plant; 8 Jul. 1994; ex. Mnesampela privata (Guenée, 1857) larvae (Lept: Geometridae); WINC.

\section{Distribution}

Currently known from Victoria and the Australian Capital Territory (from examined material and original description).

\section{Host}

Mnesampela privata (Geometridae), gregarious (from original description).

\section{Remarks}

As this species is only recently described and we feel that the description is relatively complete, we provide only new characters or measurements relevant to its diagnosis, and refer otherwise to the description in Schumacher et al. (2000).

Cotesia glomerata (Linnaeus, 1758)

Fig. 18A, C-D

Ichneumon glomeratus Linnaeus, 1758: 568 (holotype unknown).

Apanteles glomeratus Nixon, 1974: 492 (redescription).

Cotesia glomerata - Mason 1981: 112 (transferred from Apanteles s.1.).

For a full list of synonyms and bibliography, see Shenefelt (1972: 519), Yu et al. (2016) and FernándezTriana et al. (2020).

\section{Diagnosis}

Cotesia glomerata can be separated from all other species of Cotesia currently described from Australia and Papua New Guinea by the following combination of characters: ventral hypopygium deeply emarginate; T1 parallel sided; fore wing 2RS not creating a 'stub' at junction with r; T3 only sparsely setose, mostly in posterior third; anteromescutum punctate but smoother than most other species.

\section{Material examined}

\section{Other material}

AUSTRALIA - Victoria • 1 q; St. Arnaud, Australian Bible Museum Butterfly Garden; $36.61281^{\circ} \mathrm{S}$, 143.25478 ${ }^{\circ}$ E; 2013; E. Reid leg.; reared from Pieris rapae; BOLD COI code for specimens from same rearing event: AUMIC014-18 and AUMIC022-18; WINC - 1 \%; Hastings; emerged 29 Aug. 2018 from bright yellow cocoons; P. Zacchariah leg.; BOLD COI code for specimen from same rearing

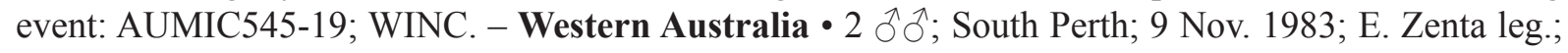
Apanteles glomeratus det. A.D. Austin 1984; WINC C.I.E. Coll. A. 15750. 


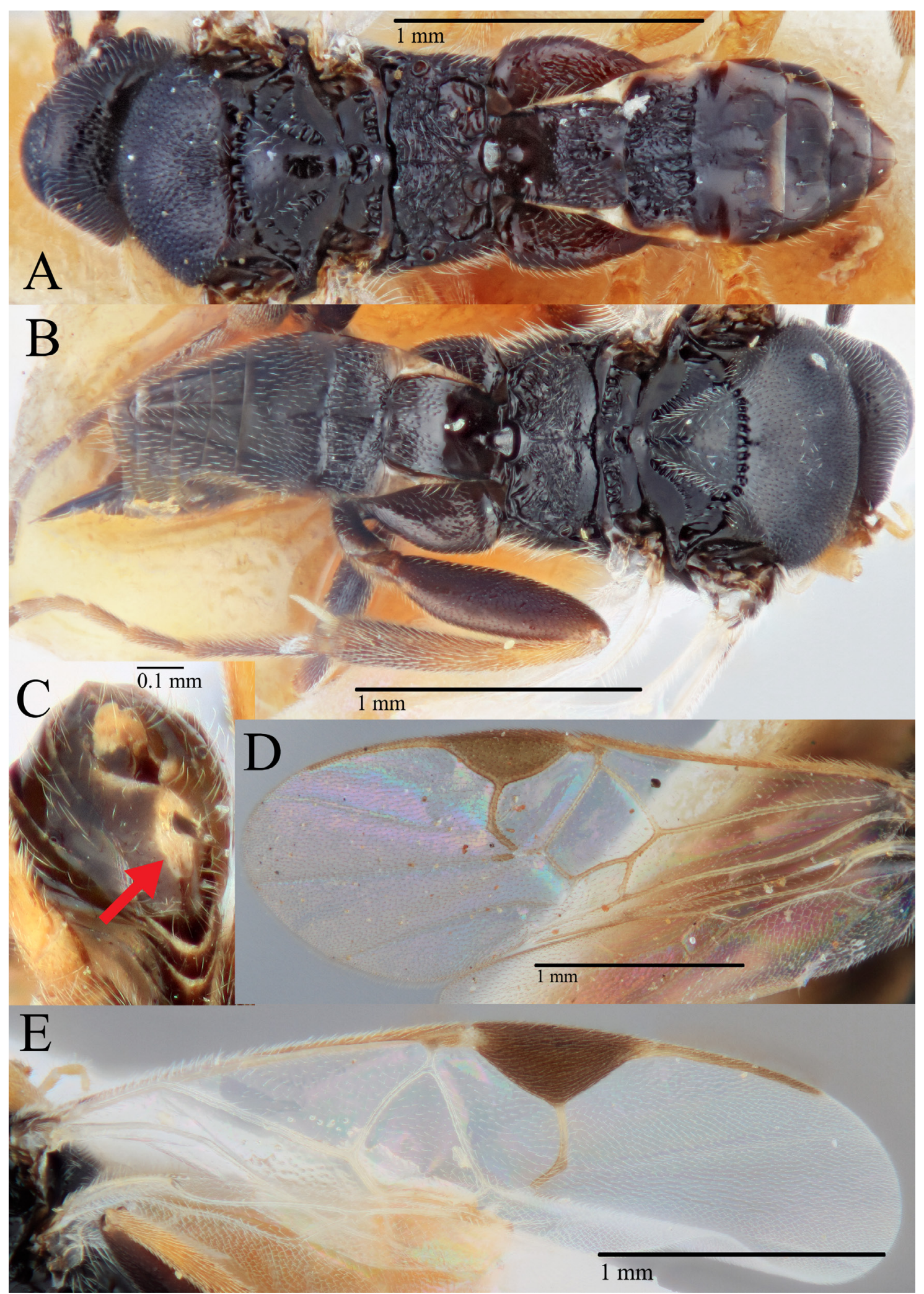

Fig. 18. A. Cotesia glomerata (Linnaeus, 1758), specimen from South Perth (WINC), habitus in dorsal view. B. C. kazak (Telenga, 1949), specimen from Mariginiup (WINC), habitus in dorsal view. C. C. glomerata, specimen from Victoria (WINC), hypopygium in ventral view, arrow pointing towards emarginated area. D. C. glomerata, fore wing. E. C. kazak, fore wing. 


\section{Distribution}

Found in all states and territories of Australia, see Fernández-Triana et al. (2020) for global distribution.

\section{Host}

Pieris rapae (Pieridae); see Shenefelt (1972: 519), Nixon (1974: 492) and Yu et al. (2016) for extralimital host records.

Cotesia kazak (Telenga, 1949)

Figs $8 \mathrm{~A}, 18 \mathrm{~B}, \mathrm{E}$

Apanteles kazak Telenga, 1949: 385 (lectotype,, , ZIN).

Cotesia kazak - Papp 1988: 153 (transfer from Apanteles s.1.).

\section{Diagnosis}

Cotesia kazak can be separated from all other species of Cotesia currently described from Australia and Papua New Guinea by the following combination of characters: anteromesoscutum punctulate, smoother than most species; T3 densely setose; fore wing $2 \mathrm{RS}$ not creating a 'stub' at junction with r; T1 parallel sided.

\section{Material examined}

\section{Other material}

AUSTRALIA - Western Australia • 2 q $q$; "Maraginiup” [Mariginiup]; 20 Mar. 1990; P. Hutchinson leg.; ex. Heliothis on Lucerne; emerged 2 Apr. 1990; Cotesia kazak determined A. Austin 1990; WINC - 1 Ĵ; Carabooda; 1 Mar. 1990; S. Harrington leg.; ex. Heliothis on Lucerne; emerged 9 Mar. 1990; Cotesia kazak determined A. Austin 1990; WINC • 4 우, 2 §ิ ô; Wokalup RS [Research Station]; 17 Feb. 1988; P. Lawrence leg.; ex. Heliothis punctiger; Cotesia kazak determined A. Austin 1990; WINC.

\section{Distribution}

Palearctic. Introduced to WA (Michael et al. 1984) and New Zealand (Carl 1978; Cameron \& Valentine 1985) for the biological control of Helicoverpa armigera (Hübner, 1808).

\section{Host}

Helicoverpa armigera (Noctuidae) (record from description and biological control literature), solitary (le Masurier 1987). Helicoverpa punctigera (Wallengren, 1860), solitary (from examined material).

Cotesia lasallei sp. nov. urn:1sid:zoobank.org:act:84A4B9CE-BFA1-44E5-ACE1-37E75E5CBB01

Figs 9B, 11C, 19

\section{Diagnosis}

Cotesia lasallei sp. nov. can be separated from all other species of Cotesia currently described from Australia and Papua New Guinea by the following combination of characters: Antennal flagellomere 14 length/width $<1.5$ in females, clearly shorter than most other species; fore wing $r$ vein straight; $\mathrm{T} 1$ parallel sided, T1-2 mostly smooth; T2 with indistinct or shallowly indented border with T3; T3 dark with sparse setae over most of tergite; anteromesoscutum reticulate rugose; scultellar disk smooth with only shallow punctures; centre of medial posterior band of the scutellum (directly posterior to scutellar disk) smooth; fore wing $2 \mathrm{RS}$ not creating a 'stub' at junction with $\mathrm{r}$. 


\section{Etymology}

We dedicate this species in honour of the late Dr John La Salle, hymenopterist, biodiversity researcher, director of the Atlas of Living Australia, and great friend to ADA.

\section{Material examined}

\section{Holotype}

AUSTRALIA • $\odot$; South Australia, Flinders Ranges, Brachina Gorge; $31.34125^{\circ} \mathrm{S}, 138.56679^{\circ} \mathrm{E} ; 5 \mathrm{Apr}$. 2011; R. Kittel leg.; sweeping creek vegetation; BOLD: AUMIC300-18; Genbank COI: MH138642; SAMA 32-44401.

\section{Paratypes}

AUSTRALIA - South Australia • 1 o; Andamooka; $30.72701^{\circ}$ S, $137.2036^{\circ}$ E; 30 Aug. 2016; B.A. Parslow leg.; sweeping; Bush Blitz Lake Torrens; in ethanol; BOLD: AUMIC131-18, Genbank COI: MH139126; WINC • 1 क; Witchelina Stn; $30.09556^{\circ}$ S, $138.13583^{\circ}$ E; 14 Oct. 2010; S. Mantel leg.; BOLD: AUMIC321-18, Genbank COI: MH138639; SAMA 32-44402 • 1 đ Andamooka Station; Andamooka Homestead; $30.72627^{\circ} \mathrm{S}, 137.20149^{\circ} \mathrm{E}$ to Wirrda Well $30.67943^{\circ} \mathrm{S} 137.07232^{\circ} \mathrm{E}$; vehicle net; 31 Sep. 2016; R. Leijs leg.; Bushblitz Lake Torrens; BOLD: AUMIC534-19, Genbank COI: MK567157; SAMA 32-44403.

\section{Description}

\section{Female}

Colour. Head, antenna and mesosoma dark, all tergites and most of metasoma dark, non sclerotised areas of T1-2 and anterior sternites paler; (fore-, mid-, hind coxa) dark, dark, dark; femora (fore-, mid-, hind femur) pale, light brown, dark; tibiae (fore-, mid-, hind tibia) pale, pale darkening distally, pale darkening distally or completely dark; tegula and humeral complex light brown to dark; pterostigma light brown to dark; fore wing veins light brown to dark.

Body LENGTH. Head to apex of metasoma: 2.3 (2.4) mm.

HeAD. Antenna slightly shorter than body length; OOL/posterior ocellus diameter 1.7 (1.8); POL/ posterior ocellus diameter 2.1 (2.5); antennal flagellomere 2 length/width 2.4; antennal flagellomere 14 length/width 1.3 .

Mesosoma. Anteromesoscutum reticulate rugose, finer in anterior half; number of pits in scutoscutellar sulcus 10 (11); scutellar disc with only shallow punctures; maximum height of mesoscutellum lunules/ maximum height of lateral face of mesoscutellum 0.7 (0.5).

WINGS. Fore wing length 2.3 (2.7) $\mathrm{mm}$; length of veins r/2RS 1.3; length of veins $2 \mathrm{RS} / 2 \mathrm{M} 1.5$ (1.2); length of veins $2 \mathrm{M} /(\mathrm{RS}+\mathrm{M}) \mathrm{b} 0.8$; pterostigma length/width 2.4 .

LEGS. Hind tibia inner spur length/metabasitarsus length 0.6.

PROPODEUm. Relatively smooth, but with scattered carina and rugosity, particularly short carina radiating from posterior centre, and in posterior lateral corners. Medial carina indistinct.

Metasoma. T1 length/T1 width at posterior margin 1.4 (1.3); parallel sided, mostly smooth with only shallow indistinct sculpturing; T2 width at posterior margin/T2 length 3.0 (2.7), rectangular with curved anterior corners, in paratypes more trapezoid shaped, mostly smooth, border with T3 indistinct in holotype, indented in paratypes; T2 length / T3 length 0.8 (0.7); T3 sculpture smooth and shiny; ovipositor sheaths length/hind tibial length $0.3(0.2)$. 


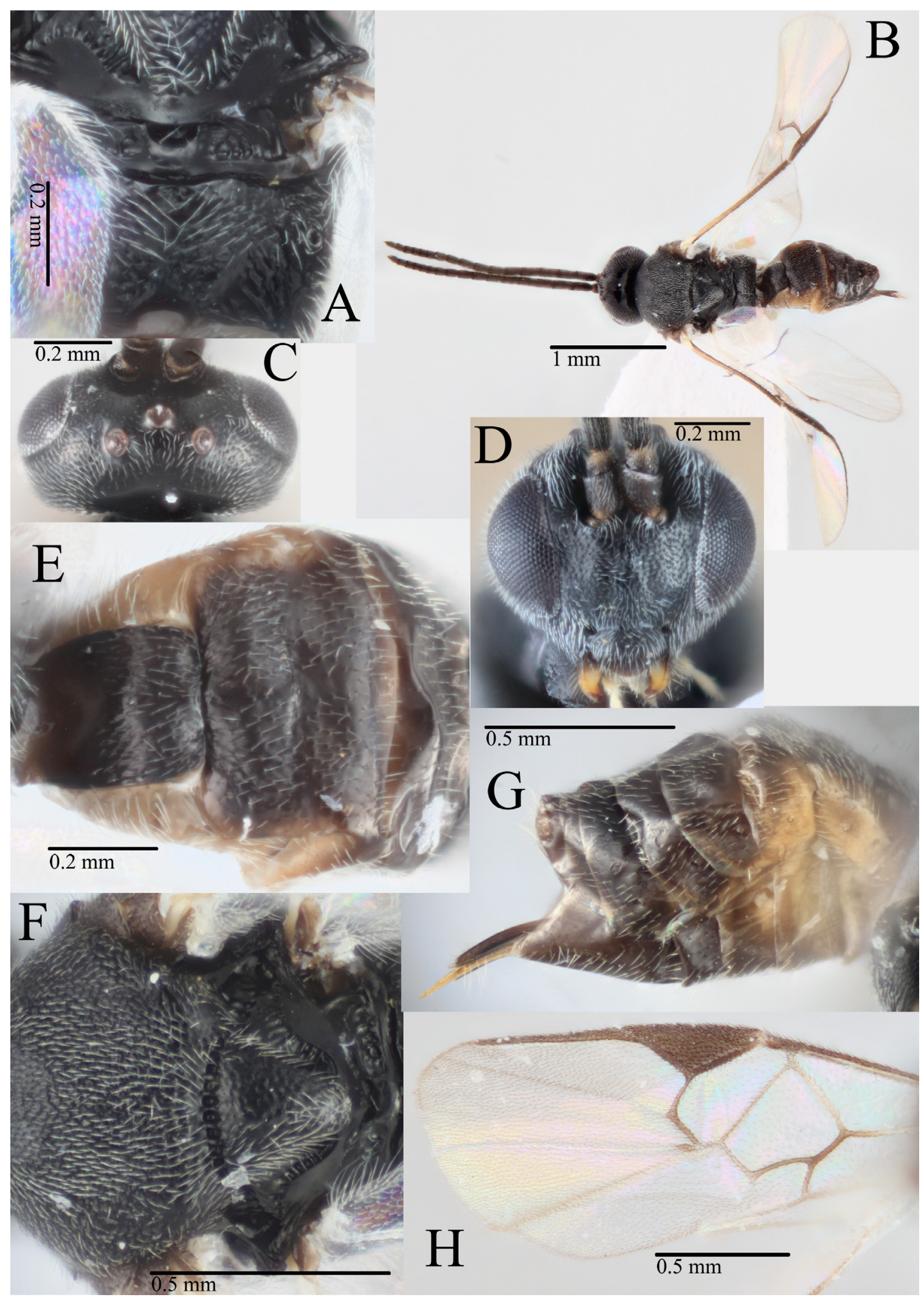

Fig. 19. Cotesia lasallei sp. nov., holotype, $q$ (SAMA 32-44401). A. Mesoscutellum and propodeum. B. Habitus in dorsal view. C. Head in dorsal view. D. Head in anterior view. E. Metasoma in dorsal view. F. Anteromesoscutellum and scutellar disk. G. Metasoma in lateral view. H. Fore wing. 


\section{Male}

As female but hind leg all dark, body longer ( $2.5 \mathrm{~mm}$ body length), 14 pits in the scutoscutellar sulcus, some variation in measurements including $\mathrm{T} 1$ length / $\mathrm{T} 1$ width at posterior margin 1.6, and notably the antenna lengthened: antennal flagellomere 2 length/width 2.8; antennal flagellomere 14 length/width 3.6.

\section{Distribution}

Currently only known from arid South Australia, in regions surrounding Lake Torrens.

\section{Host}

Unknown.

\section{Remarks}

This species constitutes the BIN BOLD:ADL2795, and is greater than 3\% divergent from any other sequences available on the database.

Cotesia medusae sp. nov. urn:lsid:zoobank.org:act:DEE8E0E8-BD4D-4780-AAD2-326505BA750A

Figs $10 \mathrm{C}, 11 \mathrm{D}, 12 \mathrm{~A}, 20$

\section{Diagnosis}

Cotesia medusae sp. nov. can be separated from all other species of Cotesia currently described from Australia and Papua New Guinea by the following combination of characters: anteromesoscutum punctate reticulate; antennal flagellomere 14 length/width $>2$; scutellar disk smooth with only shallow punctures associated with setae and with centre of medial posterior band of the scutellum smooth; fore wing $r$ vein straight and fore wing $2 \mathrm{RS}$ not creating a 'stub' at junction with $\mathrm{r}$; T2 semicircle shaped, border with T3 often shallowly crenulate; T3 mostly dark with some pale areas and sparse setae over most of tergite, notauli clearly differentiated from surrounding anteromesoscutum sculpturing.

\section{Etymology}

This species is named after Medusa, the 'Gorgon' or monster in Greek mythology. Gorgonphone, the species name of the host (Catopsilia gorgophone Boisduval, 1836) means 'Gorgon-Slayer'. Thus, there seems to be an appropriate amount of irony in the lethal parasitoid of this species being named for the original monster.

\section{Material examined}

\section{Holotype}

AUSTRALIA - ; Queensland, Brisbane; emg. Jun. 2013; R. Kendall leg.; reared from larva of Catopsilia gorgophone (Lepidoptera: Pieridae); BOLD (from co-reared specimen): AUMIC543-19; Genbank COI (from co-reared specimen): MN182699; QM T246704.

\section{Paratypes}

AUSTRALIA • 2 우, 2 ○ึ; same collection data as for holotype; QM T246705-8.

\section{Description}

\section{Female}

Colour. Head, antenna and mesosoma dark, dorsal metasoma dark but lighter than mesosoma, darkening posterior to T3, non-sclerotised areas of T1-2 and lateral edges of T3 pale; anterior sternites pale, 
darkening posteriorly; (fore-, mid-, hind coxa) dark, dark, dark but lighter than fore- and mesocoxa; femora (fore-, mid-, hind femur) pale, pale, pale darkening distally; tibiae (fore-, mid-, hind tibia) pale, pale, light brown darkening distally; tegula and humeral complex dark; pterostigma dark; fore wing veins light brown to dark.

Body LENGTH. Head to apex of metasoma: 2.2 (2.3) mm.

HEAD. Antenna slightly longer than body length; OOL/posterior ocellus diameter 2.2; POL/posterior ocellus diameter 1.9 (1.7); antennal flagellomere 2 length/width 2.7 (2.5); antennal flagellomere 14 length/width 1.8 (2.0).

Mesosoma. Anteromesoscutum sculpturing punctate reticulate, transitioning to almost reticulate rugose along lines of notauli; number of pits in scutoscutellar sulcus 8 (9); scutellar disc with only shallow pits associated with setae; maximum height of mesoscutellum lunules/maximum height of lateral face of mesoscutellum $0.7(0.6)$.

WINGS. Fore wing length $2.3 \mathrm{~mm}$; length of veins $\mathrm{r} / 2 \mathrm{RS} 1.1$ (1.0); length of veins $2 \mathrm{RS} / 2 \mathrm{M} 1.6$ (2.1); length of veins $2 \mathrm{M} /(\mathrm{RS}+\mathrm{M}) \mathrm{b} 1.0(0.9)$; pterostigma length/width 2.7 (2.8).

LEGS. Hind tibia inner spur length/metabasitarsus length 0.5 .

Propodeum. Posterolateral thirds smooth, centre third rugose, medial carina only faintly distinct from surrounding rugosity.

Metasoma. T1 length/T1 width at posterior margin 1.6; parallel sided, mostly smooth, only small punctures associated with setae; T2 width at posterior margin/T2 length 2.3 (2.2), semicircle shaped, smooth with shallow crenulate border all the way round, T2 length / T3 length $0.6(0.8)$; T3 sculpture smooth and shiny; ovipositor sheaths length/hind tibial length 0.07 (0.1).

\section{Male}

As female, only slight variations in measurements.

\section{Host}

Catopsilia gorgophone (Pieridae), gregarious.

\section{Distribution}

Currently only known from the type locality in Brisbane, although as the host is found through much of New South Wales and Queensland, this parasitoid also likely has a wider range than currently documented.

\section{Remarks}

Whilst only a 340 bp section of COI was obtained for this species, which is not long enough to be assigned a BIN on BOLD, it is clearly distinct morphologically and genetically from any publically available sequence of Cotesia, and as host data is available we felt the description was warranted despite not possessing a full COI barcode.

Cotesia nonagriae (Olliff, 1893)

Figs $5 \mathrm{~A}, 6 \mathrm{~A}-\mathrm{B}, 21$

Apanteles nonagriae Olliff, 1893: 376 (holotype unknown). 


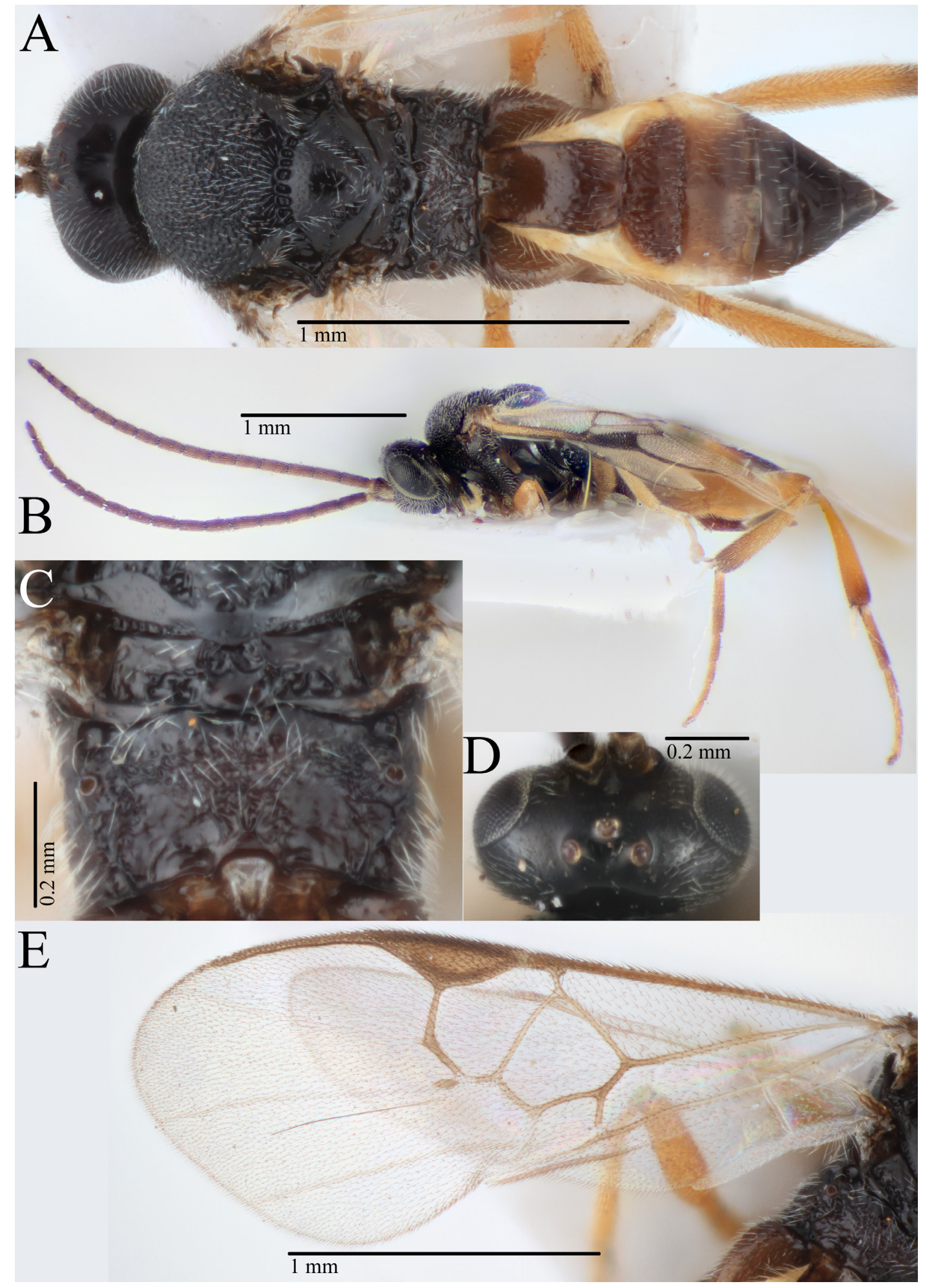

Fig. 20. Cotesia medusae sp. nov., paratype (QM T246705). A. Habitus in dorsal view. B. Habitus in lateral view. C. Propodeum. D. Head in dorsal view. E. Fore wing. 
Apanteles nonagriae - Wilkinson 1928b: 136.

Apanteles flavipes - Wilkinson 1928a: 93 (synonymy of A. nonagriae Viereck); 1929: 108 (synonymy of $A$. nonagriae Olliff).

Cotesia flavipes - Mason (1981): 113 (resurrected the genus with C. flavipes as type). - Austin \& Dangerfield (1992): 21.

Cotesia nonagriae - Muirhead et al. 2008: 38 (revised status and confirmed presence within Australia).

\section{Diagnosis}

Cotesia nonagriae can be separated from nearly all other species of Cotesia currently described from Australia and Papua New Guinea by the dorsoventrally flattened mesosoma, and can be separated from the closely related C. flavipes (recorded from Papua New Guinea, presence in Australia unconfirmed) most easily by molecular data (see Muirhead et al. 2012) but also by the shape of the face projection between the antennal bases; when viewed under SEM, the projection is flatter (less rounded/prominent) than that of $C$. flavipes, and has a margin that appears tri-lobed, compared to the smooth margin of the face projection of $C$. flavipes.

\section{Material examined}

\section{Other material}

AUSTRALIA • 1 +, 1 §ं; Queensland, Bundaberg; reared from Bathytricha truncata (Walker, 1856) on sugarcane; 12-30 Nov. 04 [2004]; K. Muirhead leg.; WINC・ 2 우, 1 रं; Queensland, Mackay; reared from Bathytricha tuncata on sugarcane; 12-30 Nov. 04 [2004]; K. Muirhead leg.; WINC • 1 ;; Queensland, Giru; reared from Bathytricha truncata on sugarcane; 5 Oct. 2003; M. Sallam leg.; WINC.

\section{Distribution}

NSW (from original type material), Qld (from examined material and Muirhead et al. 2008), possibly Papua New Guinea (Muirhead et al. 2012).

\section{Host}

Bathytricha truncata (Noctuidae), gregarious (Muirhead et al. 2008).

\section{Remarks}

Cotesia nonagriae was recently removed from synonmy with C. flavipes (Muirhead et al. 2008) based on distinct molecular $\mathrm{COI}$ and $16 \mathrm{~S}$ data and subtle morphological characters. Genbank numbers for verified C. nonagriae specimens are: JQ396711-13, JQ396704, JQ396747. The C. flavipes complex is a monophyletic group of seven described species (Fujie et al. 2018) that possess a dorsoventrally compressed mesosoma, most likely an adaptation for parasitising their stemboring hosts. Wilkinson synonymised Apanteles flavipes firstly with A. nonagriae Viereck, 1913 from Taiwan, and then later with A. nonagriae Olliff, 1893 from Australia. Muirhead et al. (2008) then raised C. nonagriae Olliff from synonymy with $C$. flavipes and redescribed the species. As this species is only recently redescribed and the description is relatively complete, we provide only new characters or measurements relevant to the diagnosis, and refer otherwise to the description in Muirhead et al. (2008). 


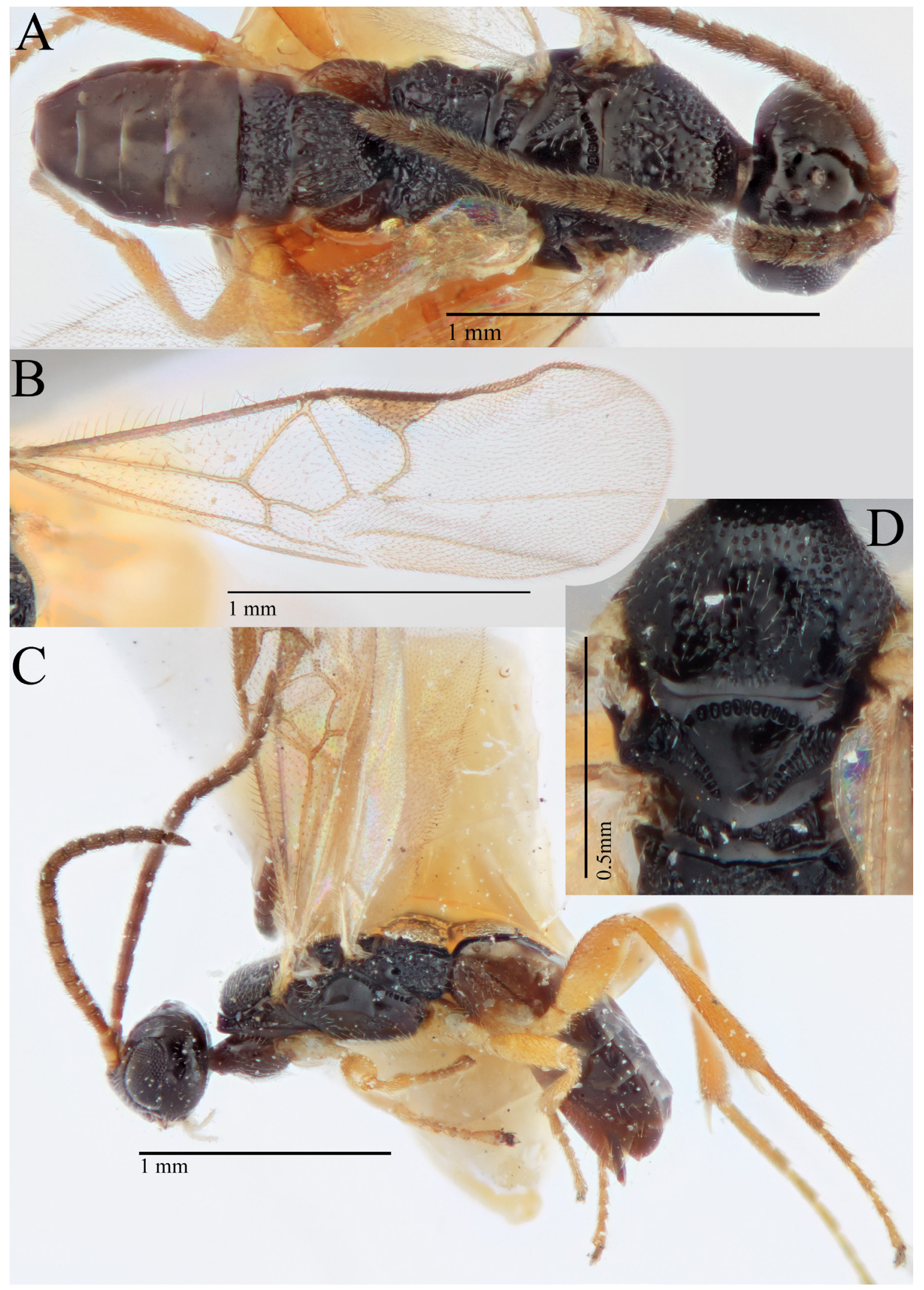

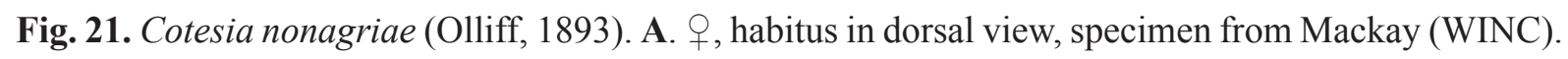
B. , , fore wing, specimen from Mackay (WINC). C. $ᄋ$, habitus in lateral view, specimen from Mackay (WINC). D. $\hat{0}$, mesosoma in dorsal view, specimen from Bundaberg (WINC). 
Cotesia ocellata sp. nov.

urn:1sid:zoobank.org:act:0C7082C6-35A3-4771-A141-607E6861930D

Figs $2 \mathrm{~A}, 22$

\section{Diagnosis}

Cotesia ocellata sp. nov. can be separated from all other species of Cotesia currently described from Australia and Papua New Guinea primarily by the small ocelli, OOL/posterior ocellus diameter $>2.5$ (and normally greater) and $\mathrm{T} 1$ broadening consistently posteriorly, almost wedge shaped.

\section{Etymology}

The species name is from the Latin adjective 'ocellatus', meaning 'small eyed' and reflecting the small size of the ocelli of this species compared to other Australian Cotesia. It is a feminine nominative singular adjective.

\section{Material examined}

\section{Holotype}

AUSTRALIA • $q$; South Australia, Cox Scrub Conservation Park; $35.33111^{\circ}$ S, $138.7475^{\circ}$ E; 20 Jan.10 Feb. 2008; A.D. Austin leg.; M/T; BOLD: AUMIC261-18, Genbank COI: MH138653; SAMA 3244404.

\section{Paratypes}

AUSTRALIA - 1 क ; same collection data as for holotype but 7-28 Oct. 2007, BOLD: AUMIC504-18, Genbank COI: MH138920; SAMA 32-44405 • 1 क; South Australia, Fleurieu Peninsula, Mt Billy Conservation Park; $35.45361^{\circ}$ S, $138.60611^{\circ}$ E; 25 Oct. 2000; C. Stephens leg.; M/T in bridal creeper invaded eucalypt woodland, BOLD AUMIC294-18, Genbank COI: MH138651; SAMA 32-44406 • 1 ; same collection data as for preceding; in ethanol; BOLD AUMIC256-18, Genbank COI: MH13864; WINC.

\section{Description}

\section{Female}

Colour. Head, antenna and mesosoma dark; all tergites and most of metasoma dark, non sclerotised areas of T1-2 and anterior sternites pale; (fore-, mid-, hind coxa) dark, dark, dark; hind tegular pale, femora (fore-, mid-, hind femur) dark lightening posteriorly, dark, dark; tibiae (fore-, mid-, hind tibia) dark, dark, dark; tegula and humeral complex dark; pterostigma dark; fore wing veins light brown to dark.

Body LENGTH. Head to apex of metasoma: $2.1(2.4-2.8) \mathrm{mm}$.

HEAD. Antenna approximately equal to body length; OOL/posterior ocellus diameter 2.9 (3.3-4.0); POL/ posterior ocellus diameter 2.2 (2.4-2.5); antennal flagellomere 2 length/width 3.4 (3.8-4.0); antennal flagellomere 14 length/width $2.0(1.8-2.2)$.

Mesosoma. Anteromesoscutum reticulate rugose, in holotype relatively consistent across anteromesoscutum, in paratypes much smoother in centre and lateral sides; number of pits in scutoscutellar sulcus 9 (8); scutellar disc with only shallow pits associated with setae; maximum height of mesoscutellum lunules/maximum height of lateral face of mesoscutellum $0.6(0.7)$.

WINGS. Fore wing length $2.0 \mathrm{~mm}$; length of veins $\mathrm{r} / 2 \mathrm{RS} 0.8(0.7-0.8)$; length of veins $2 \mathrm{RS} / 2 \mathrm{M} 0.8$ (0.9-1.0); length of veins $2 \mathrm{M} /(\mathrm{RS}+\mathrm{M}) \mathrm{b} 1.8$ (1.3-1.4); pterostigma length/width 2.8 (2.5-2.6).

LEGs. Hind tibia inner spur length/metabasitarsus length $0.3(0.4)$. 


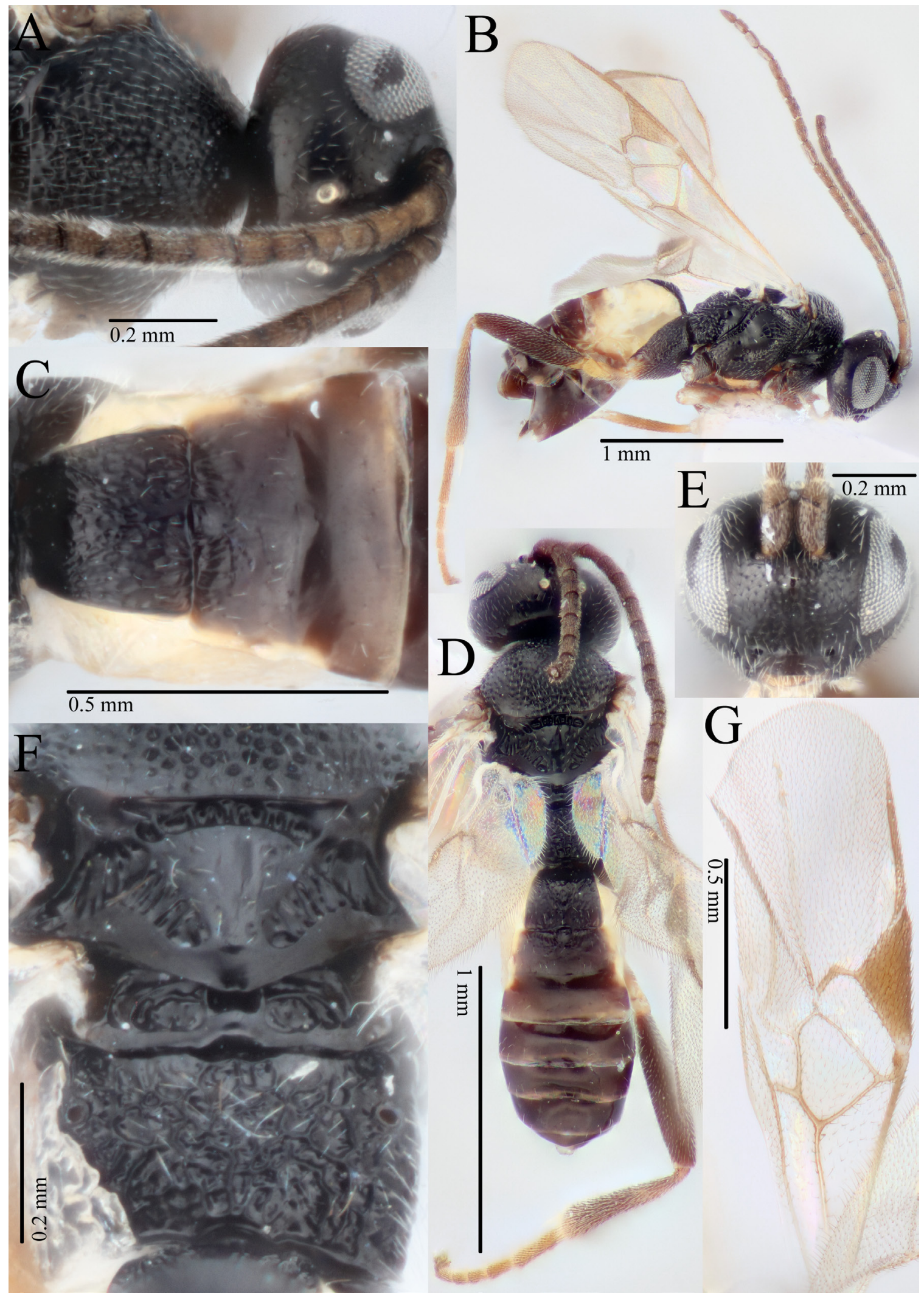

Fig. 22. Cotesia ocellata sp. nov., holotype, $q$ (SAMA 32-44404). A. Head in dorsal view and anteromesoscutum. B. Habitus in lateral view. C. T1-3. D. Habitus in dorsal view. E. Head in anterior view. F. Mesoscutum and propodeum. G. Fore wing. 
Propodeum. Medial carina present but indistinguishable from surrounding carina in paratypes (clearer in holotype), propodeum coarsely rugose.

Metasoma. T1 length / T1 width at posterior margin 1.0; slightly broadening posteriorly, rugose to rugulose sculpturing; T2 width at posterior margin / T2 length $2.0(1.8-2.0)$, rectangular, sclerotised area well differentiated from surrounding tergite on paratype but not in holotype, some strigose or rugose sculpturing on anterior half, border with T3 not strongly indented in holotype, indented to slightly crenulate in paratypes; T2 length / T3 length 0.9 (0.8-1.1); T3 sculpture smooth and shiny; ovipositor sheaths length/hind tibial length $0.1(0.08)$.

\section{Male \\ Unknown.}

\section{Distribution}

Currently only known from the wider Adelaide region, South Australia.

\section{Host}

Unknown.

\section{Remarks}

This species constitutes the BIN BOLD:ADL5560, and has a maximum intraspecific distance of $0.16 \%$ and a distance of $2.59 \%$ to the nearest neighbour.

Cotesia philoeampa (Cameron, 1911)

Fig. 23A-B

Apanteles philoeampus Cameron, 1911: 342 (lectotype,, , NHMUK).

Apanteles philoeampus - Wilkinson 1928a: 96 (redescription).

Cotesia philoempa - Austin \& Dangerfield 1992: 22 (transfer from Apanteles s.1., designation of lectotype).

\section{Diagnosis}

Cotesia philoeampa can be separated from all other species of Cotesia currently described from Australia and Papua New Guinea primarily by the fore wing vein 2 RS extending past junction with r, creating a 'stub'; T1 parallel sided; anteromesoscutum punctate; fore wing vein $r$ generally shorter than $2 \mathrm{RS}$ (occasionally of similar length).

\section{Material examined}

Lectotype

AUSTRALIA • + ; NSW, Wattle Flat; bred from caterpillar; 23 Jan. 92; W.W.F; NHMUK 3.c.997.

\section{Paralectotype}

AUSTRALIA • 1 q; same collection data as for lectotype; NHMUK 3.c.997.

\section{Redescription}

Female (from lectotype)

CoLOUR. Head, antenna and mesosoma dark, T1-2 dark, rest of metasoma pale on non-sclerotised areas with dark sclerotised areas on dorsal surface, pale laterally; (fore-, mid-, hind coxa) dark, dark, dark; 


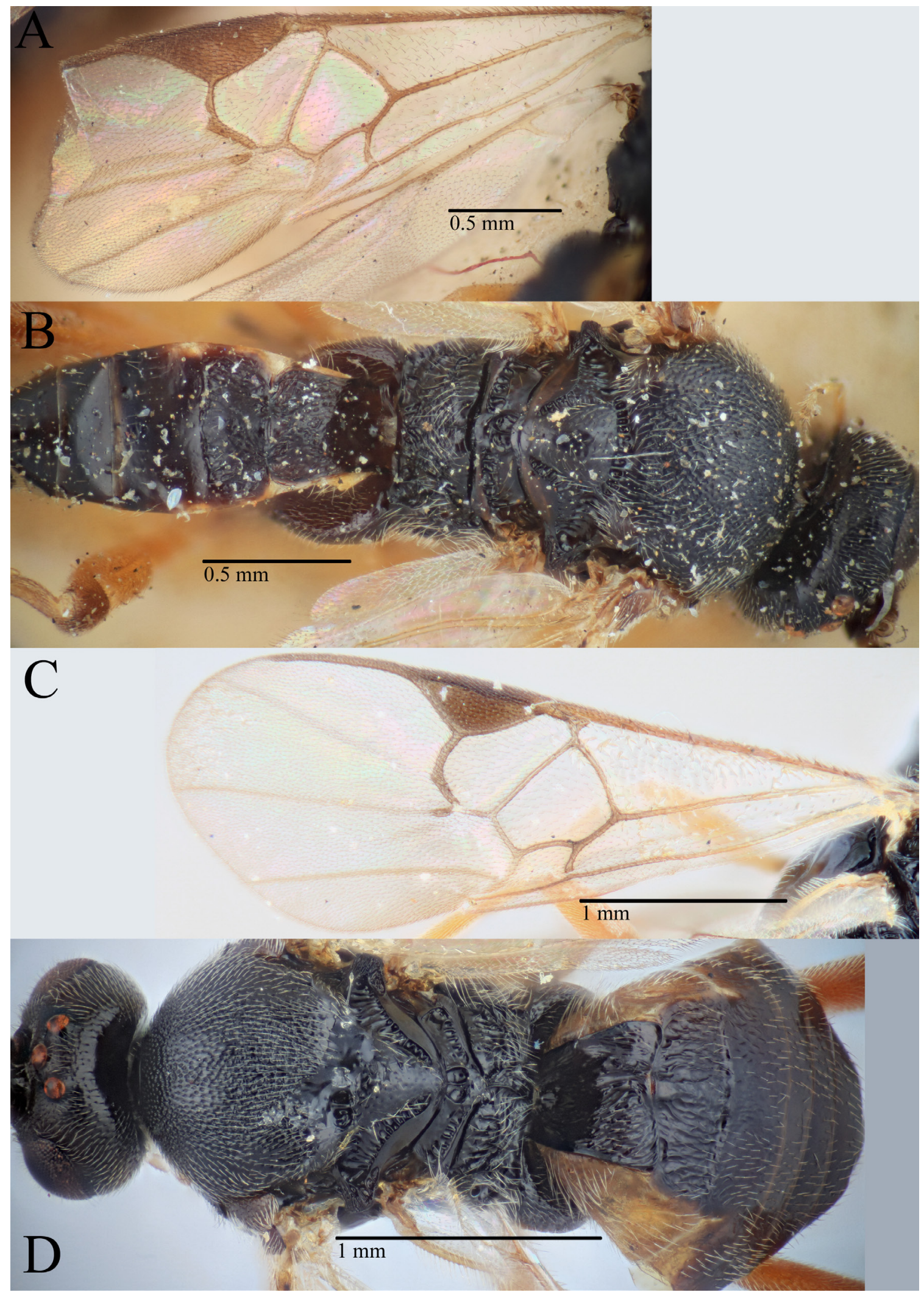

Fig. 23. A-B. Cotesia philoeampa (Cameron, 1911), lectotype, $q$ (NHMUK 3.c.997). A. Fore wing. B. Habitus in dorsal view. C-D. C. rubecula (Marshall, 1885), ㅇ, Urrbrae (WINC). C. Fore wing D. Habitus in dorsal view. 
femora (fore-, mid-, hind femur) pale, pale, pale darkening distally; tibiae (fore-, mid-, hind tibia) pale, pale, pale darkening distally; tegula and humeral complex pale to light brown; pterostigma light brown; fore wing veins light brown.

Body LENGTH. Head to apex of metasoma: $2.9 \mathrm{~mm}$.

HEAD. Antenna broken in types; OOL/posterior ocellus diameter 1.6; POL/posterior ocellus diameter 1.6; antennal flagellomere 2 length/width 3.1; antennal flagellomere 14 missing in type specimens.

Mesosoma. Anteromesoscutum punctate, punctures denser and tending towards rugose along notauli lines compared to lateral areas and centre area, where punctures are shallower and ateromesoscutum appears smoother; number of pits in scutoscutellar sulcus 9; scutellar disc mostly smooth with some shallow punctures associated with setae; maximum height of mesoscutellum lunules/maximum height of lateral face of mesoscutellum 0.5 .

WINGS. Fore wing length $3.0 \mathrm{~mm}$; length of veins r/2RS 0.7-0.9; length of veins $2 \mathrm{RS} / 2 \mathrm{M} 1.8$; length of veins $2 \mathrm{M} /(\mathrm{RS}+\mathrm{M}) \mathrm{b} 0.9$; pterostigma length/width 3.2 .

LEGS. Hind tibia inner spur length/metabasitarsus length 0.6.

PROPODEum. Medial carina present, but carina not more prominent than other carinae on propodeum, all of propodeum irregularly rugose.

MetasOMA. T1 length/T1 width at posterior margin 1.3; mostly parallel-sided, curving in right at posterior edge and bulging outwards a small amount in the posterior third, smooth in anterior half, posterior half with rugose and reticulate rugose sculpturing; T2 width at posterior margin/T2 length 2.3, wide and flat, covering most of metasoma width, slightly curved from anterior corners, very shallow indistinct sculpturing around edges - rugulose at anterior end, crenulate at posterior margin; T2 length / T3 length 0.7; T3 sculpture smooth and shiny; ovipositor sheaths length/hind tibial length 0.16 .

\section{Male \\ Unknown.}

\section{Distribution}

Only known from the type locality, Wattle Flat, NSW.

\section{Host}

Unknown.

Cotesia radiantis (Wilkinson, 1929)

Fig. 24

Apanteles radiantis Wilkinson, 1929: 110 (holotype,, , NHMUK).

Cotesia radiantis - Austin \& Dangerfield 1992: 22 (transfer from Apanteles s.1.).

\section{Diagnosis}

Cotesia radiantis can be separated from all other species of Cotesia currently described from Australia and Papua New Guinea by the following combination of characters: T1 broadening posteriorly, wedge shaped; fore wing vein $\mathrm{r}$ shorter than 2RS; anteromesoscutum sculpturing considerably stronger along 


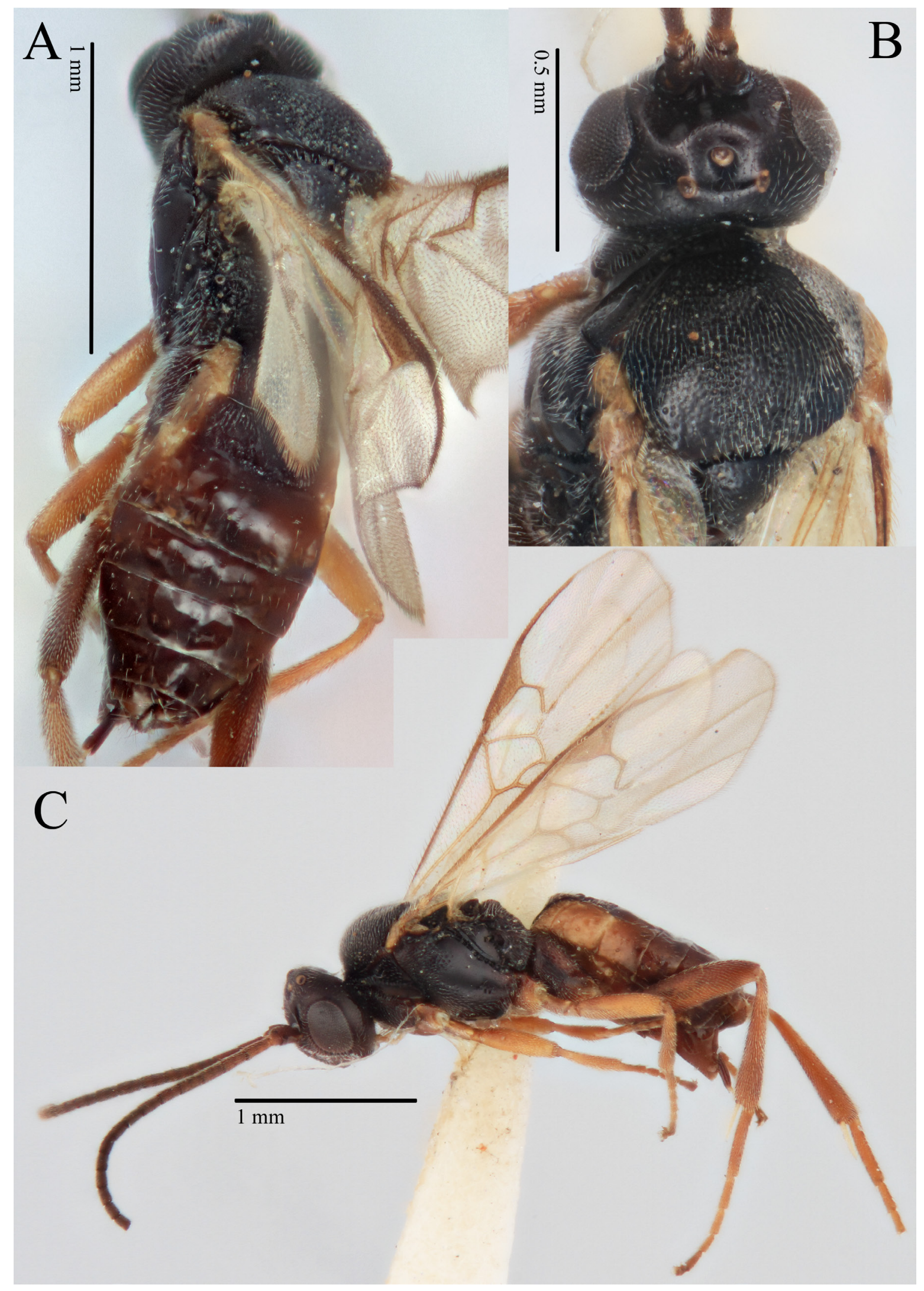

Fig. 24. Cotesia radiantis (Wilkinson, 1929), holotype, $q$ (NHMUK 3.c.1036) A. Metasoma. B. Anteromesoscutum. C. Habitus in lateral view. 
lines of notauli than elsewhere, almost smooth laterally - basal area of anteromesoscutum almost reticulate rugose; scutellar disk with shallow punctures; mesosoma not dorsoventrally flattened; hind coxa and metasoma only slightly paler than mesosoma; ocelli normal sized, OOL/posterior ocellus diameter $<2.4$.

\section{Material examined}

\section{Holotype}

AUSTRALIA • O; Queensland, Gatton; 3 Dec. 1925; E. Ballard leg.; ex. larvae of "Euxoa radians" attacking cotton seedlings; NHMUK 3.c.1036.

\section{Redescription}

Female (from holotype)

Colour. Head, antenna and mesosoma dark, T1-2 dark, rest of dorsal metasoma pale on non-sclerotised areas with dark sclerotised areas, pale laterally at anterior end, darkening posteriorly; (fore-, mid-, hind coxa) dark, dark, dark; femora (fore-, mid-, hind femur) pale, pale, light brown; tibiae (fore-, mid-, hind tibia) pale, pale, light brown; tegula and humeral complex pale to light brown; pterostigma light brown; fore wing veins light brown.

Body LENGTH. Head to apex of metasoma: $2.3 \mathrm{~mm}$.

HEAD. Antenna broken in types; OOL/posterior ocellus diameter 2.2; POL/posterior ocellus diameter 2.3; antennal flagellomere 2 length/width 2.8; antennal flagellomere 14 length/width 1.4.

Mesosoma. Anteromesoscutum punctate reticulate, much smother on lateral edges with deep sculpturing along lines of the notauli, posterior quarter of anteromesoscutum with sculpturing tending towards reticulate rugose; number of pits in scutoscutellar sulcus 11; scutellar disc with shallow punctures; mesoscutellum hidden by wings in type.

WINGS. Fore wing length $2.2 \mathrm{~mm}$; length of veins r/2RS 0.6 ; length of veins $2 \mathrm{RS} / 2 \mathrm{M} 1.5$; length of veins $2 \mathrm{M} /(\mathrm{RS}+\mathrm{M}) \mathrm{b} 0.9$; pterostigma length/width 2.8 .

LEGS. Hind tibia inner spur length/metabasitarsus length 0.5 .

Propodeum. Medial carina present but barely distinguishable amongst strong rugose sculpturing.

Metasoma. T1 partially hidden by wings in type, broadening posteriorly, wedge shaped, length unable to be measured, reticulate rugose in posterior third, posterior edge with some striate sculpturing; T2 width at posterior margin/T2 length 2.5 , rectangular, lateral sides slightly curved, irregularly striate sculpturing tending towards rugose in some parts; border between T2 and T3 straight, slightly indented, T2 length/T3 length 0.7; T3 sculpture smooth and shiny; ovipositor sheaths length/hind tibial length 0.13 .

\section{Male}

Not examined, male included in the original description of Wilkinson as not remarkably different from female type.

\section{Distribution}

Only known from type locality in south-eastern Queensland. 


\title{
Host
}

Agrotis munda (Walker, 1857) (Noctuidae). Record from type specimens. Note that the host name given in the original description is Euxoa radians Guénée, 1852, but that the actual host is not conspecific with Agrotis radians Guénée, 1852 due to confusion historically in the Australian literature. See Common (1958) for details. Gregarious (based on multiple specimens from description with identical label data).

\section{Remarks}

There are a large number of specimens sequenced as part of this project (BIN: BOLD:ABA6232, Fig. 1) that are broadly distributed across Australia and that strongly resemble $C$. radiantis. As this group of specimens cannot be separated definitively from the holotype of $C$. radiantis, we do not describe them as a new species, but also hesitate to confirm their identity as $C$. radiantis until a specimen reared from Agrotis munda is sequenced and the COI barcode compared (no attempt was made to extract DNA from the holotype of $C$. radiantis).

\author{
Cotesia reidarum $\mathrm{sp}$. nov. \\ urn:1sid:zoobank.org:act:F2856B1F-B81F-4910-8A9E-8FDC012CF367
}

Figs $2 \mathrm{~B}, 25$

\section{Diagnosis}

Cotesia reidarum sp. nov. can be separated from all other species of Cotesia currently described from Australia and Papua New Guinea by the following combination of characters: all of T3 pale; T1-2 mostly dark; antennae dark; anteromesoscutum sculpturing intermediate between punctate reticulate and reticulate rugose.

\section{Etymology}

Named for Ellen and Jean Reid, who run the Australian Bible Museum Butterfly Garden and provided numerous microgastrine specimens with valuable host data to the authors over recent years.

\section{Material examined}

\section{Holotype}

AUSTRALIA - $q$; Queensland, Burra Range, White Mountains National Park; $20.72461^{\circ}$ S, 145.17805 E; coll. 4 Apr. 2017; emg. 22 Apr. 2017; M.F. Braby leg.; reared from larva of Candalides delospila (Waterhouse, 1903) (Lepidoptera: Lycaenidae; BOLD AUMIC491-18; Genbank COI: MH138904); QM T246703.

\section{Description}

\section{Female}

Colour. Head, antenna and mesosoma dark; T1 dark, T2 dark with orange centre area, rest of dorsal metasoma pale and then darkening, non sclerotised areas of T1-2 and anterior sternites pale; (fore-, mid-, hind coxa) dark, dark, dark; femora (fore-, mid-, hind femur) pale, pale, pale darkening distally; tibiae (fore-, mid-, hind tibia) pale, pale, pale darkening distally; tegula and humeral complex dark; pterostigma dark; fore wing veins light brown to dark.

BODY LENGTH. Head to apex of metasoma: $2.5 \mathrm{~mm}$.

HEAD. Antenna slightly longer than body length; OOL/posterior ocellus diameter 2; POL/posterior ocellus diameter 2; antennal flagellomere 2 length/width 2.3; antennal flagellomere 14 length/width 2.5 . 


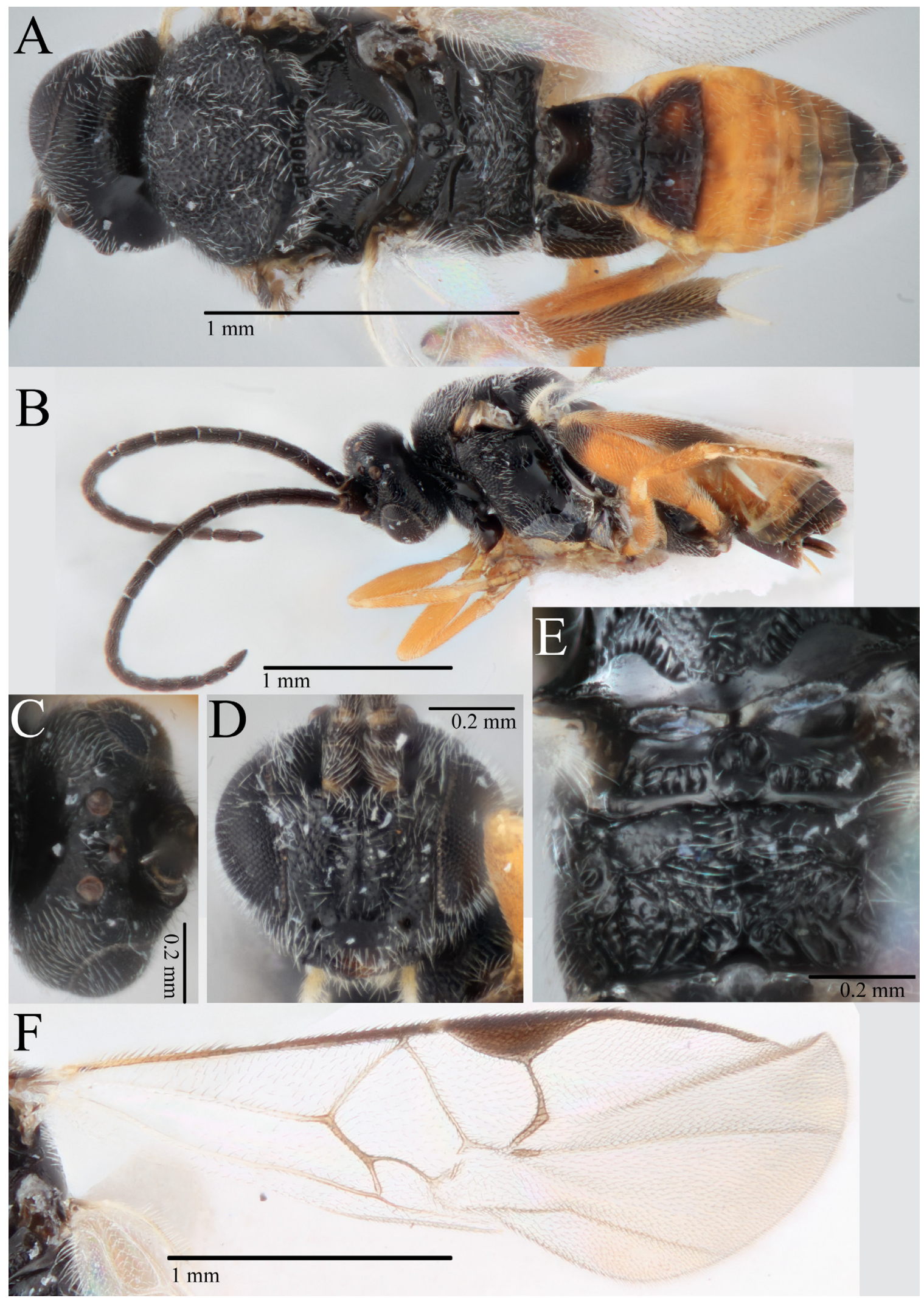

Fig. 25. Cotesia reidarum sp. nov., holotype, + (QM T246703). A. Habitus in dorsal view. B. Habitus in lateral view. C. Head in dorsal view. D. Head in anterior view. E. Propodeum. F. Fore wing. 
Mesosoma. Anteromesoscutum sculpturing intermediate between punctate reticulate and reticulate rugose, less strong at anterior centre and lateral edges; number of pits in scutoscutellar sulcus 8; scutellar disc with distinct pits; maximum height of mesoscutellum lunules/maximum height of lateral face of mesoscutellum 0.6.

WINGS. Fore wing length $2.7 \mathrm{~mm}$; length of veins r/2RS 1.1; length of veins 2RS/2M 1.4; length of veins $2 \mathrm{M} /(\mathrm{RS}+\mathrm{M}) \mathrm{b}$ 1.0; pterostigma length/width 3.0.

LEGS. Hind tibia inner spur length/metabasitarsus length 0.7 (hind tarsi broken off and lost in holotype after measurement taken).

Propodeum. Medial carina present, but smooth and indistinct in centre, rest of propodeum rugose, with some carinae more prominent than others.

Metasoma. T1 length / T1 width at posterior margin 1.1; parallel sided, slight bulge before curving inwards at posterior corners, mostly smooth, some wide shallow punctures in posterior third; T2 width at posterior margin / T2 length 2.5, trapezoid shaped with curved sides, smooth other than presence of setae, border with T3 very shallowly crenulate; T2 length / T3 length 0.8; T3 sculpture smooth and shiny; ovipositor sheaths length/hind tibial length 0.1 .

\section{Male \\ Unknown.}

\section{Distribution}

Only known from type locality in the White Mountains National Park, Queensland, but the host extends westward throughout the northern parts of the Northern Territory and Western Australia, reflecting the possible distribution of this parasitoid.

\section{Host}

Candalides delospila (Lycaenidae). Solitary.

\section{Remarks}

This species constitutes BIN BOLD:ADL4430, and is $2.31 \%$ divergent from the nearest neighbour on BOLD.

Cotesia rubecula (Marshall, 1885)

Figs $7 \mathrm{~B}, 23 \mathrm{C}-\mathrm{D}$

Apanteles rubecula Marshall, 1885: 175 (holotype, , NHMUK).

Cotesia rubecula - Mason 1981: 113 (transferred from Apanteles s.1.).

For a full bibliography, see Shenefelt (1972: 615), Yu et al. (2016) and Fernández-Triana et al. (2020).

\section{Diagnosis}

T1 consistently broadening posteriorly, often with a middle patch of rugosity on posterior smooth band of scutellum (under scutellar triangular disk); scutellar disk with only shallow punctures; mesosoma not dorsoventrally flattened; hind coxa and metasoma dark; ocelli normal sized, OOL/posterior ocellus diameter $<2.4$; fore wing vein $\mathrm{r}$ normally longer than, occasionally of similar length to $2 \mathrm{RS}$; distal quarter of hind tibia darkened, including in lateral view. 


\section{Material examined}

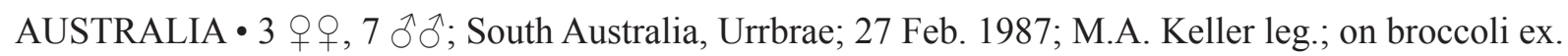
cocoon; Apanteles rubecula det A. D. Austin 1987; WINC • 2 q ; South Australia, Adelaide; reared in culture; 1 Aug. 1989; M.A. Keller leg.; "Cotesia rubecula"; WINC.

\section{Distribution}

Europe (type). Introduced into Australia and New Zealand (Wilson 1960; Cameron \& Walker 2002). For global distribution, see Fernández-Triana et al. (2020).

\section{Host}

Pieris rapae (Pieridae). Solitary. Record from original description. See Shenefelt (1972: 615) and Yu et al. (2016) for extra-limital host records.

\section{Remarks}

This species forms a distinct clade in the COI phylogeny (Fig. 1) using sequences available on BOLD from outside of Australia. No Australian specimens were sequenced in this study.

\section{Cotesia ruficrus (Haliday, 1834)}

Figs 3A, 4A, 26-27

Microgaster ruficrus Haliday, 1834: 253 (lectotype,, , NMI).

Apanteles antipoda Ashmead, 1900: 355.

Apanteles sydneyensis Cameron, 1911: 342.

Apanteles sydneyensis - Wilkinson 1928a: 95 (synonymised with A. antipoda).

Apanteles antipoda - Wilkinson 1928a: 95; 1929: 108 (synonymised with Apanteles ruficrus).

Cotesia ruficrus - Mason 1981: 113 (transferred from Apanteles s.1.).

For a full list of synonyms and bibliography, see Shenefelt (1972: 617), Yu et al. (2016) and FernándezTriana et al. (2020).

\section{Diagnosis}

Cotesia ruficrus can be separated from all other species of Cotesia currently described from Australia and Papua New Guinea by the following combination of characters: T1 consistently broadening posteriorly, wedge shaped; scutellar disk with strong punctures; T3 with only a single row of setae in posterior half.

\section{Material examined}

\section{Syntypes of $A$. sydneyensis}

AUSTRALIA • 4 우; New South Wales, Sydney; parasitic on Plusia Ochsenheimer, 1816 caterpillar; bred Jun. 1902 [by W.W. Froggart]; NHMUK 3.c.999.

\section{Other material}

AUSTRALIA - New South Wales - 1 q; Eden, Bungo Street; 21-27 Dec. 2005; C. Stephens leg.; $\mathrm{M} / \mathrm{T}$ in exotic native garden blend $\mathrm{nr}$ eucalypt forest; COI BOLD: AUMIC289-18; WINC 1 O ; Kosciuszko NP; 3.6 km SW of Thredbo, nr Dead Horse Gap; 11-13 Jan. 2004; C\&M\&N Lambkin and NT Starick leg.; ANIC bulk sample 2217; 36²'26" S, 148 '15'52" E; M/T; 1500 m a.s.l.; COI BOLD: AUMIC472-18; ANIC 32 130230. - Queensland • 1 o; Bookstead; 3 Dec. 1986; I.J. Titmarsh leg.; ex. 


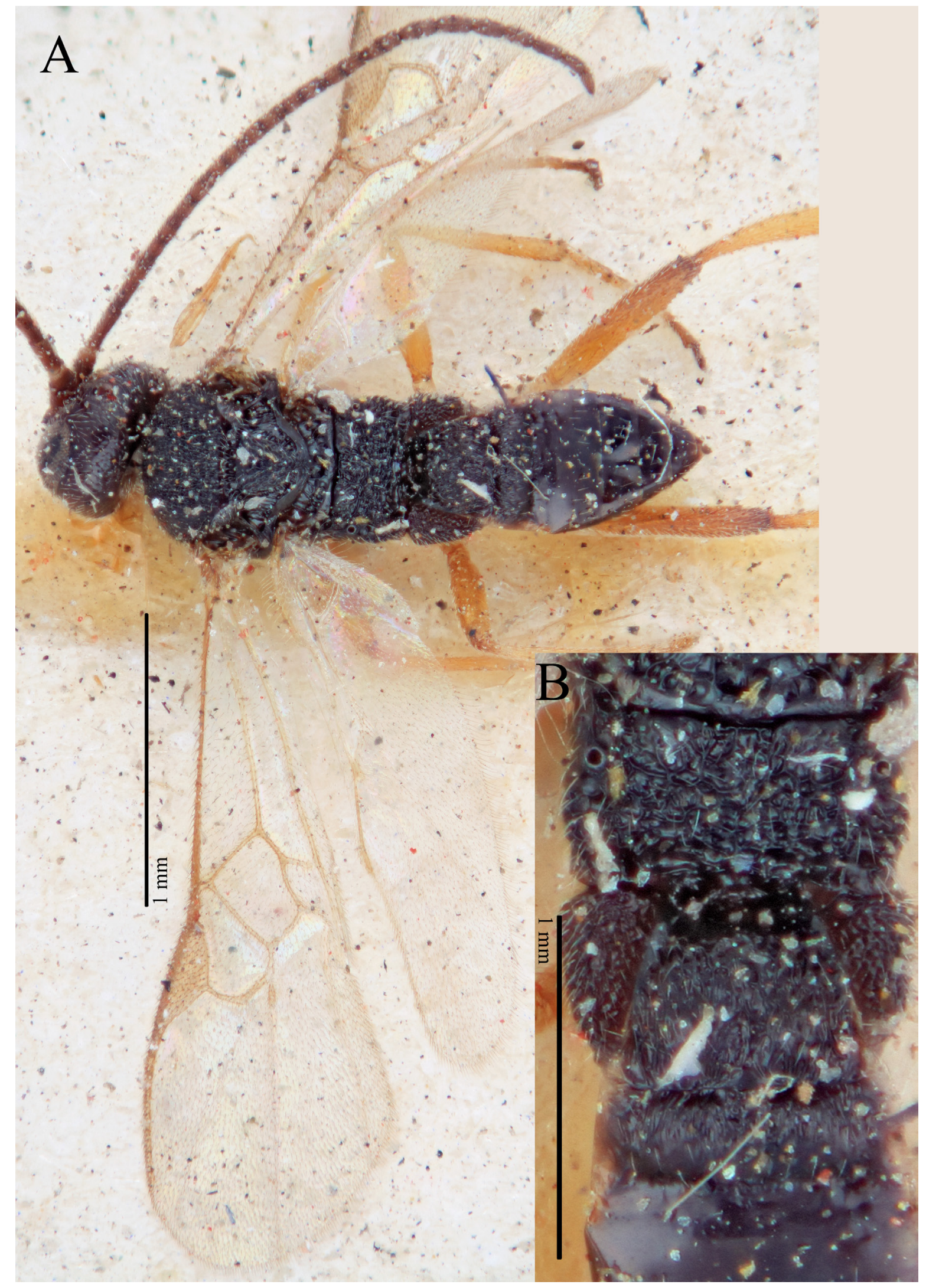

Fig. 26. Cotesia ruficrus (Haliday, 1834), syntype of C. sydneyensis (Cameron, 1911) (NHMUK 3.c.999). A. Habitus in dorsal view and fore wing B. Enlarged section of A showing propodeum and T1-2. 
fifth instar H. armigera on maize; WINC. - South Australia - 1 \% ; Goolwa; coll. 15 Nov. 85; T. Prance leg.; ex. army worms on oats; pupated 2 Dec. 85, emerged 9 Dec. 85; WINC 1 万े; Goolwa; 15 Nov. 85; T. Prance leg.; ex. army worms on oats; pupated 2 Dec. 85, emerged 9 Dec. 85; WINC. - Western Australia 1 1 ; Kununurra; 16 Sep. 79 ; reared in lab ex. Pseudaletia convecta; WINC • 1 \%; Harvey; em. 6 May 1983; C. Boyd; leg.; ex. Agrotis ipsilon [on] millet; WINC.

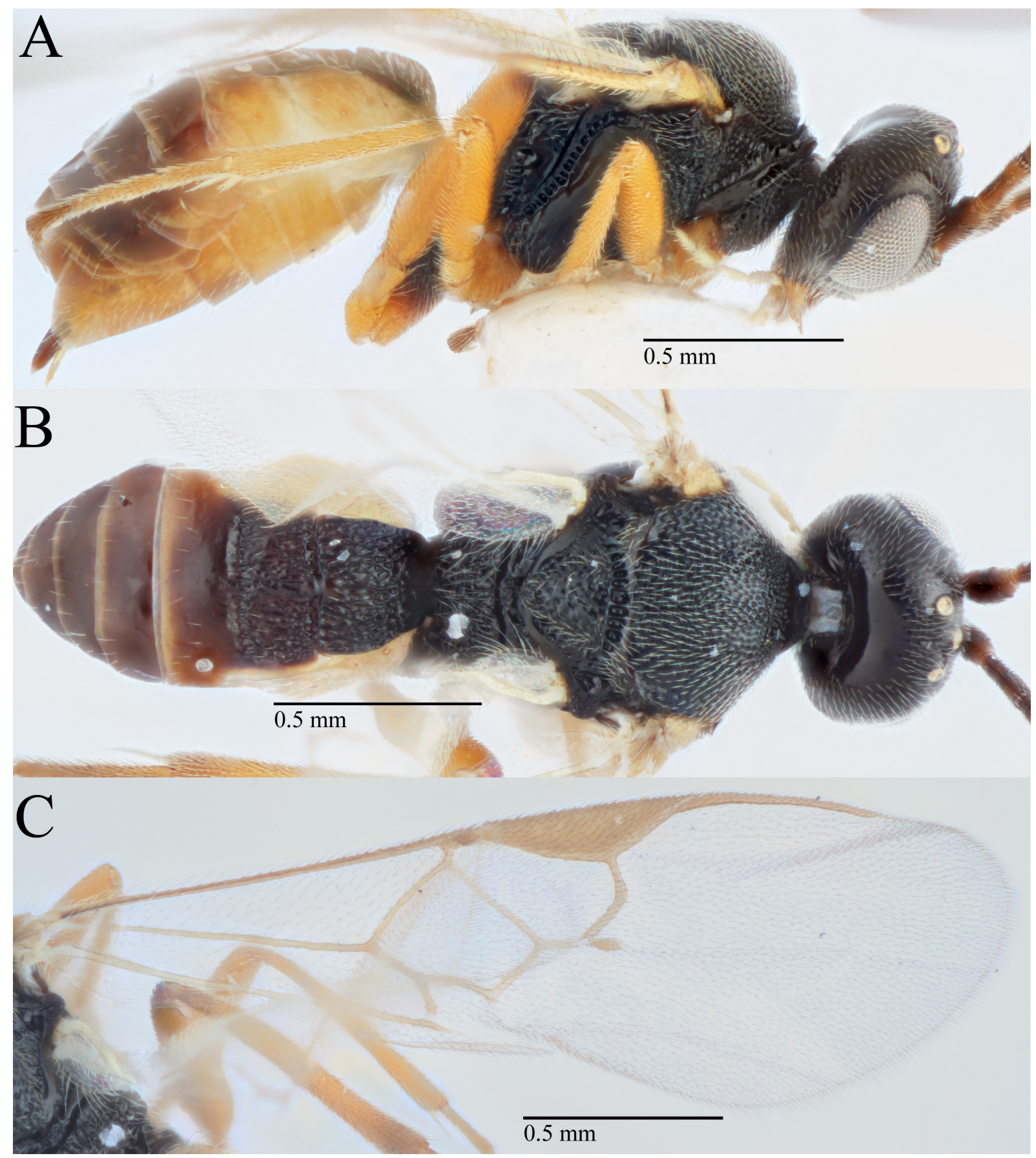

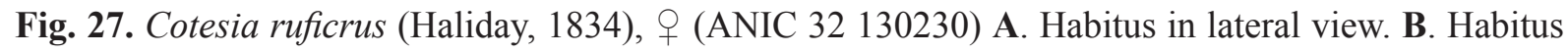
in dorsal view. C. Fore wing. 


\section{Distribution}

Cosmopolitan, see Fernández-Triana et al. (2020) for global distribution. In Australia: NSW (record from types of A. antipoda and A. sydneyensis), WA, S. Aust, Qld (records from examined material), Tas (record from Austin \& Dangerfield 1992).

\section{Host}

Agrotis sp. (Noctuidae). Record from original description of A. antipoda. Plusia sp. (Noctuidae): record from specimens from original description of A. sydneyensis. Mythimna (Pseudaletia) convecta Walker, 1857, Agrotis ipsilon (Hufnagel, 1766), Helicoverpa armigera (Hübner, 1808) (Noctuidae): records from examined material. Gregarious. Also known from a wide range of noctuid genera in Australia and across the world, including the problematic quarantine pest Spodoptera frugiperda (Smith, 1797) which has recently been identified to have arrived in Australia (see Shenefelt 1972: 617; Nixon 1974: 495; Austin \& Dangerfield 1992: 22; Gupta et al. 2019; Yu et al. 2016 for a list of host genera).

\section{Remarks}

Cotesia ruficrus represents an interesting case, in which strains were introduced from Pakistan to Australia and New Zealand (Cumber et al. 1977; Michael 1985) and possibly represent a different species to the native Apanteles sydneyensis, which was synonymised with the (also) native Apanteles antipoda by Wilkinson (1928a) and then with C. ruficrus (Wilkinson 1929). Until specimens are found which are distinct from the introduced $C$. ruficrus at a molecular level and morphologically identical to the types of $A$. sydneyensis or A. antipoda, we leave the synonymy with A. ruficrus intact, and assume the species to be cosmopolitan. We note that a similar situation occurred in the case of $C$. nonagriae and $C$. flavipes, where the two species were erroneously synonymised based on morphology and later discovered to be distinct species based on molecular evidence and subtle morphological differences (Muirhead et al. 2008), thus excluding C. flavipes from the Australian fauna. Due the uncertainty surrounding whether this species is cosmopolitan, or consists of both introduced and native unrelated lineages, we do not redescribe the species and provide only a diagnosis that encompasses both the examined types of A. sydneyensis and the sequenced specimens that are placed in a COI tree with northern hemisphere C. ruficrus specimens.

In the key of Nixon (1974), C. ruficrus is differentiated from C. vestalis by the character of the third tergite having setae restricted more or less to a single row on the anterior half of the segment (as opposed to third tergite being covered all over with fine setae, except for small mid-basal area). In the Australian specimens, the presence of only a single row of setae in C. ruficrus is valid, but it is not always in the anterior half of the tergite (more often in the posterior half). Additionally, Nixon (1974) notes that in C. ruficrus the scutellum has punctures, at least on anterior half, wide enough apart to leave smooth shiny interspaces fully equal to width of punctures, whist in $C$. vestalis there are no smooth interspaces anteriorly. In the specimens of $C$. vestalis examined for this study, there was variability in this character and some specimens had sculpturing resembling that of $C$. ruficrus - hence this character is not used in the key presented here.

Cotesia rufiventris (Bingham, 1906)

Figs 3B, 28

Protapanteles rufiventris Bingham, 1906: 127 (lectotype, ㅇ, OXUM).

Apanteles rufiventris - Wilkinson 1928a: 104 (transferred to Apanteles and redescription).

Cotesia rufiventris - Austin \& Dangerfield 1992: 22 (transferred from Apanteles s.1., lectotype designation). 


\section{Diagnosis}

Cotesia rufiventris can be separated from all other species of Cotesia currently described from Australia and Papua New Guinea by the following combination of characters: T1 evenly broadening towards posterior margin, almost wedge shaped; scutellar disk smooth with shallow punctures associated with setae; mesosoma not dorsoventrally flattened; hind coxa and metasoma significantly paler than mesosoma, dorsal metasoma light brown to yellow.

\section{Material examined}

Paralectotype

AUSTRALIA • P; Queensland; F.P. Dodd leg.; 1902-319; NHMUK.

\section{Other material}

AUSTRALIA - 1 क; Queensland, $14 \mathrm{~km}$ WSW of Torrens Creek; $20.80502^{\circ} \mathrm{S}, 144.88722^{\circ} \mathrm{E}$; emg. 20 May 2009; M.F. Braby and N. Collier leg.; reared from larva of Ogyris zosine Hewitson, 1853 (Lep: Lycaenidae) coll. 9 May 2009; ANIC 32130299.

\section{Redescription}

Female (from paralectotype)

Colour. Head and mesosoma dark, antenna and T1 light brown, rest of metasoma pale to light brown to orange; (fore-, mid-, hind coxa) pale, pale, pale; femora (fore-, mid-, hind femur) pale, pale, pale; tibiae (fore-, mid-, hind tibia) pale, pale, light brown; tegula and humeral complex pale; pterostigma light brown; fore wing veins light brown.

Body LENGTH. Head to apex of metasoma: $3.0 \mathrm{~mm}$.

HEAD. Antenna approximately equal to body length; OOL/posterior ocellus diameter 1.6; POL/posterior ocellus diameter 2.1; antennal flagellomere 2 length/width 3.1; antennal flagellomere 14 length/width 1.8 .

Mesosoma. Anteromesoscutum punctate reticulate, denser along lines of notauli; number of pits in scutoscutellar sulcus 13; scutellar disc with shallow punctures associated with setae; maximum height of mesoscutellum lunules/maximum height of lateral face of mesoscutellum 0.6.

WINGS. Fore wing length $2.9 \mathrm{~mm}$; length of veins r/2RS 1.8; length of veins 2RS/2M 1.0; length of veins $2 \mathrm{M} /(\mathrm{RS}+\mathrm{M}) \mathrm{b} 0.8$; pterostigma length/width 2.5 .

LEGS. Hind tibia inner spur length/metabasitarsus length 0.6.

Propodeum. Medial carina distinct but only in posterior half, absent in centre of propodeum, rest of propodeum irregularly rugose, other than carinae around spiracles, rugosity much less defined than medial carina.

Metasoma. T1 length/T1 width at posterior margin 1.1; broadening posteriorly, with curved posterior corners, smooth and shiny, some very shallow punctate reticulate sculpturing in posterior third; $\mathrm{T} 2$ width at posterior margin/T2 length 2.5 , trapezoid shaped with curved lateral sides, very shallow indistinct sculpturing; T2 length/T3 length 0.7; T3 sculpture smooth and shiny; ovipositor sheaths length/hind tibial length 0.17 . 


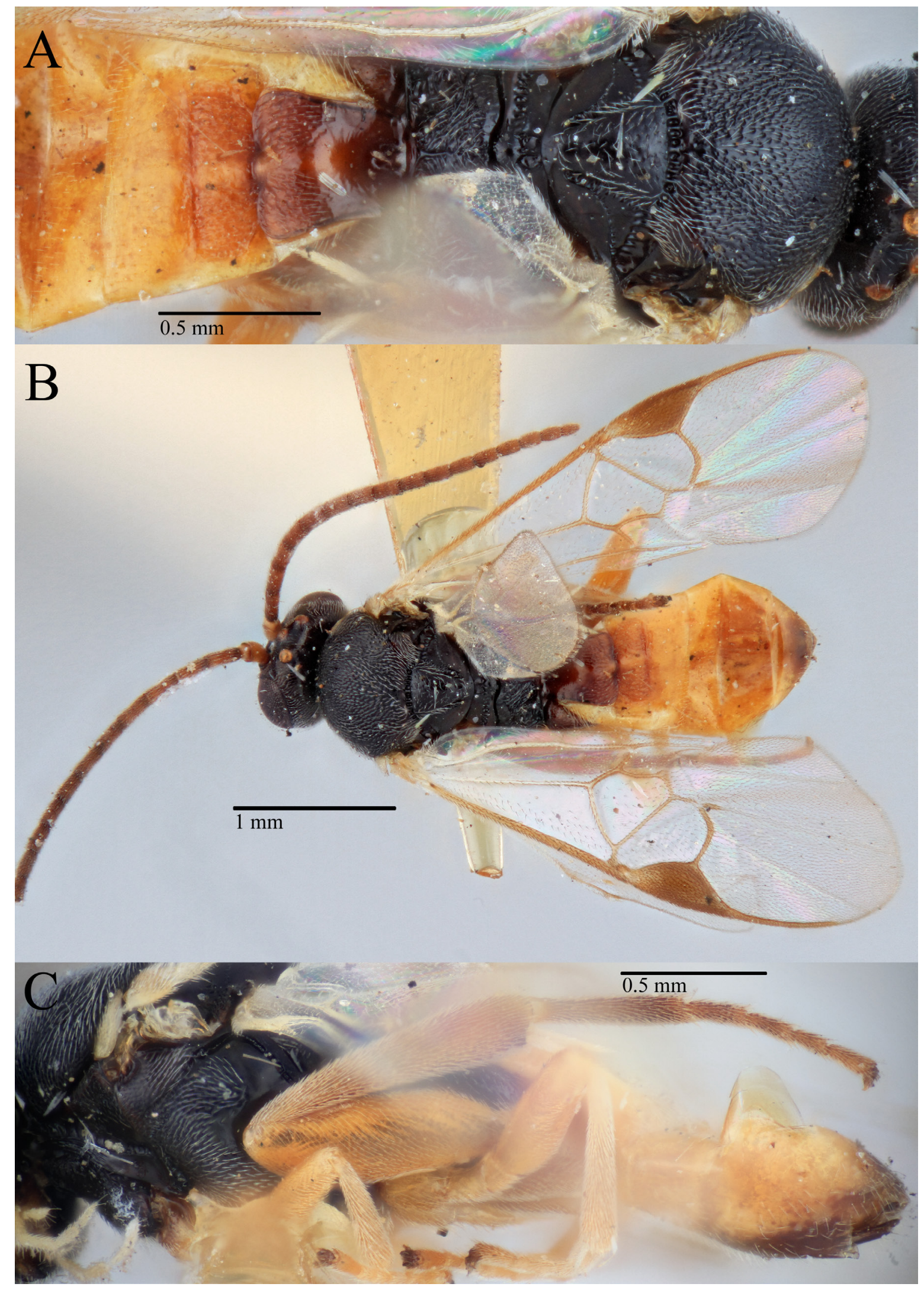

Fig. 28. Cotesia rufiventris (Bingham, 1906), paralectotype, $q$ (NHMUK). A. Mesosoma in dorsal view and T1-3 B. Habitus in dorsal view and fore wing $\mathbf{C}$. Habitus in lateral view. 


\section{Male}

Not examined (nor examined by Wilkinson 1928a), male described by Bingham (1906) as slightly shorter with abdomen shorter and more truncate posteriorly.

\section{Distribution}

Only known from Queensland.

\section{Host}

Ogyris zosine (Lycaenidae), gregarious. Record from Dodd (1906) and examined material.

Cotesia scripta sp. nov. urn:1sid:zoobank.org:act:9512A1E2-9BCD-48E2-85AC-5CDBA7FBC5A8

Figs 10D, 11B, 29

\section{Diagnosis}

Cotesia scripta sp. nov. can be separated from all other species of Cotesia currently described from Australia and Papua New Guinea by the following combination of characters: fore wing vein $r$ subtly curved; fore wing 2RS not creating a 'stub' at junction with vein r; anteromesoscutum punctate reticulate; scutellar disk smooth, or with only shallow punctures associated with setae and centre of medial posterior band of the scutellum smooth; T1 parallel sided; border between T2 and T3 smoothly indented; T3 dark with sparse setae on posterior two thirds.

\section{Etymology}

This species is derived from the Latin for 'write' as an acknowledgement of The University of Adelaide Environment Institute funded Early-Mid Career Researcher writing retreat, on which this paper was partially compiled. It is a feminine nominative singular adjective.

\section{Material examined}

\section{Holotype}

AUSTRALIA • O; Victoria, Mount Eliza; emerged Feb. 2018; R. Standen leg.; reared from Epicoma constristis on Calistomon sp.; collection code B9; BOLD: AUMIC540-19 (for co-reared specimen), Genbank COI (for co-reared specimen): MN182696; MV T22495.

\section{Paratypes}

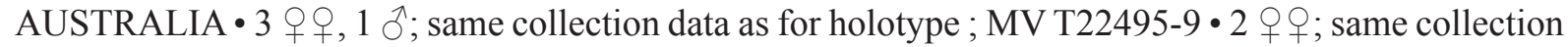
data as for holotype; WINC 4 우, 1 đ; Victoria, Mount Eliza; emerged Feb. 2018; R. Standen leg.; reared from Epicoma contristis Hübner, 1823 on Calistomon sp.; collection code B14; BOLD: AUMIC541-19 (for co-reared specimen), Genbank COI (for co-reared specimen): MN182698; MV

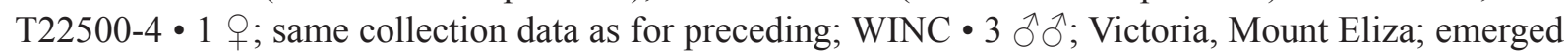
Apr. 2019; R. Standen leg.; reared from Epicoma sp. on Thyrptomene sp.; collection code B13; BOLD: AUMIC542-19 (for co-reared specimen), Genbank COI (for co-reared specimen): MN182701; MV T22505-7.

\section{Description}

\section{Female}

Colour. Head and mesosoma and dorsal metasoma other than non-sclerotised areas of T1 dark; anterior sternites pale, darkening posteriorly; (fore-, mid-, hind coxa) dark, dark, dark; femora (fore-, mid-, hind 
femur) pale/orange, pale/orange, pale/orange with dark patch distally; tibiae (fore-, mid-, hind tibia) pale/orange, pale/orange, pale/orange darkening distally; tegula and humeral complex light brown; pterostigma dark; fore wing veins dark.

BODY LENGTH. Head to apex of metasoma: $3.1(3.0) \mathrm{mm}$.

HEAD. Antennae broken in all female type specimens; OOL/posterior ocellus diameter 2.3 (2.5); POL/ posterior ocellus diameter 2.2 (2.2-2.5); antennal flagellomere 2 length/width missing in holotype (2.5); antennal flagellomere 14 missing in all specimens.

Mesosoma. Anteromesoscutum sculpturing punctate reticulate, reasonably regular but less dense and shallower in centre and on lateral sides; number of pits in scutoscutellar sulcus 12 (10); scutellar disc with only shallow pits associated with setae and no basal rugostiy; maximum height of mesoscutellum lunules/maximum height of lateral face of mesoscutellum $0.6(0.5)$.

WINGS. Fore wing length $3.0(2.7-3.0) \mathrm{mm}$; length of veins r/2RS $0.8(0.9-1.0)$; length of veins $2 \mathrm{RS} / 2 \mathrm{M}$ 1.6 (1.5-1.7); length of veins $2 \mathrm{M} /(\mathrm{RS}+\mathrm{M}) \mathrm{b} 1.0(0.8-0.9)$; pterostigma length/width 2.3 (2.5).

LEGS. Hind tibia inner spur length/metabasitarsus length $0.6(0.5-0.6)$.

Propodeum. Medial carina distinct in holotype but can be faint or nearly undiscernible in paratypes, rest of propodeum mostly smooth, some scattered rugosity and small carinae in posterior centre, posterior lateral corners, sometimes with anterior transverse carinae.

Metasoma. T1 length/T1 width at posterior margin 1.4; parallel sided, mostly smooth; T2 width at posterior margin/T2 length 2.4 (2.1-2.5), semicircle to trapezoid shaped, mostly smooth, in some specimens with scattered rugosity, T2 length/T3 length 0.6 (0.6-0.8); T3 sculpture smooth and shiny; ovipositor sheaths length/hind tibial length $0.13(0.12-0.18)$.

\section{Male}

As female, only slight variations in measurements, T2 thinner and stronger sculptured with strong indented border.

\section{Host}

Epicoma contristis Hübner, 1823 (Notodontidae), gregarious.

\section{Distribution}

Currently only known from the type locality on the Mornington Peninsula, Victoria. The host species is found throughout Australia, suggesting the wasp likely also has a wider distribution range than currently known.

\section{Remarks}

All specimens of this species, including the holotype, are not complete specimens, but the presence of DNA barcodes and host data warranted the description of this species regardless of the incompleteness of the description (missing the flagellomere 14 measurements) and poor condition of the type series. Measurements given of paratypes in description $n=2$. 


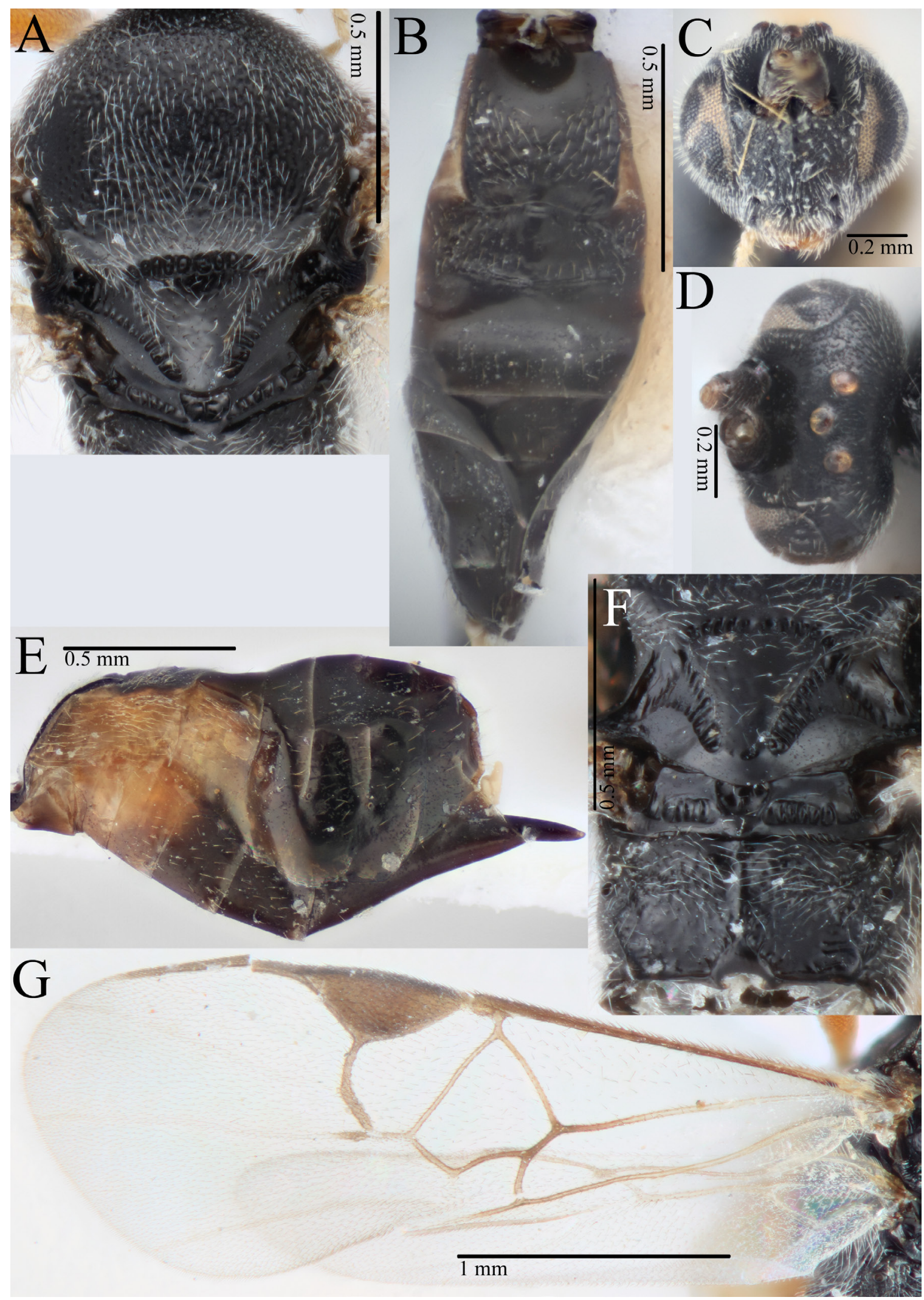

Fig. 29. Cotesia scripta sp. nov. A-C, E-G. Holotype, $q$ (MV T22495). D. Paratype, $q$ (MV T22499). A. Anteromesoscutum. B. Metasoma in dorsal view. C. Head in anterior view. D. Head in dorsal view. E. Metasoma in lateral view. F. Mesoscutellum and propodeum. G. Fore wing. 


\section{Cotesia tjapekki sp. nov. \\ urn:1sid:zoobank.org:act:92713381-3321-42C2-972C-1958ED27F5C8}

Fig. 30

\section{Diagnosis}

Cotesia tjapekki sp. nov. can be separated from all other species of Cotesia currently described from Australia and Papua New Guinea by the following combination of characters: T1 parallel sided; scutellar disk with very strong, distinct punctures scattered over whole of area; fore wing 2RS not creating a 'stub' at junction with vein r; anteromesoscutum punctate reticulate; T3 dark; centre of medial posterior band of the scutellum smooth.

\section{Etymology}

This species was named by a group of Aboriginal Summer School for Excellence in Technology and Science (ASSETS) high school students who participated in an entomology workshop in 2019 with the first author. The students chose to use an acronym for the group's members (Tiah, Jayda, Pete, Erinn, Kaitlyn, Katelen, Izzy) with the 'a' for 'ASSETS' to form the species name. The sound 't $\mathrm{j}$ ' is commonly used in the Pitjantjatjara language, which is spoken in the north-west of South Australia where the species has been collected. It is pronounced like the ' $j$ ' in the English word 'jar'. The species name is a noun in apposition.

\section{Material examined}

\section{Holotype}

AUSTRALIA - South Australia - + ; Andamooka Station, Andamooka Homestead; $30.72627^{\circ}$ S, $137.20149^{\circ}$ E to Wirrda Well $30.67943^{\circ}$ S, $137.07232^{\circ}$ E; vehicle net; 31 Sep. 2016; R. Leijs leg.; Bushblitz Lake Torrens; BOLD: AUMIC134-18, Genbank COI: MH138660; SAMA 32-035867.

\section{Paratypes}

AUSTRALIA - South Australia ${ }^{1} 1{ }^{\top}$; Great Victoria Desert, Middle road; $29.11531^{\circ} \mathrm{S}, 129.54124^{\circ} \mathrm{E}$ to $28.91363^{\circ} \mathrm{S}, 130.27775^{\circ} \mathrm{E}$; vehicle net; 24 Sep. 2017; R. Leijs leg.; Great Victoria Desert Bush Blitz; BOLD: AUMIC535-19; Genbank COI: MK567156; SAMA 32-44407 • 1 ô; same collection data as for preceding; BOLD: AUMIC536-19; Genbank COI: MK567158; SAMA 32-44408 • 1 万ै; Great Victoria Desert, Rodinia Road, Standard Survey Site 2; $28.8161^{\circ} \mathrm{S}, 129.5358^{\circ}$ E to Airstrip $29.11530^{\circ} \mathrm{S}, 129.54124^{\circ}$ E; vehicle net; 18 Sep. 2017; R. Leijs leg.; Great Victoria Desert Bush Blitz; BOLD: AUMIC537-19; Genbank COI: MK567155; SAMA 32-44409 • 1 ô; Great Victoria Desert, between Oak Valley $29^{\circ} 00^{\prime} 24.23^{\prime \prime} \mathrm{S}, 130^{\circ} 15^{\prime} 37.37^{\prime \prime} \mathrm{E}$ and $64 \mathrm{~km}$ NW of Oak Valley $29^{\circ} 24^{\prime} 57.70^{\prime \prime} \mathrm{S}$, 130 43'51.83" E; vehicle net; 3 Sep. 2015; J.A. Forrest and R. Leijs leg.; BOLD: AUMIC538-19, Genbank COI: MK567154; SAMA 32-44410.

\section{Description}

\section{Female}

Colour. Head, antenna and mesosoma dark, all tergites and most of metasoma dark, non sclerotised areas of T1-2 and anterior sternites paler; (fore-, mid-, hind coxa) dark, dark, dark; femora (fore-, mid-, hind femur) pale, pale though darker anteriorly, light brown darkening distally; tibiae (fore-, mid-, hind tibia) pale, pale, light brown darkening distally; tegula and humeral complex dark; pterostigma dark; fore wing veins light brown to dark.

Body LENGTH. Head to apex of metasoma: $2.7 \mathrm{~mm}$.

HEAD. Antenna slightly shorter than body length; OOL/posterior ocellus diameter 1.9; POL/posterior ocellus diameter 1.9; antennal flagellomere 2 length/width 3.4; antennal flagellomere 14 broken off in holotype. 


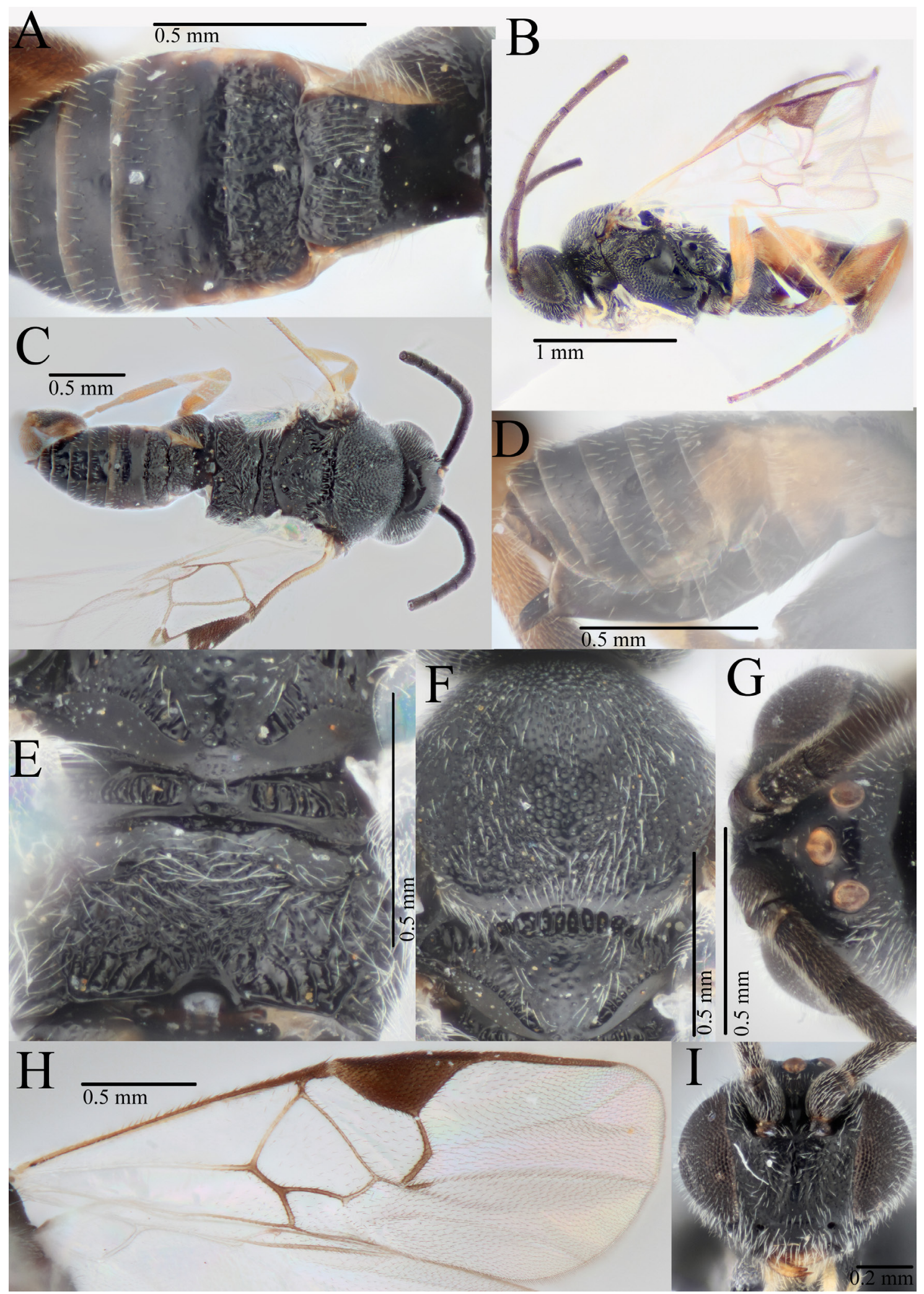

Fig. 30. Cotesia tjapekki sp. nov., holotype, + (SAMA 32-035867) A. Metasoma in dorsal view. B. Habitus in lateral view. C. Habitus in dorsal view. D. Metasoma in lateral view. E. Mesoscutellum and propodeum. F. Anteromesoscutellum and scutellar disk. G. Head in dorsal view. H. Fore wing. I. Head in anterior view. 
Mesosoma. Anteromesoscutum punctate reticulate, tending towards reticulate rugose on posterior lateral areas, punctures less dense in anterior centre; number of pits in scutoscutellar sulcus 9; scutellar disc with shallow but distinct punctures; maximum height of mesoscutellum lunules/maximum height of lateral face of mesoscutellum 0.6.

WINGS. Fore wing length $2.7 \mathrm{~mm}$; length of veins r/2RS 1.2; length of veins $2 \mathrm{RS} / 2 \mathrm{M} 1.2$; length of veins $2 \mathrm{M} /(\mathrm{RS}+\mathrm{M}) \mathrm{b}$ 1.0; pterostigma length/width 2.2 .

LEGS. Hind tibia inner spur length/metabasitarsus length 0.6.

Propodeum. Medial carina indistinct in holotype, but clearly visible in male paratypes suggesting that female specimens may also have variable carina, holotype propodeum strongly rugose with some areas leaning towards reticulate rugose, but sculpturing less strong in some male paratypes.

Metasoma. T1 length/T1 width at posterior margin 1.3; mostly parallel sided, slightly bulging at posterior curved corners, reticulate rugose to rugose in posterior half, sculpturing 'messy' and not easily categorise; 2 width at posterior margin / T2 length 2.5, trapezoid with curved lateral sides, messy rugose sculpturing, crenulate border on lateral sides and with $\mathrm{T} 3$ although less distinct in some male paratypes; T2 length/T3 length 0.7 ; T3 sculpture smooth and shiny; ovipositor sheaths length/hind tibial length 0.1 .

\section{Male}

As female but with slight variations in measurements, including antennal flagellomere 2 length/width 2.9; antennal flagellomere 14 length/width 3.0.

\section{Distribution}

Currently, this species is only recorded from arid South Australia, in the Lake Torrens and Great Victoria Desert regions.

\section{Host}

Unknown.

\section{Remarks}

This species constitutes the BIN BOLD:ADL5542, which has a maximum intraspecific distance of $1.28 \%$, and a $2.41 \%$ distance to the nearest neighbour.

\section{Cotesia urabae Austin \& Allen, 1989}

Fig. 31A-B

Cotesia urabae Austin \& Allen, 1989: 171 (holotype,, , ANIC).

Cotesia urabae - Austin \& Dangerfield 1992: 22.

\section{Diagnosis}

Cotesia urabae can be separated from all other species of Cotesia currently described from Australia and Papua New Guinea by the following combination of characters: T1 broadening consistently posteriorly, almost wedge shaped; scutellar disk smooth with small punctures associated with setae; mesosoma not dorsoventrally flattened; hind coxa and metasoma as dark; ocelli normal sized, ocular-ocellar line/ posterior ocellus diameter $<2.4$; fore wing vein $\mathrm{r}$ normally longer than, occasionally of similar length to 2RS; hind tibia with only a very small darkened patch, mainly in dorsal view. 


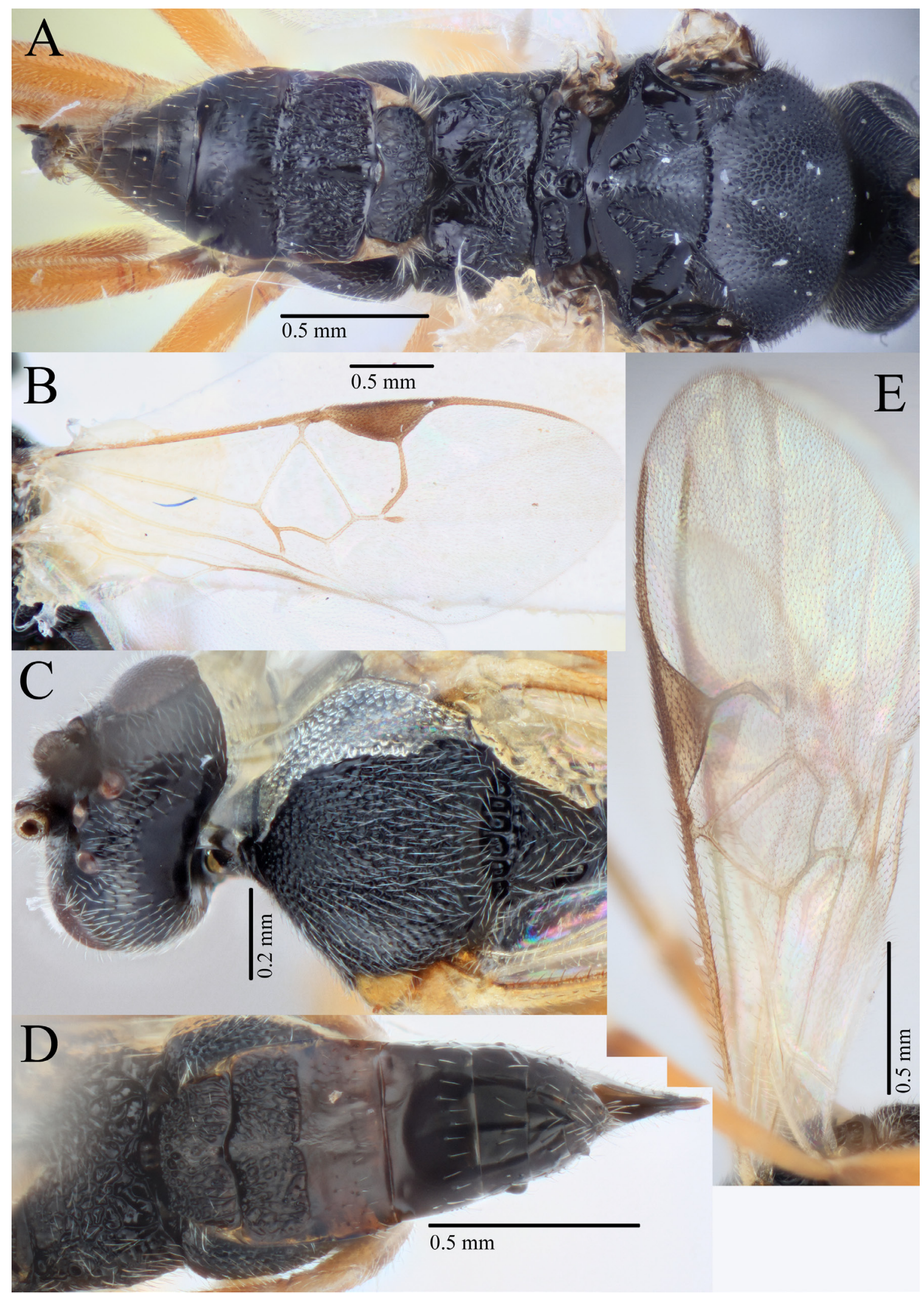

Fig. 31. A-B. Cotesia urabae Austin \& Allen, 1989, paratype, ㅇ (WINC). A. Habitus in dorsal view. B. Fore wing. C-E. Cotesia vestalis (Haliday, 1834), o (WINC). C. Head in dorsal view and anteromesoscutum. D. Propodeum and dorsal metasoma E. Fore wing. 


\section{Material examined}

Paratype

AUSTRALIA • ; ; South Australia, Waite Agricultural Research Institute lab colony; Jan. 1986; G.R. Allen leg.; ex. Uraba lugens; WINC.

\section{Distribution}

SA (record from original description), Tas (record from Muirhead et al. 2006; Rowbottom et al. 2013), New Zealand (introduced, see Avila et al. 2015).

\section{Host}

Uraba lugens Walker, 1866 (Noctuidae), solitary (record from original description).

\section{Remarks}

As this species is only recently described and the description is relatively complete, here we provide only new characters or measurements relevant to the diagnosis, and refer otherwise to the description in Austin \& Allen (1989).

Cotesia vestalis (Haliday, 1834)

Figs 4B, 31C-E

Microgaster vestalis Haliday, 1834: 253 (lectotype, ㅇ, NMI).

Apanteles plutellae Kurdjumov, 1912: 226.

Apanteles vestalis - Marshall 1872: 106 (transferred to Apanteles s.1.).

Cotesia plutellae - Mason 1981: 113 (transferred from Apanteles s.1).

Cotesia vestalis - Shaw 2003 (synonymy with C. plutellae).

For a full list of synonyms and bibliography, see Shenefelt (1972: 604, 659), Shaw (2003), Yu et al. (2016) and Fernández-Triana et al. (2020).

\section{Diagnosis}

Cotesia vestalis can be separated from all other species of Cotesia currently described from Australia and Papua New Guinea by the following combination of characters: T1 broadening consistently posteriorly, almost wedge shaped; scutellar disk with large, strong circular punctures; T3 with multiple rows of setae.

\section{Material examined}

TAIWAN • 1 \%; Shanhua (AVRDC); 2 Mar. 1998; M. Keller leg.; “Cotesia plutellae Kurd.” Ex Plutella xylostella (1.); WINC.

\section{Distribution}

Theoretically introduced to all states of Australia, but recently found only in "southern states" and only infrequently (Furlong et al. 2008).

\section{Host}

Plutella xylostella (Linnaeus, 1758) (Plutellidae). See Shenefelt (1972: 604, 659) and Yu et al. (2016) for extra-limital host records. 


\section{Remarks}

Introduced to Australia in 1951 from Italy as a biological control agent against $P$. xylostella, but not considered well established or a significant parasitoid of this lepidopteran pest (Furlong et al. 2008). This species forms a distinct clade in the COI phylogeny (Fig. 1) using sequences available on BOLD from outside of Australia. No Australian specimens were sequenced in this study. See remarks under C. ruficrus for issues using the diagnostic characters presented in the key of Nixon (1974) for this species.

Cotesia wonboynensis sp. nov.

urn:1sid:zoobank.org:act:67EECA2C-26A3-401A-A0A7-98B6DF264677

Figs $10 \mathrm{~B}, 32$

\section{Diagnosis}

Cotesia wonboynensis sp. nov. can be separated from all other species of Cotesia currently described from Australia and Papua New Guinea by the following combination of characters: T2 ovoid, occasionally semicircle shaped, with very strong, wide crenulate border; scutoscutellar sulcus with approximately 9-11 pits; T1 parallel sided; T3 dark with sparse setae on most of tergite; anteromesoscutum sculpturing punctate reticulate; scutellar disk smooth with shallow punctures associated with setae; centre of medial posterior band of the scutellum smooth; fore wing 2RS not creating a 'stub' at junction with $r$.

\section{Etymology}

This species is named for the town Wonboyn, from where the type series was collected and reared by Paul Whitington and Kerri-Lee Harris.

\section{Material examined}

\section{Holotype}

AUSTRALIA • + ; NSW, Wonboyn; 37.24417 S, $149.90306^{\circ}$ E; emerged 25 Mar. 2019; P. Whitington and K-L. Harris leg.; reared from Anthela sp., cf A. connexa, on Allocasuarina littoralis (Salisb.) L.A.S.Johnson; BOLD (for co-reared specimen): AUMIC539-19; Genbank COI (for co-reared specimen): MN182700; ANIC 32130294.

\section{Paratypes}

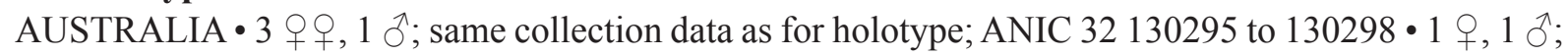
same collection data as for holotype; WINC.

\section{Description}

\section{Female}

Colour. Head, antenna and mesosoma and dorsal metasoma other than non-sclerotised areas of T1 dark; anterior sternites pale, darkening posteriorly; (fore-, mid-, hind coxa) dark, dark, dark; femora (fore-, mid-, hind femur) pale, pale, pale darkening distally; tibiae (fore-, mid-, hind tibia) pale, pale, light brown darkening distally; tegula and humeral complex dark; pterostigma dark; fore wing veins dark.

Body Length. Head to apex of metasoma: 2.7 (2.4-2.7) mm.

HEAD. Antenna slightly longer than body length; OOL/posterior ocellus diameter 2.0 (2.0-2.1); POL/ posterior ocellus diameter 1.8 (1.7-1.9); antennal flagellomere 2 length/width 3.0 (3.3-3.4); antennal flagellomere 14 length/width 3.0 (2.7-3.2). 


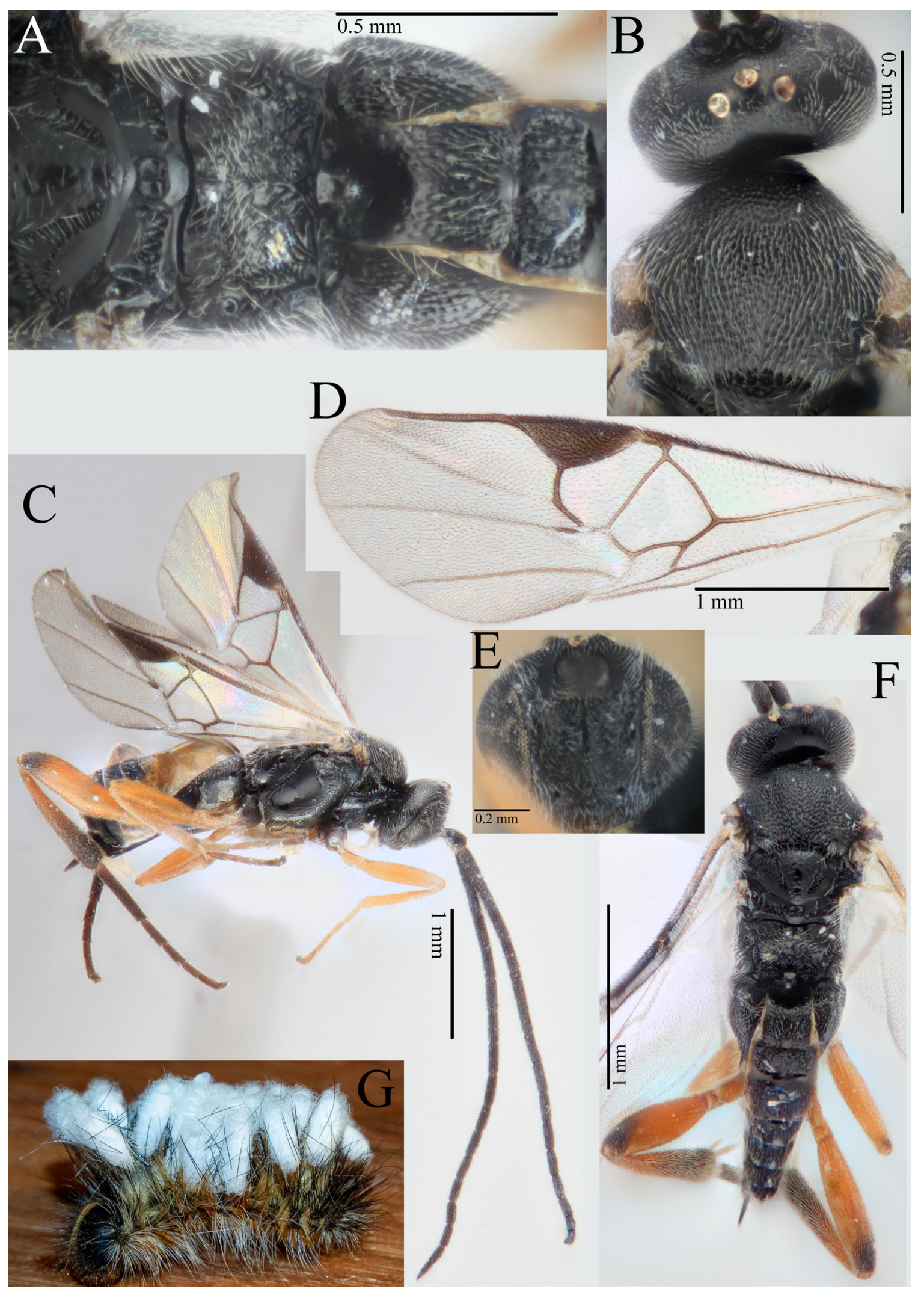

Fig. 32. Cotesia wonboynensis sp. nov., + , holotype (ANIC 32 130294) A. Mesoscutellum, propodeum, T1-2. B. Head in dorsal view and anteromesoscutum. C. Habitus in lateral view. D. Fore wing. E. Head in anterior view. F. Habitus in dorsal view. G. Cocoons on host caterpillar (image credit: P. Whitington). 
Mesosoma. Anteromesoscutum sculpturing punctate reticulate, reasonably regular but less dense and shallower in centre and on lateral sides; number of pits in scutoscutellar sulcus $9(9,11)$; scutellar disc with only shallow pits associated with setae and no basal rugostiy; maximum height of mesoscutellum lunules/maximum height of lateral face of mesoscutellum 0.52 (0.55).

WiNGS. Fore wing length $2.8(2.4-2.8) \mathrm{mm}$; length of veins $\mathrm{r} / 2 \mathrm{RS} 0.9$; length of veins $2 \mathrm{RS} / 2 \mathrm{M} 1.3$ (1.5-1.6); length of veins $2 \mathrm{M} /(\mathrm{RS}+\mathrm{M}) \mathrm{b} 1.6$ (1.2); pterostigma length/width 2.9 (2.6-3.1).

LEGS. Hind tibia inner spur length/metabasitarsus length $0.5(0.5-0.6)$.

Propodeum. Medial carina distinct, rest of propodeum rugose, in paratypes with stronger, less dense carinae and smoother posterio-lateral corners.

Metasoma. T1 length/T1 width at posterior margin 1.6; parallel sided, irregularly punctured in posterior third; T2 width at posterior margin / T2 length 1.7, semicircle shaped, almost ovoid in holotype, irregularly sculptured with strong crenulate border on all sides, T2 length / T3 length 0.7; T3 sculpture smooth and shiny; ovipositor sheaths length/hind tibial length 0.1 (0.15-0.17).

\section{Male}

As female, only slight variations in measurements.

\section{Host}

Anthela sp., most likely A. connexa (Walker, 1855) (Anthelidae) (identification from image of larvae by E.P. Beaver).

\section{Distribution}

Currently known only from type locality on the southern NSW coastal region, although as the host occurs throughout the east coast of Australia and into Tasmania, this parasitoid is likely to have a wider range than is currently known.

\section{Cotesia sp. nr C. icipe Fernández-Triana \& Fiaboe, 2017}

Figs 9A, 33

\section{Diagnosis}

This species, which is likely C. icipe Fernández-Triana \& Fiaboe, 2017, can be separated from all other species of Cotesia currently described from Australia and Papua New Guinea by the sculptured area on the centre of the medial band of the scutellar disk and T1 parallel sided.

\section{Material examined}

\section{Other material}

AUSTRALIA - Northern Territory • 1 क; 76.9 km NNE of Lajamanu; 1740'30" S, 130 54'14" E; 11-17 Jun. 2001; M.E. Irwin, F.D. Parker and C. Lambkin leg.; Malaise trap in deep dry gully below water hold; BOLD: AUMIC050-18; Genbank COI: MH138638; ANIC 32 130196. - Queensland • 1 \% ; Kuranda; $16.81538^{\circ}$ S, $145.6425^{\circ}$ E; M.S. Moulds leg.; 16 Mar. 2017; M/T; BOLD: AUMIC341-18; Genbank COI: MH138648; WINC • 1 क; Cudmore NP, CM3M; $22.969^{\circ} \mathrm{S}, 146.379^{\circ} \mathrm{E} ; 351 \mathrm{~m}$ a.s.1.; 28 Oct. 2010-2 Aug. 2011; Lambkin, Starick and Bailey leg.; Melaleuca heath nr drying creek; M/T; QM bulk sample 18517; BOLD: AUMIC424-18; Genbank COI: MH138809; QM T208388. - South

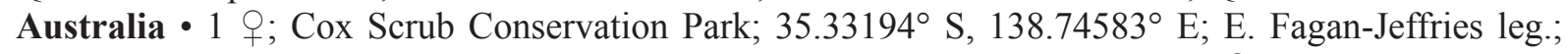
17 Apr. 2016; M/T; BOLD: AUMIC194-18; Genbank COI: MH138655; WINC • 1 +; Mt Remarkable NP; 3250'18" S, 138 $2^{\prime} 12^{\prime \prime}$ E, 22 Jan. - 18 Feb. 2017; E. Fagan-Jeffries leg.; M/T; BOLD: AUMIC152-18; Genbank COI: MH138657; WINC. 


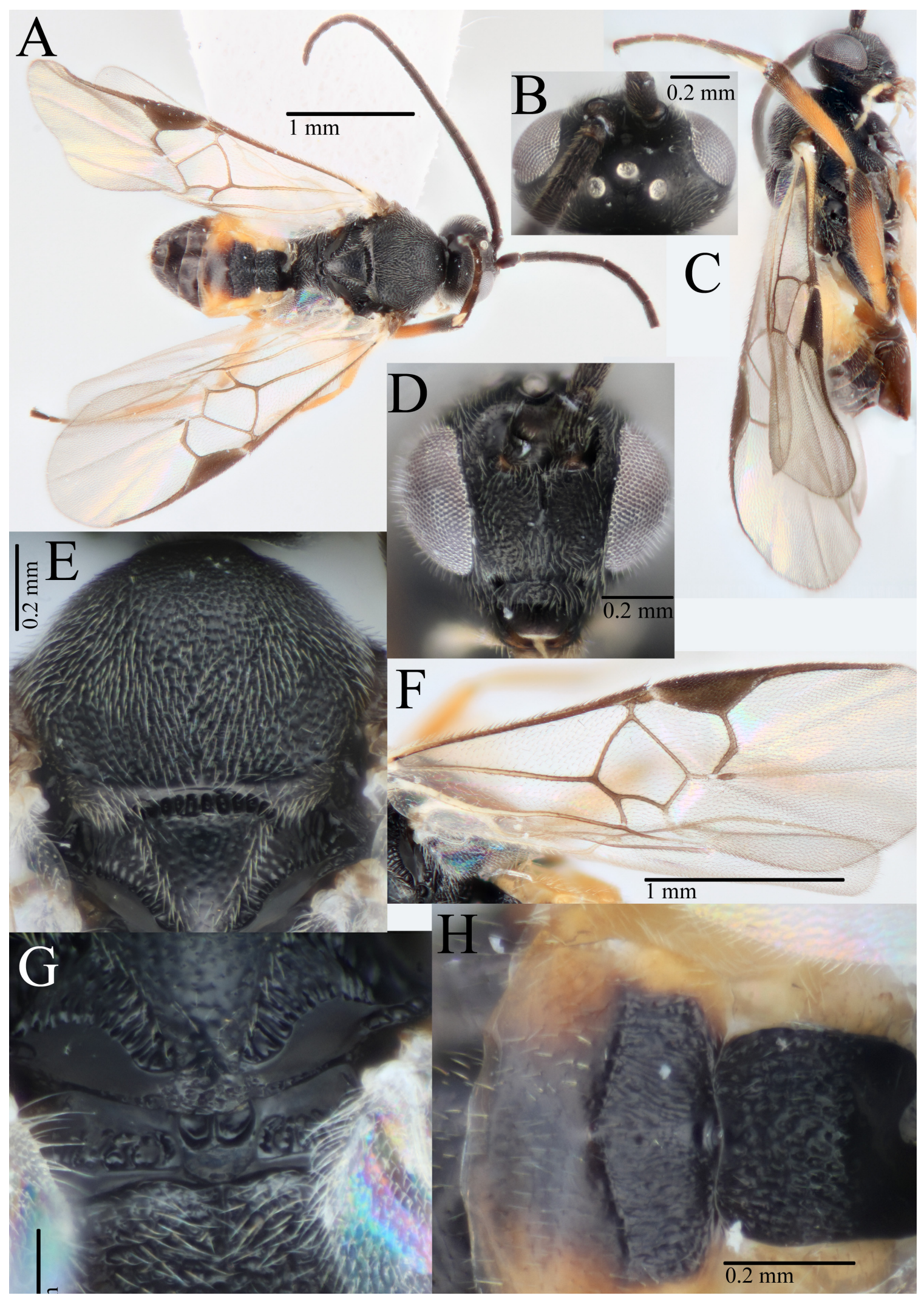

Fig. 33. Cotesia sp. nr C. icipe., $q$ (Cox Scrub, S Australia) A. Habitus in dorsal view. B. Head in dorsal view. C. Habitus in lateral view. D. Head in anterior view. E. Anteromesoscutum. F. Fore wing. G. Posterior scutellar disk, mesoscutellum and propodeum. H. T1-3. 


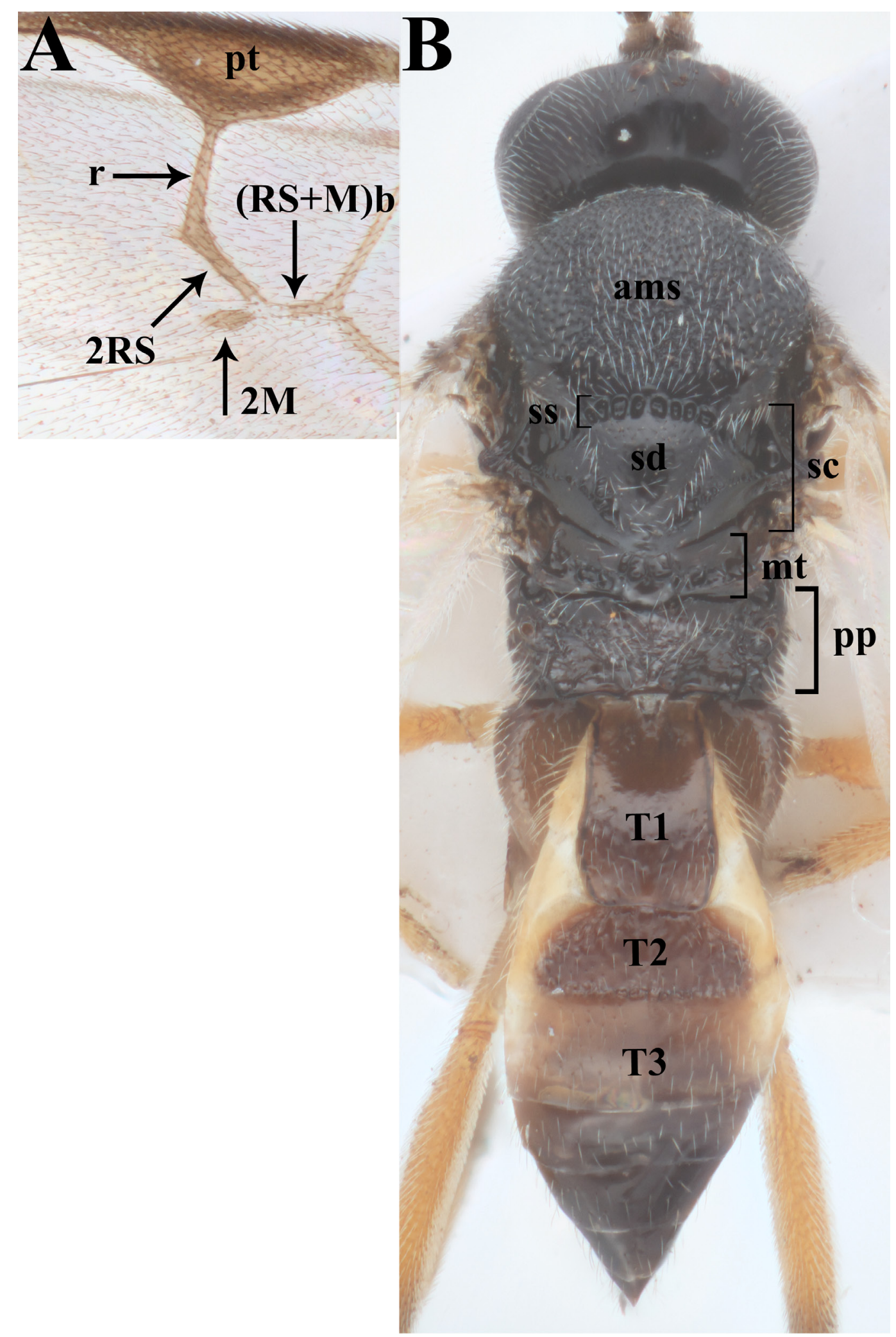

Fig. 34.A. Fore wing terminology, abbreviation: $\mathrm{pt}=$ pterostigma. $\mathbf{B}$. General morphological terminology, abbreviations: $\mathrm{ams}=$ anteromesoscutum, $\mathrm{mt}=$ metanotum, $\mathrm{pp}=$ propodeum, $\mathrm{sc}=$ scutellum $($ also referred to as the mesoscutellum), $\mathrm{sd}=$ scutellar disk, $\mathrm{ss}=$ scutellar sulcus, $\mathrm{T} 1=$ first metasomal tergite, $\mathrm{T} 2=$ second metasomal tergite, $\mathrm{T} 3=$ third metasomal tergite. 


\section{Distribution}

In Australia, known from Queensland, the Northern Territory and South Australia - see remarks.

\section{Host}

No host data available for specimens from Australia.

\section{Remarks}

This species, although clearly different from any currently described from Australia, is morphologically and genetically (1-1.5\% divergent in the COI barcoding region) extremely similar to C. icipe. Cotesia icipe was described from specimens reared in Africa from Spodoptera littoralis (Boisduva, 1833) and Spodoptera exigua (Hübner, 1808) (Lepidoptera, Noctuidae). Spodoptera exigua is present in Australia as an invasive pest on a wide range of plants (Hill 2014).

The BOLD BIN Cluster IDs for this species are BOLD:ADL3257 (South Australian specimens) and BOLD:ABZ7318 (Queensland and Northern Territory specimens). BIN BOLD:ABZ7318 contains the DNA barcodes for the described C. icipe species as well as other specimens from Australia, Madagascar, Africa, Pakistan, French Polynesia, Bangladesh, Saudi Arabia, Colombia and Malaysia, and is less than $2 \%$ divergent from BIN BOLD:ADL3257.

In the original description of C. icipe (Fiaboe et al. 2017), the authors present a COI phylogeny showing the closely related specimens on BOLD from elsewhere in the world, which cluster by geographic location, but take the conservative approach of excluding those sequences from the species. Considering that the host species are widespread pests of agricultural crops, we believe it is likely that $C$. icipe is also therefore now a widespread species, and that these closely related DNA barcodes from outside Africa, including those from Australia, likely represent specimens of $C$. icipe.

However, without host data for the Australia specimens, we are reluctant to definitively confirm the presence of $C$. icipe in Australia until further specimens with host data become available. We do however present here the specimens, images and DNA data in the hope that it can assist applied research on the parasitoids of Spodoptera exigua.

\section{Discussion}

In this study we describe seven new species of Cotesia and place them in the context of historically described native species and introduced taxa found in the country. Whilst this raises the number of Cotesia species found in Australia from 14 to 21 (22 including the species suspected to be C. icipe), Cotesia in Australia is expected to be much larger than currently documented. In the COI phylogeny presented in this study, an additional seven species are identified but not treated due to lack of specimens, and broader geographical sampling will undoubtedly increase this number substantially. The purpose of this study is to provide a solid framework for the genus in Australia from which future work can build, and to create an identification resource that will be useful to workers in applied entomology.

Future work should aim to obtain DNA barcodes, where possible, from described species that do not currently have genetic data available, as Cotesia is a difficult genus to identify conclusively using only morphological information. Whilst many of these species are represented by single or very few specimens, non-destructive future technologies may increase the success rate, and lower the risk, of obtaining DNA from type material. The resolution of Cotesia will benefit significantly from having this data for all described species. 
In this study we make the assumption that the newly described Australian species are endemic and new species are therefore not compared or diagnosed against species found elsewhere in the world, other than by comparing COI barcodes with those available on BOLD. We feel this is generally a realistic assumption based on the isolation of Australia and the high rate of endemism of the insect fauna (Austin et al. 2004; Chapman 2009), but note that cosmopolitan species are theoretically possible. However, their recognition needs to be based on more than just comparative morphology. See for example the unresolved synonymy of $C$. ruficrus with $C$. sydneyensis, and the case of the synonymy of $A$. nonagriae with $C$. flavipes, which is now known to be erroneous. Species distributions can be further complicated by the undocumented introduction of species in conjunction with their hosts, such as the possible presence of $C$. icipe in Australia.

\section{Acknowledgements}

This work was funded by an Australian Biological Resources Study (ABRS) Bush Blitz Tactical Taxonomy grant (TTC217-02) and an ABRS research grant (RG19-25). The authors thank colleagues and members of the public who reared specimens which were used in this study: Michael Braby, Roger Standen, Paul Whitington and Kerri-Lee Harris, Jean and Ellen Reid, and Phil Zacchariah. We thank P. Whitington for the image of cocoons of C. wonboynensis sp. nov., and Ethan Beaver for the identification of Anthela connexa. We thank Madalene Giannotta and Ben Parslow for testing and improving the key. The authors also thank the numerous museum collection staff who assisted with the loaning and accessing of specimens: Gavin Broad (NHMUK), Peter Hudson and Ben Parslow (SAMA), Susan Wright and Karin Koch (QM), Simon Hinkley and Catriona McPhee (MV), Olivia Evangelista (ANIC). We thank José Fernández-Triana for discussions surrounding C. icipe. José Fernández-Triana and an anonymous reviewer provided helpful comments that greatly improved quality of the paper, and we thank them and editor Gavin Broad for their time and insight. We also thank Kristiaan Hoedemakers for his meticulous production of the manuscript. This paper was partially compiled on a University of Adelaide Environment Institute funded Early-Mid Career Researcher writing retreat. The phylogenetic analysis was supported with supercomputing resources provided by the Phoenix HPC service at the University of Adelaide. The authors acknowledge the facilities of the Australian Microscopy \& Microanalysis Research Facility at Adelaide Microscopy, and thank Ken Neubauer and Michael Scholich for their assistance with the SEM imaging.

\section{References}

Ashmead W.H. 1900. Notes on some New Zealand and Australian parasitic Hymenoptera, with descriptions of new genera and new species. Proceedings of the Linnean Society of New South Wales 25: $353-60$.

Austin A.D. \& Allen G.R. 1989. Parasitoids of Uraba lugens Walker (Lepidoptera: Noctuidae) in South Australia, with description of two new species of Braconidae. Transactions of the Royal Society of South Australia 113 (4): 169-184.

Austin A.D. \& Dangerfield P.C. 1992. Synopsis of Australasian Microgastrinae (Hymenoptera: Braconidae), with a key to genera and description of new taxa. Invertebrate Systematics 6: 1-76. https://doi.org/10.1071/IT9920001

Austin A.D., Yeates D.K., Cassis G., Fletcher M.J., La Salle J., Lawrence J.F., McQuillan P.B., Mound L.A., Bickel D.J., Gullan P.J., Hales D.F. \& Taylor G.S. 2004. Insects 'Down Under' - Diversity, endemism and evolution of the Australian insect fauna: Examples from select orders. Australian Journal of Entomology 43 (3): 216-234. https://doi.org/10.1111/j.1326-6756.2004.00448.x

Avila G.A., Withers T.M. \& Holwell G.I. 2015. Host testing of the parasitoid Cotesia urabae (Austin \& Allen, 1989) (Hymenoptera: Braconidae) to assess the risk posed to the New Zealand nolid moth Celama 
parvitis (Howes, 1917) (Lepidoptera: Nolidae): Do host deprivation and experience influence accept. Austral Entomology 54 (3): 270-277. https://doi.org/10.1111/aen.12121

Bingham C.T. 1906. New species of Braconidae and Chalcididae from N. Queensland, bred by F.P. Dodd. Transactions of the Royal Entomological Society of London 44: 125-132.

Cameron P. 1891. Hymenopterological Notices. On some Hymenoptera parasitic in Indian injurious insects. Memoirs and proceedings of the Manchester Literary \& Philosophical Society 4: 182-194.

Cameron P. 1911. On a collection of parasitic Hymenoptera (chiefly bred), made by Mr W.W. Froggatt, F.L.S., in New South Wales, with descriptions of new genera and species. Part 1. Proceedings of the Linnean Society of New South Wales 36: 333-46. https://doi.org/10.5962/bhl.part.21909

Cameron P.J. \& Valentine E.W. 1985. Evaluation of Cotesia kazak (Hymenoptera: Braconidae), a parasite of larval Heliothis armigera conferta (Lepidoptera: Noctuidae) in New Zealand. New Zealand Journal of Agricultural Research 28 (4): 545-553. https://doi.org/10.1080/00288233.1985.10418001

Cameron P.J. \& Walker G.P. 2002. Field evaluation of Cotesia rubecula (Hymenoptera: Braconidae), an introduced parasitoid of Pieris rapae (Lepidoptera: Pieridae) in New Zealand. Environmental Entomology 31 (2): 367-374. https://doi.org/10.1603/0046-225x-31.2.367

Carl K.P. 1978. Heliothis armigeru Parasite Survey and Introduction of Apanteles kazak to New Zealand. Report of work in 1977-78. Switzerland.

Chapman A.D. 2009. Numbers of Living Species in Australia and the World: A Report for the Australian Biological Resources Study. Toowoomba, Australia.

Common I.F.B. 1958. The Australian cutworms of the genus Agrotis (Lepidoptera: Noctuidae). Australian Journal of Zoology 6: 69-88.

Cumber R.A., Allan D.J. \& Helmore L. 1977. Introduction and successful establishment in New Zealand of further strains of Apanteles ruficrus Haliday (Hymenoptera: Braconidae) to combat Pseudaletia (Mythimna) separata (Walk.) (Lepidoptera: Noctuidae). New Zealand Journal of Agricultural Research 20 (2): 255-258. https://doi.org/10.1080/00288233.1977.10427331

Dodd F.P. 1906. Notes upon some remarkable parasitic insects from North Queensland. Transactions of the Entomological Society of London: 119-124. https://doi.org/10.1111/j.1365-2311.1906.tb02468.x

Eady R.D. 1968. Some illustrations of microsculpture in the Hymenoptera. Proceedings of the Royal Entomological Society of London. Series A, General Entomology 43 (4-6): 66-72.

https://doi.org/10.1111/j.1365-3032.1968.tb01029.x

Fagan-Jeffries E.P., Cooper S.J.B., Bertozzi T., Bradford T.M. \& Austin A.D. 2018. DNA barcoding of microgastrine parasitoid wasps (Hymenoptera: Braconidae) using high-throughput methods more than doubles the number of species known for Australia. Molecular Ecology Resources 18 (5): 1132-1143. https://doi.org/10.1111/1755-0998.12904

Fernández-Triana J.L., Whitfield J.B., Rodriguez J.J., Smith M.A., Janzen D.H., Hallwachs W.D., Hajibabaei M., Burns J.M., Solis M.A., Brown J., Cardinal S., Goulet H. \& Hebert P.D.N. 2014. Review of Apanteles sensu stricto (Hymenoptera, Braconidae, Microgastrinae) from Area de Conservación Guanacaste, northwestern Costa Rica, with keys to all described species from Mesoamerica. ZooKeys 383: 1-565. https://doi.org/10.3897/zookeys.383.6418

Fernandez-Triana J., Shaw M.R., Boudreault C., Beaudin M. \& Broad G.R. 2020. Annotated and illustrated world checklist of Microgastrinae parasitoid wasps (Hymenoptera, Braconidae). ZooKeys 920: 1-1089. https://doi.org/10.3897/zookeys.920.39128 
Fiaboe K.K.M., Fernández-Triana J., Nyamu F.W. \& Agbodzavu K.M. 2017. Cotesia icipe sp. n., a new Microgastrinae wasp (Hymenoptera, Braconidae) of importance in the biological control of Lepidopteran pests in Africa. Journal of Hymenoptera Research 61: 49-64. https://doi.org/10.3897/jhr.61.21015

Fujie S., Shimizu S. \& Fernández-Triana J.L. 2018. A new species and a key to world species of the flavipes species-group of the genus Cotesia Cameron, 1891 (Hymenoptera: Braconidae: Microgastrinae) from Japan. Zootaxa 4527 (3): 372-380. https://doi.org/10.11646/zootaxa.4527.3.6

Furlong M.J., Spafford H., Ridland P.M., Endersby N.M., Edwards O.R., Baker G.J., Keller M.A. \& Paull C.A. 2008. Ecology of diamondback moth in Australian canola: landscape perspectives and the implications for management. Australian Journal of Experimental Agriculture 48 (12): 1494.

https://doi.org/10.1071/ea07413

Gupta A., Babu S.R. \& Kumar M.S. 2019. Cotesia ruficrus (Haliday, 1834) (Hymenoptera: Braconidae) emerging as a common natural parasitoid of Spodoptera frugiperda (J.E. Smith) (Lepidoptera: Noctuidae) in Indian maize fields. Journal of Biological Control 33: 193-196.

https://doi.org/10.18311/jbc/2019/24118

Haliday A.H. 1834. Essay on the Classification of parasitic Hymenoptera, \&c. The Entomological Magazine 2 (3): 225-259.

Hebert P.D.N., Penton E.H., Burns J.M., Janzen D.H. \& Hallwachs W. 2004. Ten species in one: DNA barcoding reveals cryptic species in the neotropical skipper butterfly Astraptes fulgerator. Proceedings of the National Academy of Sciences of the United States of America 101 (41): 14812-14817. https://doi.org/10.1073/pnas.0406166101

Hill L. 2014. Lesser armyworm, Spodoptera exigua (Hubner) (Lepidoptera: Noctuidae), a vagrant moth in Tasmania. Plant Protection Quarterly 29 (4): 131-142.

Kurdjumov N.V. 1912 Hyménoptères-parasites nouveaux ou peu connus. Revue russe d'Entomologie 12: $223-240$.

le Masurier A.D. 1987. A comparative study of the relationship between host size and brood size in Apanteles spp. (Hymenoptera: Braconidae). Ecological Entomology 12 (4): 383-393.

https://doi.org/10.1111/j.1365-2311.1987.tb01019.x

Li C.S. 1990. Status and control of Chilo spp., their distribution, host range and economic importance in Oceania. International Journal of Tropical Insect Science 11: 535-539.

https://doi.org/10.1017/s1742758400021081

Linnaeus C. 1758. Hymenoptera. In: Systema Naturae Regnum Animalia 10: 553-583.

Marshall T.A. 1872. A catalogue of British Hymenoptera; Chrysididae, Ichneumonidae, Braconidae, and Evaniidae. The Entomological Society of London, A. Napier, London.

Marshall T.A. 1885. Monograph of British Braconidae Part I. Transactions of the Royal Entomological Society of London: 1-208.

Mason W.R.M. 1981. The polyphyletic nature of Apanteles Foerster (Hymenopera: Braconidae): A phylogeny and reclassification of Microgastrinae. Memoirs of the Entomological Society of Canada 113 (S115): 1-147. https://doi.org/10.4039/entm113115fv

Michael P.J. 1985. Importation and establishment of natural enemies of Heliothis Australia (Lep.: Noctuidae). In: King E.G. \& Jackson E. (eds) Increasing the Effectiveness of Natural Enemies. Proceedings of the Workshop on Biological Control of Heliothis, 11-15 November 1985, New Delhi, India: 363-373. Far Eastern Regional Research Office, United States Department of Agriculture, New Delhi. 
Michael P.J., Woods W., Lawrence P.J. \& Fisher W. 1984. Introduced parasites for the control of Australian noctiud pests. In: Bailey P. \& Swincer D. (eds) Proceedings of the Fourth Australian Applied Entomological Research Conference: 294-303. D.J. Woolman, Government Printer, South Australia.

Muirhead K.A., Murphy N.P., Sallam M.N., Donnellan S.C. \& Austin A.D. 2006. Mitochondrial DNA phylogeography of the Cotesia flavipes complex of parasitic wasps (Hymenoptera: Braconidae). Annales de la Société entomologique de France 42 (3-4): 309-318.

https://doi.org/10.1080/00379271.2006.10697462

Muirhead K., Austin A. \& Sallam M. 2008. The systematics and biology of Cotesia nonagriae (Olliff) stat. rev. (Hymenoptera: Braconidae: Microgastrinae), a newly recognized member of the Cotesia flavipes species complex. Zootaxa 1846: 35-46.

Muirhead K.A., Murphy N.P., Sallam N., Donnellan S.C. \& Austin A.D. 2012. Phylogenetics and genetic diversity of the Cotesia flavipes complex of parasitoid wasps (Hymenoptera: Braconidae), biological control agents of lepidopteran stemborers. Molecular Phylogenetics and Evolution 63 (3): 904-14. https://doi.org/10.1016/j.ympev.2012.03.003

Nixon G.E.J. 1974. A revision of the north-western European species of the glomeratus-group of Apanteles Forster (Hymenoptera, Braconidae). Bulletin of Entomological Research 64: 453-524.

Okolle J.N., Mansor M. \& Ahmad A.H. 2006. Seasonal abundance of the banana skipper, Erionota thrax (Lepidoptera : Hesperiidae) and its parasitoids in a commercial plantation and a subsistence farm in Penang, Malaysia. International Journal of Tropical Insect Science 26 (3): 197-206.

Olliff A.S. 1893. Report on a visit to the Clarence River District for the purpose of ascertaining the nature and extent of insect ravages in the sugar cane crops. Agricultural Gazette of New South Wales 4: 373-89.

Papp J. 1988. A survey of the European species of Apanteles Forst. (Hymenoptera, Braconidae: Microgastrinae) XI. 'Homologization' of the species-groups of Apanteles s.l. with Mason's generic taxa. Check-list of genera. Parasitoid/host list 1. Annales Historico-naturales Musei Nationalis Hungarici 80: $145-75$.

Rambaut A., Drummond A.J., Xie D., Baele G. \& Suchard M.A. 2018. Tracer ver. 1.7. Available online from https://beast.community/tracer [accessed 27 Apr. 2020].

Ronquist F., Teslenko M., Van der Mark P., Ayres D.L., Darling A., Hohna S., Larget B., Liu L., Suchard M.A. \& Huelsenbeck J.P. 2012. MrBayes 3.2: Efficient Bayesian phylogenetic inference and model choice across a large model space. Systematic Biology 61 (3): 539-542.

https://doi.org/10.1093/sysbio/sys029

Rowbottom R.M., Allen G.R., Walker P.W. \& Berndt L.A. 2013. Phenology, synchrony and host range of the Tasmanian population of Cotesia urabae introduced into New Zealand for the biocontrol of Uraba lugens. BioControl 58 (5): 625-633. https://doi.org/10.1007/s10526-013-9524-0

Schumacher R.K., Austin A.D. \& Floyd R.B. 2000. Parasitoids of the Autumn gum moth, Mnesampela privata (Guenée) (Lepidoptera: Geometridae) in South-Eastern Australia, with description of two new larval parasitoids. Transactions of the Royal Society of South Australia 124 (1): 1-15.

Seltmann K.C., Yoder M.J., Mikó I., Forshage M., Bertone M.A., Agosti D., Austin A.D., Balhoff J.P., Borowiec M.L., Brady S.G., Broad G.R., XBrothers G.R., Burks R.A., Buffington M.L., Campbell H.M., Dew K.J., Ernst A.F., Fernández-Triana J.L., Gates M.W., Gibson G.A.P., Jennings J.T., Johnson N.F., Karlsson D., Kawada R., Krogmann L., Kula R.R., Mullins P.L., Ohl M., Rasmussen C., Ronquist F., Schulmeister S., Sharkey M.J., Talamas E., Tucker E., Vilhelmsen L., Ward P.S., Wharton R.A. \& 
Deans A.R. 2012. A hymenopterists' guide to the Hymenoptera Anatomy Ontology: Utility, clarification, and future directions. Journal of Hymenoptera Research 27 (1): 67-88.

https://doi.org/10.3897/JHR.27.2961

Shaw M.R. 2003. Revised synonymy in the genus Cotesia (Hymenoptera: Braconidae: Microgastrinae): The identity of Microgaster vestalis Haliday, 1834, as a senior synonym of Apanteles plutellae Kurdjumov, 1912. Entomologist’s Gazette 54: 187-189.

Shenefelt R.D. 1972. Braconidae 4: Apanteles. In: Van der Vecht J. \& Shenefelt R.D. (eds) Hymenopteroeum Catalogus 7: 429-668. W. Junk N.V., The Hague.

Smith M.A., Rodriguez J.J., Whitfield J.B., Deans A.R., Janzen D.H., Hallwachs W. \& Hebert P.D.N. 2008. Extreme diversity of tropical parasitoid wasps exposed by iterative integration of natural history, DNA barcoding, morphology, and collections. Proceedings of the National Academy of Sciences of the United States of America 105 (34): 12359-64. https://doi.org/10.1073/pnas.0805319105

Smith M.A., Fernández-Triana J.L., Eveleigh E., Gómez J., Guclu C., Hallwachs W., Hebert P.D.N., Hrcek J., Huber J.T., Janzen D., Mason P.G., Miller S., Quicke D.L.J., Rodriguez J.J., Rougerie R., Shaw M.R., Várkonyi G., Ward D.F., Whitfield J.B. \& Zaldívar-Riverón A. 2013. DNA barcoding and the taxonomy of Microgastrinae wasps (Hymenoptera, Braconidae): impacts after 8 years and nearly 20000 sequences. Molecular Ecology Resources 13 (2): 168-76. https://doi.org/10.1111/1755-0998.12038

Telenga N.A. 1949. A survey of the fauna of the family Braconidae (Hymenoptera) of Tadzhikistan. Entomologicheskoe Obozrenie, Moscow 30: 381-8.

Viereck H.L. 1913. Descriptions of six new genera and twelve new species of ichneumon-flies. Proceedings of the United States National Museum 44 (1974): 639-648.

https://doi.org/10.5479/si.00963801.1974.639

Waterhouse D., Dillon B. \& Vincent D. 1998. Economic benefits To Papua New Guinea and Australia from the biological control of banana skipper (Erionota thrax). ACIAR Impact Assessment Series IAS12: 36.

Waterhouse D.F. \& Norris K.R. 1989. Biological Control Pacific prospects - Supplement 1. ACIAR, Canberra.

Whitfield J.B. 1997. Subfamily Microgastrinae. In: Wharton R., Marsh P. \& Sharkey M.J. (eds) Manual of the New World Genera of the Family Braconidae (Hymenoptera): 333-366. Special Publication of the International Society of Hymenopterists, Washington.

Wilkinson D.S. 1928a. A revision of the Indo-Australian species of the genus Apanteles (Hym. Bracon.). Part I. Bulletin of Entomological Research 19: 79-105.

Wilkinson D.S. 1928b. A revision of the Indo-Australian species of the genus Apanteles (Hym. Bracon.). Part II. Bulletin of Entomological Research 19: 109-146.

Wilkinson D.S. 1929. New parasitic Hymenoptera and Notes on other Species. Bulletin of Entomological Research 20 (01): 103. https://doi.org/10.1017/S000748530002099X

Wilkinson D.S. 1930. New species and host records of Braconidae. Bulletin of Entomological Research 21 (4): 481-487. https://doi.org/10.1017/S0007485300024822

Wilson F. 1960. A Review of the Biological Control of Insects and Weeds in Australia and Australian New Guinea. Commonwealth Agricultural Bureau, Bucks, England.

Yoder M.J., Mikó I., Seltmann K.C., Bertone M.A. \& Deans A.R. 2010. A Gross Anatomy Ontology for Hymenoptera. PLoS ONE 5 (12): e15991. https://doi.org/10.1371/journal.pone.0015991 
Yu D., van Achterberg C. \& Horstmann K. 2016. World Ichneumonoidea 2015. Taxonomy, Biology, Morphology and Distribution, Taxapad, Vancouver, Canada.

Manuscript received: 29 November 2019

Manuscript accepted: 14 March 2020

Published on: 16 June 2020

Topic editors: Gavin Broad and Nesrine Akkari

Desk editor: Kristiaan Hoedemakers

Printed versions of all papers are also deposited in the libraries of the institutes that are members of the EJT consortium: Muséum national d'histoire naturelle, Paris, France; Meise Botanic Garden, Belgium; Royal Museum for Central Africa, Tervuren, Belgium; Royal Belgian Institute of Natural Sciences, Brussels, Belgium; Natural History Museum of Denmark, Copenhagen, Denmark; Naturalis Biodiversity Center, Leiden, the Netherlands; Museo Nacional de Ciencias Naturales-CSIC, Madrid, Spain; Real Jardín Botánico de Madrid CSIC, Spain; Zoological Research Museum Alexander Koenig, Bonn, Germany; National Museum, Prague, Czech Republic. 